\title{
MODELOS AGROMETEOROLÓGICOS PARA ESTIMAÇÃO DO NÚMERO DE FRUTOS POR PLANTA EM CULTIVARES DE LARANJA DOCE NA REGIÃO DE LIMEIRA-SP
}

\section{SILVIA ELISANDRA PASQUA PAULINO}

\author{
Tese apresentada à Escola Superior de Agricultura \\ "Luiz de Queiroz", Universidade de São Paulo, para \\ obtenção do título de Doutor em Agronomia, Área de \\ Concentração: Fitotecnia.
}

P I R A C I C A B A

Estado de São Paulo - Brasil

Janeiro - 2005 


\title{
MODELOS AGROMETEOROLÓGICOS PARA ESTIMAÇÃO DO NÚMERO DE FRUTOS POR PLANTA EM CULTIVARES DE LARANJA DOCE NA REGIÃO DE LIMEIRA-SP
}

\section{SILVIA ELISANDRA PASQUA PAULINO}

Engenheiro Agrônomo

Orientador: Prof. Dr. FRANCISCO DE ASSIS ALVES MOURÃO FILHO

Co-Orientador: Prof. Dr. DURVAL DOURADO NETO

\begin{abstract}
Tese apresentada à Escola Superior de Agricultura "Luiz de Queiroz", Universidade de São Paulo, para obtenção do título de Doutor em Agronomia, Área de Concentração: Fitotecnia.
\end{abstract}

P I R A C I C A B A

Estado de São Paulo - Brasil

Janeiro - 2005 
Dados I nt er naci onai s de Cat al ogação na Publ i cação ( CI P) DI VI SÃO DE BI BLI OTECA E DOCUMENTAÇÃO - ESALQI USP

Paulino, Silvia Elisandra Pasqua

Modelos agrometeorológicos para estimação do número de frutos por planta em cultivares de laranja doce na região de Limeira-SP / Silvia Elisandra Pasqua Paulino. - - Piracicaba, 2005.

$107 \mathrm{p}$.

Tese (Doutorado) - - Escola Superior de Agricultura Luiz de Queiroz, 2005. Bibliografia.

1. Agrometeorologia 2. Influência climática 3. Laranja 4. Modelos matemáticos I. Título

CDD 634.31 
OFEREÇO,

aos meus queridos pais, José e Maria, pelo amor, dedicação e apoio em todos os momentos de minha vida,

e aos meus irmãos, José (in memorian) e Daiane, pelo carinho e amizade.

DEDICO,

ao meu amado esposo, Wilton, pelo amor incondicional, apoio e companheirismo,

e à minha filhinha, Ana Clara, o maior dos muitos presentes que Deus já me deu. 


\section{AGRADECIMENTOS}

À Universidade de São Paulo, Escola Superior de Agricultura "Luiz de Queiroz", especialmente ao Departamento de Produção Vegetal, pela oportunidade de poder realizar o Curso de Doutorado;

Ao Prof. Dr. Francisco de Assis Alves Mourão Filho pela orientação, amizade e grande incentivo;

Ao Prof. Dr. Durval Dourado Neto pela co-orientação, amizade e por seu exemplo incalculável de vida e de profissionalismo;

À Sucocítrico Cutrale, em nome dos Srs. José Luís Cutrale Junior e Marcos Neves Penteado Moraes, por ter possibilitado a execução deste trabalho;

À Dra. Aline de Holanda Nunes Maia, pela imensa colaboração, apoio e amizade;

Ao Dr. Luis Carlos Timm, pela colaboração e amizade;

Ao Prof. Dr. Paulo Cesar Sentelhas, pela colaboração e disponibilidade; e

Ao $\mathrm{CNPq}$, pelo fomento à pesquisa. 


\section{SUMÁRIO}

Página

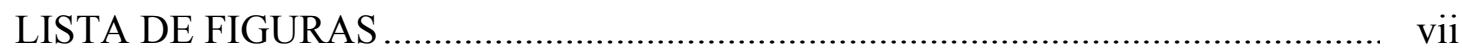

LISTA DE TABELAS _....................................................................................... ix

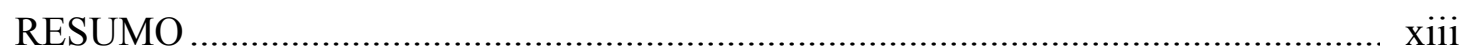

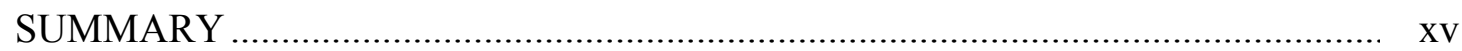

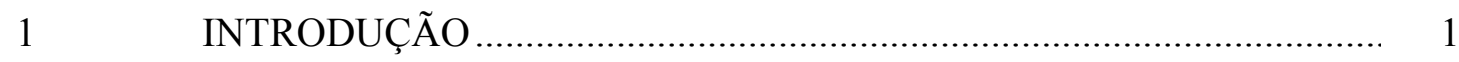

2 REVISÃO DE LITERATURA............................................................ 3

$2.1 \quad$ PRÉ-FLORESCIMENTO E FLORESCIMENTO .................................. 5

2.2 FIXAÇÃO, CRESCIMENTO E MATURAÇÃO DO FRUTO ................. 9

2.3 MODELOS DE PREVISÃO DE PRODUTIVIDADE DE FRUTOS CÍTRICOS ………..................................................................... 14

3 MATERIAL E MÉTODOS _........................................................... 19

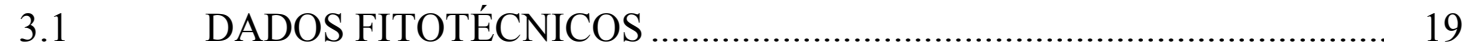

D.2 DADOS METEOROLÓGICOS _.......................................................... 22

3.3 BALANÇO HÍDRICO .................................................................. 22

3.3.1 Evapotranspiração de referência (ou potencial) ….................................. 22

3.3.2 Evapotranspiração máxima................................................................ 26

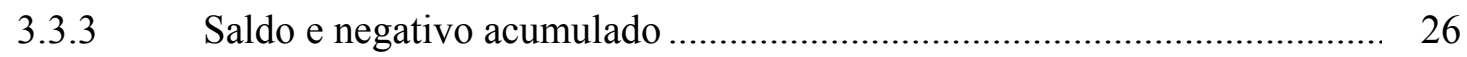

3.3.4 Critério de iniciar o balanço hídrico ...................................................... 27

3.3.5 Capacidade de água disponível.......................................................... 28

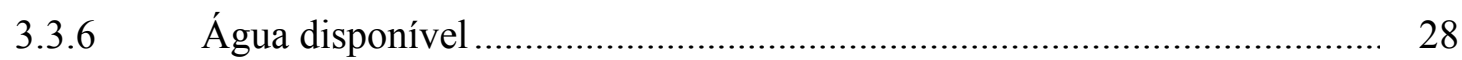

3.3.7 Estimativa do armazenamento inicial ................................................... 29

3.3.8 Evapotranspiração real....................................................................... 29

3.3.9 Deficiência hídrica ............................................................................. 29 
3.3.10 Excedente hídrico …................................................................ 30

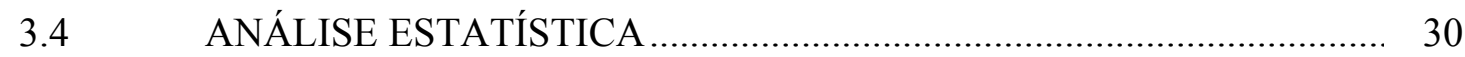

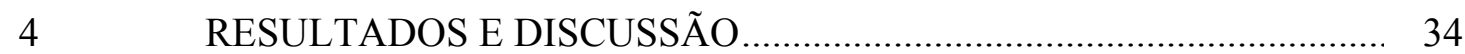

4.1 CONDIÇÕES METEOROLÓGICAS ENTRE 1989 E 2004 .................... 34

4.2 NÚMEROS DE FRUTOS POR PLANTA OBSERVADOS ................... 38

INFLUÊNCIA DA CLASSE DE IDADE ............................................ 41

4.4 INFLUÊNCIA DO NÚMERO DE FRUTOS DO ANO ANTERIOR ....... 42

4.5 INFLUÊNCIA DAS VARIÁVEIS AGROMETEOROLÓGICAS NO CICLO DA CULTURA................................................................. 45

4.5.1 Cultivar 'Pêra' ............................................................................... 46

4.5.2 Cultivar 'Valência' ........................................................................ 51

4.5.3 Cultivar 'Hamlin' .................................................................................. 55

4.6 MODELOS AGROMETEOROLÓGICOS _.......................................... 60

4.6.1 Descrição dos modelos obtidos …............................................................. 60

4.6.1.1 Cultivar 'Pêra' ...................................................................................... 61

4.6.1.2 Cultivar 'Valência' ......................................................................... 63

4.6.1.3 Cultivar 'Hamlin' ................................................................................... 65

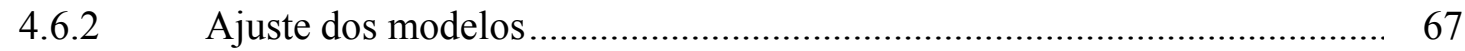

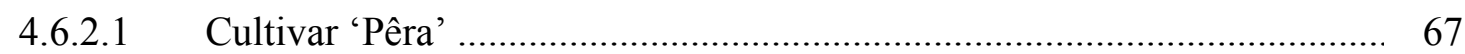

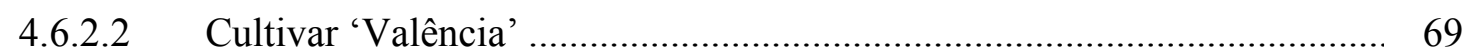

4.6.2.3 Cultivar 'Hamlin' .............................................................................. 73

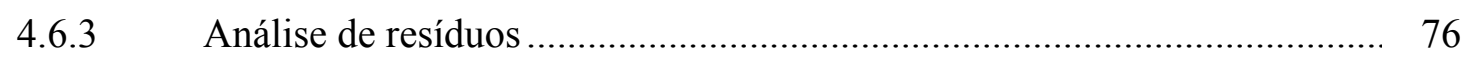

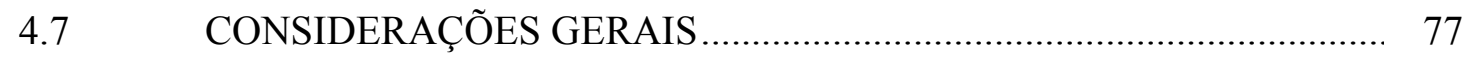

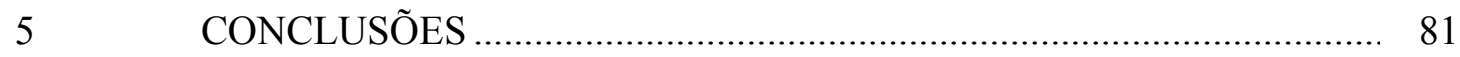

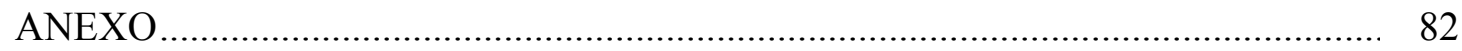

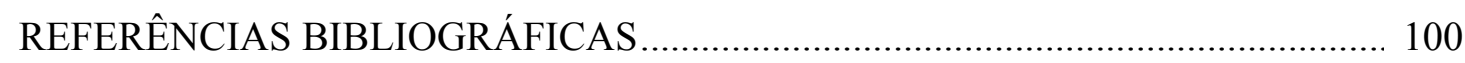




\section{LISTA DE FIGURAS}

Página

1 Fases fenológicas dos citros, considerando-se as condições climáticas das regiões produtoras do norte do Estado de São Paulo (Sentelhas, 2005): IF: indução floral; RV: repouso vegetativo; F: antese; DVC: divisão celular; DFC: diferenciação celular; EC: expansão celular; M: maturação; PC: colheita.

2 Temperaturas máxima e mínima $\left({ }^{\circ} \mathrm{C}\right)$ diária entre os anos de 1989 e 2004. Limeira-SP.

3 Precipitação (mm) diária entre os anos de 1989 e 2004. Limeira-SP.

4 Componentes do balanço hídrico, para CAD de $100 \mathrm{~mm}$, entre os anos de 1989 e 2004. Limeira-SP.

5 Relações entre o número de frutos produzidos por planta numa safra e na safra imediatamente anterior. Cultivares 'Pêra' (A), 'Valência' (B) e 'Hamlin' (C).

6 Valores observados e preditos do número de frutos por planta com respectivos limites inferior (LI) e superior (LS) dos intervalos de confiança de 95\%. 'Pêra', idades 1 (A), 2 (B) e 3 (C).

7 Relação entre valores observados do número de frutos por planta e valores preditos pelos modelos agrometeorológicos para as variedades cultivadas 'Pêra' (A), 'Valência' (B) e 'Hamlin' (C) em três classes de idades. 
8 Valores observados e preditos do número de frutos por planta com limites inferior (LI) e superior (LS) dos intervalos de confiança de 95\%. 'Valência', idades 1 (A), 2 (B) e 3 (C).

9 Valores observados e preditos do número de frutos por planta com respectivos limites inferior (LI) e superior (LS) dos intervalos de confiança de 95\%. 'Hamlin', idades 1 (A), 2 (B) e 3 (C). 


\section{LISTA DE TABELAS}

Página

1 Número de amostras realizadas por cultivar, classe de idade (CI) e ano. Limeira-SP.

2 Parâmetros empíricos do modelo proposto por Paltridge \& Platt (1976) para estimativa da declinação solar.

3 Números de frutos por planta observados da variedade cultivada 'Pêra' por safra e classe de idade. Limeira-SP.

4 Números de frutos por planta observados da variedade cultivada 'Valência' por safra e classe de idade. Limeira-SP.

5 Números de frutos por planta observados da variedade cultivada 'Hamlin' por safra e classe de idade. Limeira-SP.

6 Coeficientes das equações de regressão linear entre número de frutos por planta $(Y)$ por cultivar e classe de idade $(x)$, coeficiente de determinação $\left(\mathrm{R}^{2}\right)$ e valor $\mathrm{p}$.

7 Estimativas dos parâmetros $\alpha_{\mathrm{ij} 1}$ (equação 20) dos modelos autoregressivos usados para investigar presença de correlação entre o número de frutos produzidos na safra anterior $\left(\mathrm{Y}_{\mathrm{t}-1}\right)$ e na corrente safra $\left(\mathrm{Y}_{\mathrm{t}}\right)$ por cultivar $(\mathrm{P}$ : 'Pêra', V: 'Valência', H: 'Hamlin') e por classe de idade (CI - 1: 3 a 5 anos, 2: 6 a 10 anos, 3: superior a 10 anos). 
8 Estimativas dos parâmetros dos modelos de regressão múltipla que descrevem o padrão de variação do número de frutos por planta em função de variáveis agrometeorológicas, coeficientes de determinação $\left(\mathrm{R}^{2}\right)$ e valores $\mathrm{p}$ associados aos testes F para a variedade cultivada 'Pêra' em três classes de idade $(\mathrm{CI})$.

9 Estimativas dos parâmetros dos modelos de regressão múltipla que descrevem o padrão de variação do número de frutos por planta em função de variáveis agrometeorológicas, coeficientes de determinação $\left(\mathrm{R}^{2}\right)$ e valores p associados aos testes F para a variedade cultivada 'Valência' em três classes de idade $(\mathrm{CI})$.

10 Estimativas dos parâmetros dos modelos de regressão múltipla que descrevem o padrão de variação do número de frutos por planta em função de variáveis agrometeorológicas, coeficientes de determinação $\left(R^{2}\right)$ e valores p associados aos testes F para a variedade cultivada 'Hamlin' em três classes de idade.

11 Estimativas dos parâmetros $\theta_{\mathrm{ij} 1}$ (equação 22) dos modelos autoregressivos utilizados para investigar a presença de autocorrelação de ordem um entre os resíduos ( $\varepsilon$ ) em cada modelo que escreve a relação entre o número de frutos por planta e variáveis agrometeorológicas por cultivar (P: 'Pêra', V: 'Valência' e H: 'Hamlin') e classe de idade.

12 Temperatura média $\left({ }^{\circ} \mathrm{C}\right)$ mensal entre os anos de 1989 e 2004, em LimeiraSP.

13 Temperatura máxima $\left({ }^{\circ} \mathrm{C}\right)$ mensal entre os anos de 1989 e 2004, em LimeiraSP.

14 Temperatura mínima $\left({ }^{\circ} \mathrm{C}\right)$ mensal entre os anos de 1989 e 2004, em LimeiraSP.

15 Precipitação total (mm) mensal entre os anos de 1989 e 2004, em LimeiraSP. 
16 Evapotranspiração máxima total (mm) mensal entre os anos de 1989 e 2004, em Limeira-SP.

17 Evapotranspiração real total (mm) mensal entre os anos de 1989 e 2004, em Limeira-SP.

18 Deficiência hídrica total (mm) mensal entre os anos de 1989 e 2004, em Limeira-SP.

19 Excedente hídrico total (mm) mensal entre os anos de 1989 e 2004, em Limeira-SP.

20 Número de dias por mês com deficiência hídrica (NDH) entre os anos de 1989 e 2004, em Limeira-SP.

21 Relação mensal entre evapotranspiração real e máxima (ER/EM) entre os anos de 1989 e 2004, em Limeira-SP.

22 Coeficientes de correlação (r) entre número de frutos por planta e variáveis agrometeorológicas de diferentes períodos, entre as safras de 1990 e 2004. Cultivar 'Pêra'. Idade 1. Limeira-SP.

23 Coeficientes de correlação (r) entre número de frutos por planta e variáveis agrometeorológicas de diferentes períodos, entre as safras de 1990 e 2004. Cultivar 'Pêra'. Idade 2. Limeira-SP.

24 Coeficientes de correlação (r) entre número de frutos por planta e variáveis agrometeorológicas de diferentes períodos, entre as safras de 1990 e 2004. Cultivar 'Pêra'. Idade 3. Limeira-SP.

25 Coeficientes de correlação (r) entre número de frutos por planta e variáveis agrometeorológicas de diferentes períodos, entre as safras de 1990 e 2004. Cultivar 'Valência'. Idade 1. Limeira-SP.

26 Coeficientes de correlação (r) entre número de frutos por planta e variáveis agrometeorológicas de diferentes períodos, entre as safras de 1990 e 2004. Cultivar 'Valência'. Idade 2. Limeira-SP. 
27 Coeficientes de correlação (r) entre número de frutos por planta e variáveis agrometeorológicas de diferentes períodos, entre as safras de 1990 e 2004. Cultivar 'Valência'. Idade 3. Limeira-SP.

28 Coeficientes de correlação (r) entre número de frutos por planta e variáveis agrometeorológicas de diferentes períodos, entre as safras de 1990 e 2004. Cultivar 'Hamlin'. Idade 1. Limeira-SP.

29 Coeficientes de correlação (r) entre número de frutos por planta e variáveis agrometeorológicas de diferentes períodos, entre as safras de 1990 e 2004. Cultivar 'Hamlin'. Idade 2. Limeira-SP.

30 Coeficientes de correlação (r) entre número de frutos por planta e variáveis agrometeorológicas de diferentes períodos, entre as safras de 1990 e 2004. Cultivar 'Hamlin'. Idade 3. Limeira-SP.

31 Valores observados e preditos do número de frutos por planta com respectivos erros padrão e resíduos para 'Pêra' em três classes de idade.

32 Valores observados e preditos do número de frutos por planta com respectivos erros padrão e resíduos para 'Valência' em três classes de idade. ... 98

33 Valores observados e preditos do número de frutos por planta com respectivos erros padrão e resíduos para 'Hamlin' em três classes de idade. 


\section{MODELOS AGROMETEOROLÓGICOS PARA ESTIMAÇÃO DO NÚMERO DE FRUTOS POR PLANTA EM CULTIVARES DE LARANJA DOCE NA REGIÃO DE LIMEIRA-SP}

Autor: SILVIA ELISANDRA PASQUA PAULINO

Orientador: Prof. Dr. FRANCISCO DE ASSIS ALVES MOURÃO FILHO

Co-Orientador: Prof. Dr. DURVAL DOURADO NETO

\section{RESUMO}

O estabelecimento de modelos que permitam previsões de tendências de produtividade, apontando se as colheitas serão menores ou maiores, é de grande importância para todos os elos da cadeia citrícola. Este trabalho teve por objetivo identificar e avaliar a influência de variáveis agrometeorológicas, em diferentes fases do ciclo da cultura, para propor modelos empíricos para estimação do número de frutos por planta nas variedades cultivadas de laranja doce 'Pêra', 'Valência' e 'Hamlin', na região de Limeira-SP. Foram utilizados dados amostrais de número de frutos por planta, em três classes de idade, referentes à estimativa anual de produção da indústria de suco paulista, no total de 15 safras (1990/91 a 2004/05), e dados meteorológicos (temperatura máxima e mínima e precipitação) para o município de Limeira $\left(22^{\circ} 32^{\prime} \mathrm{S}, 4^{\circ} 27^{\prime} \mathrm{W}, 639\right.$ metros). Foram determinados inicialmente os coeficientes de correlação linear entre número de frutos por planta e variáveis agrometeorológicas componentes do balanço hídrico e temperatura, em diferentes períodos. Foram desenvolvidos modelos de regressão linear múltipla, mediante procedimento 'stepwise', para os subconjuntos de variáveis agrometeorológicas que apresentaram as maiores correlações significativas com o número de frutos por planta em diferentes fases do ciclo da cultura. As condições meteorológicas durante as fases de crescimento vegetativo de verão, pré-florescimento, 
florescimento e início de crescimento dos frutos, influenciam a produção de frutos por planta. Os modelos obtidos apresentaram ajustes satisfatórios entre valores observados e estimados, com coeficiente de determinação variando de 0,72 a 0,87 . 


\title{
AGROMETEOROLOGICAL MODELS TO ESTIMATE THE NUMBER OF FRUITS PER PLANT OF SWEET ORANGE CULTIVARS TO LIMEIRA-SP, BRAZIL
}

\author{
Author: SILVIA ELISANDRA PASQUA PAULINO
}

Adviser: Prof. Dr. FRANCISCO DE ASSIS ALVES MOURÃO FILHO

Co-Adviser: Prof. Dr. DURVAL DOURADO NETO

\section{SUMMARY}

The establishment of models that allows forecasting of yield tendencies, pointing if the harvest will be minors or majors, is important for the citrus industry. This work had the purpose of evaluating the influence of meteorological variables in different phases of the crop cycle to propose empirical models to estimate the number of fruits per plant on the cultivated varieties of sweet orange 'Pêra', 'Valência' and 'Hamlin', to the region of Limeira-SP, Brazil. Samples of number of fruits per plant have been used, classified in three age classes, related to the annual juice production estimative from citrus industry of the State of São Paulo, on the total of 15 harvests (1990/91 to 2004/05), and meteorological data of maximum and minimum air temperature and precipitation of Limeira-SP $\left(22^{\circ} 32^{\prime} \mathrm{S}, 47^{\circ} 27^{\prime} \mathrm{W}, 639\right.$ meters), Brazil. The correlation coefficients among number of fruits per plant and meteorological variables components of the water balance and air temperature in different periods were initially computed. The linear multiple regression models were developed using 'stepwise' procedure, for all variables that presented the major significant correlations with the number of fruits per plant in different phases of the crop cycle. The meteorological conditions during the phases of vegetative growth of summer, pre-flowering, flowering and beginning of fruits growth influenced the fruits per plant production. The proposed models presented 
satisfactory adjustments among observed and estimated values, with determination coefficients from 0.72 to 0.87 . 


\section{INTRODUÇÃO}

Os citros, em função de sua produtividade, composição química e valor nutritivo, constituem-se nas frutas mais produzidas em volume, sendo que o Brasil é, atualmente, o maior produtor mundial, com cerca de 18\% do total de frutos em 2002/03 (FAO, 2003). A produção brasileira é orientada basicamente para o cultivo de laranjas para processamento, visando produção de suco concentrado congelado voltado ao mercado internacional. São Paulo é o principal Estado produtor, superando a produção dos EUA (Neves, 2000).

Modelo é uma simplificação de um sistema real e é definido como sua representação matemática. Modelagem é o processo de desenvolvimento dessa representação matemática (Wit, 1982). O estabelecimento de modelos que permitam previsões de tendências de produtividade, apontando se as colheitas serão menores ou maiores, é de suma importância para todos os elos da cadeia citrícola, trazendo consideráveis vantagens econômicas, possibilitando sobretudo transações comerciais meses antes do início da safra.

O crescimento e o desenvolvimento das plantas perenes são influenciados por vários fatores, tais como genótipo, clima, solo, idade, pragas, doenças e manejo cultural. Dentre esses fatores, o clima tem sido relatado como preponderante na determinação do desempenho produtivo de plantas cítricas entre locais e entre safras. Dessa forma, conhecer relações entre o ciclo das plantas cítricas e as condições meteorológicas, além de ser útil para o estabelecimento de manejo fitotécnico adequado, para a programação de colheitas, na regionalização dos cultivos e na elaboração de modelos de previsão de início e duração de períodos fenológicos, é indispensável para previsão de produtividade e qualidade dos frutos de uma safra. 
Anualmente a indústria de suco paulista realiza levantamentos amostrais nas regiões onde atua visando estimar a produção de frutos por planta das principais variedades cultivadas de laranja doce destinadas ao processamento. Tais levantamentos ocorrem sempre em meados de abril para fins de previsão de safra, a qual se presta ao estabelecimento de estratégias de comercialização do setor.

Este trabalho teve por objetivo identificar e avaliar a influência de variáveis agrometeorológicas em diferentes fases do ciclo das plantas, para propor modelos matemático-empíricos que possibilitem antecipar a estimação do número de frutos por planta nas variedades cultivadas de laranja doce 'Pêra', 'Valência' e 'Hamlin', em três classes de idade, na região de Limeira-SP. 


\section{REVISÃO DE LITERATURA}

Uma larga variação de condições edáficas e ambientais é tolerada pelas plantas cítricas. Plantios comerciais ocorrem em regiões tropicais e subtropicais entre as latitudes de $40^{\circ}$ Norte e Sul, excetuando-se microclimas em que as temperaturas mínimas são inferiores a $-7^{\circ} \mathrm{C}$. Nessas regiões, os fatores ambientais exercem influência decisiva no crescimento, desenvolvimento e produtividade das plantas cítricas, sendo os principais responsáveis pela amplitude de produções de pomares adultos, que varia de até 100 toneladas por hectare em regiões subtropicais a 15 toneladas por hectare em regiões trópicais (Davies \& Albrigo, 1994).

Fatores externos, bem como fatores internos cíclicos envolvidos com o passado fisiológico e o histórico de frutificação da planta, determinam o desenrolar da seqüência de fases fenológicas dos citros. Crescimento, florescimento e fatores metabólicos interagem de modo complexo com fatores climáticos, os quais influenciam a produtividade, o crescimento do fruto e seu processo de maturação (Reuther, 1988).

Por ser perene, a planta cítrica apresenta um crescimento vegetativo, incluindo o desenvolvimento de sistema radicular e de copa, tipicamente dominante sobre o crescimento reprodutivo (Syvertsen \& Lloyd, 1994). De um modo geral, as plantas cítricas apresentam uma seqüência natural de repouso ou pré-florescimento, florescimento, pegamento ou fixação do fruto, crescimento do fruto e maturação (Ben Mechlia \& Carrol, 1989). 


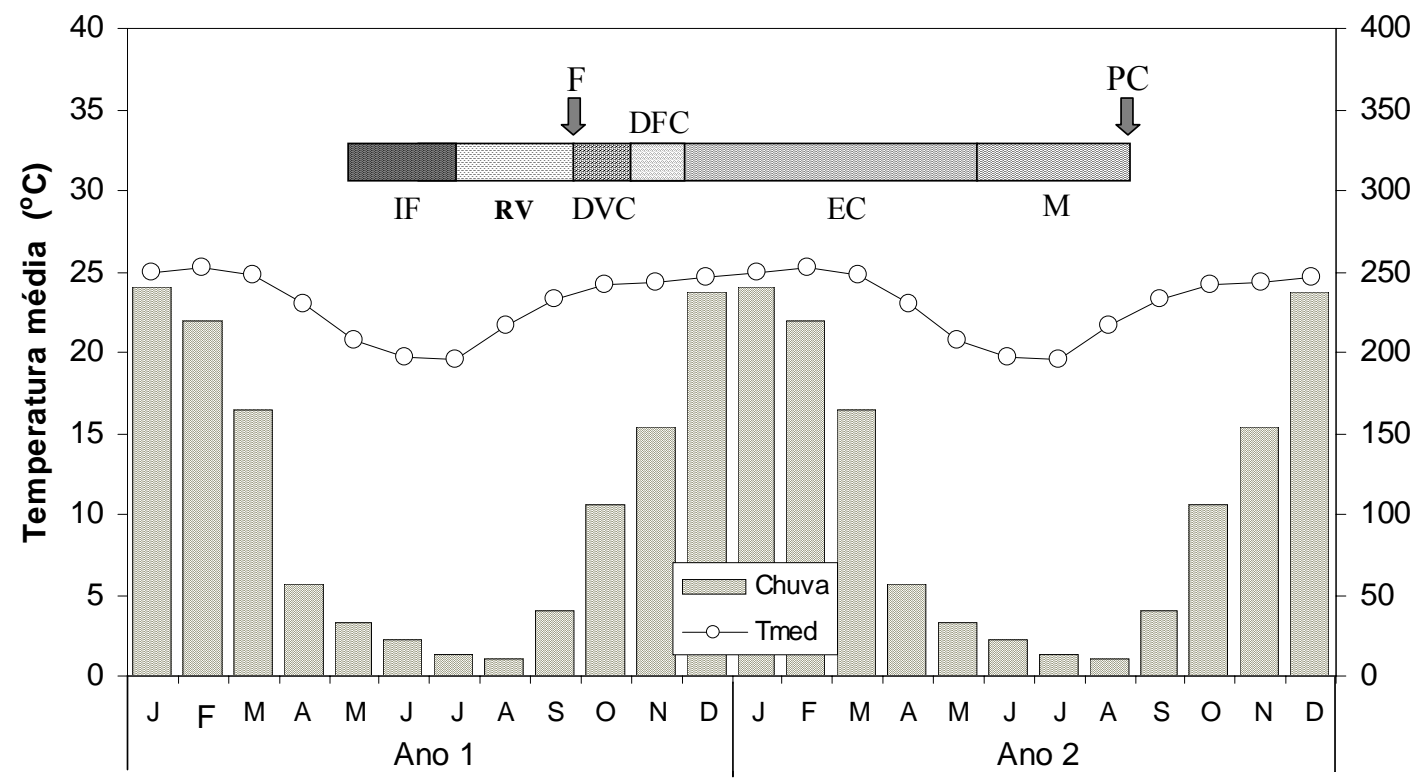

Figura 1 - Fases fenológicas dos citros, considerando-se as condições climáticas das regiões produtoras do norte do Estado de São Paulo (Sentelhas, 2005): IF: indução floral; RV: repouso vegetativo; F: antese; DVC: divisão celular; DFC: diferenciação celular; EC: expansão celular; M: maturação; PC: colheita

Para as condições climáticas do Estado de São Paulo, quando as chuvas e as temperaturas começam a diminuir, por volta de abril, maio e junho, inicia-se a indução floral, com as gemas vegetativas se transformando em gemas reprodutivas (Figura 1). Condicionadas por fatores ambientais, nas condições paulistas, pelo estresse hídrico, as plantas entram em fase de repouso vegetativo ou pré-florescimento, o que gera acúmulo de reservas. Após dois a quatro meses, com o fim do período de estresse, entre o final do inverno e o início da primavera, as temperaturas entram em elevação e a estação chuvosa se inicia, resultando em condições favoráveis ao florescimento (antese), seguido do período de crescimento dos frutos (divisão celular, diferenciação celular, expansão celular e maturação) até a colheita (Sentelhas, 2005). 


\subsection{Pré-florescimento e florescimento}

O florescimento de citros consiste de períodos de indução, iniciação, diferenciação e antese. Fatores ambientais regulam o início e a extensão do florescimento em citros, o tipo de flores produzidas, sua distribuição na árvore, a porcentagem de frutos fixados e a produtividade (Guardiola, 1992; Davies \& Albrigo, 1994).

$\mathrm{Na}$ fase de pré-florescimento ou repouso ocorre uma redução do crescimento vegetativo, estando o mesmo associado à indução floral. Pode ser desencadeado por estresse hídrico, nas regiões tropicais, ou por baixas temperaturas, nas regiões subtropicais, sendo que o restabelecimento das condições climáticas favoráveis ao crescimento resultam em florescimento. Provavelmente, este repouso gera acúmulo de reservas pelas plantas, as quais são direcionadas ao desenvolvimento de estruturas reprodutivas durante o florescimento. $\mathrm{O}$ grau de indução é proporcional à severidade e à duração do estresse (Southwick \& Davenport, 1986; Volpe, 1992; Davies \& Albrigo, 1994).

A indução envolve os eventos que direcionam a transição do crescimento vegetativo para a produção de inflorescências, após interação de fatores externos e internos nas gemas. Durante a fase do pré-florescimento, as gemas vegetativas se transformam em reprodutivas devido a mudanças bioquímicas e fisiológicas e ao rápido aumento subseqüente na divisão celular (iniciação floral). A diferenciação se constitui de mudanças histológicas e morfológicas, através da divisão e diferenciação celular, elongamento e desenvolvimento de órgãos (primórdios florais) (Davenport, 1990). O tempo entre indução da gema floral e antese varia consideravelmente de uma safra para outra dependendo da temperatura e da disponibilidade de água. Na região subtropical, o processo pode se iniciar em abril-maio, com a antese ocorrendo a partir de setembrooutubro, no hemisfério sul (Volpe, 1992; Davies \& Albrigo, 1994).

Além dos fatores ambientais, a indução floral se relaciona também com fatores internos cíclicos, como balanço hormonal, nutrição, entre outros, envolvendo o passado fisiológico das plantas. Em regiões tropicais, por exemplo, sob altas temperaturas, sem 
períodos de estresse hídrico ou por baixa temperatura, as plantas cítricas emitem, ao longo do ano, vários surtos vegetativos, seguidos de fluxos florais, que induzem à maturação dos frutos em diversas épocas (Reuther, 1973). Tal fato indica que o repouso vegetativo ou a diminuição do crescimento vegetativo não determina por si a ocorrência do florescimento, mas sua ausência resulta em florescimento de menor intensidade (Sentelhas, 2005).

A ocorrência de fluxos de crescimento e subseqüente período de repouso, é função da combinação copa/porta-enxerto, idade da árvore, estado nutricional, crescimento em estações anteriores e condições climáticas (Reuther, 1973; Nogueira, 1979).

Os citros são plantas de dia neutro, não sendo seu florescimento induzido pelo fotoperíodo, podendo florescer em qualquer época, se outras condições forem indutoras. Com relação à temperatura, os citros podem florescer sob várias condições térmicas, desde 4 a $40^{\circ} \mathrm{C}$, corroborando sua alta capacidade de adaptação climática (Ortolani et al., 1991).

Nas regiões subtropicais, as plantas cítricas necessitam de um período com baixas temperaturas para induzir um período de repouso ou pré-florescimento (Southwick \& Davenport, 1986; García-Luís et al., 1992). Já em condições tropicais com período de seca, o repouso vegetativo é devido ao estresse hídrico, podendo, dependendo da intensidade e da duração desse estresse, resultar em florescimento concentrado. Nas condições brasileiras, onde há até três floradas por ano, geralmente ocorre alta radiação solar ou temperatura do ar no inverno, além da existência de um período com estresse hídrico que interfere no repouso e na época de florescimento (Ortolani et al., 1991).

Baixas temperaturas e estresse hídrico reduziram ou eliminaram o crescimento vegetativo em limoeiro de acordo com estudo de Chaikiattiyos et al. (1994), sendo que o florescimento foi menor na falta de estresse hídrico nas condições subtropicais da Austrália e foi muito maior após um período de estresse hídrico, embora este estresse hídrico fosse acompanhado de um período mais longo até a emergência floral. 
Para condições subtropicais, o início do florescimento depende da temperatura da estação de inverno anterior, sendo a duração deste período também dependente de temperatura, havendo uma relação direta entre a intensidade do frio e o tempo para ocorrer a antese. No pré-florescimento, temperaturas mais baixas resultam em florescimento concentrado e tardio, quando as condições climáticas são mais adequadas para a polinização e para a fixação do fruto (Lomas \& Burd, 1983; Bellows \& Morse, 1986). Temperaturas diurnas e noturnas mais altas diminuíram o tempo para iniciação floral e florescimento, com temperaturas diurnas tendo um efeito mais forte que as noturna, em região subtropical (Susanto et al., 1992).

A antese ocorre após a indução e diferenciação com o restabelecimento de condições de temperaturas e umidades de solo favoráveis. As flores de citros são formadas em cimeiras com a gema floral terminal saindo primeiro, seguida pelas gemas basais no ramo. A segunda gema floral abaixo da posição terminal é a última a abrir, provavelmente, devido à dominância apical. O tamanho da flor geralmente decresce da posição terminal para a última flor aberta. Portanto, a posição da segunda flor abaixo do ápice usualmente produz as menores flores, mas também tem a mais alta porcentagem de fixação de fruto no ramo. Baixas temperaturas no início da estação podem limitar o crescimento do tubo polínico. Flores que abrem mais tarde crescem mais rapidamente e persistem mais tempo do que flores que abrem cedo (Davies \& Albrigo, 1994).

A fase fenológica mais sensível ao estresse hídrico é o florescimento, seguida pela fixação dos frutos, com diminuição clara da produção de citros (Ginestar \& Castel, 1996). Há que se lembrar também que, estresses térmicos por temperaturas elevadas ou baixas também afetam a polinização, danificando e destruindo o grão de pólen, prejudicando o tubo polínico e causando atrofia floral. A abertura floral é mais favorecida com temperaturas moderadas e ar atmosférico relativamente seco (Nogueira, 1979). A temperatura ótima para crescimento do tubo polínico varia entre 25 e $30^{\circ} \mathrm{C}$, enquanto temperaturas abaixo de $20^{\circ} \mathrm{C}$ praticamente paralisam o processo (Frost \& Soost, 1968).

Os ramos vegetativos formam folhas maiores, com entrenós maiores e mais numerosos que os ramos reprodutivos, que são mais curtos, com folhas menores, e 
apresentam diferentes tipos de inflorescências. Antes do florescimento e no início da formação dos frutos, crescimento vegetativo vigoroso pode prejudicar a produção de frutos de boa qualidade (Volpe, 1992).

O crescimento de ramos ocorre em fluxos, sendo que, dependendo do clima, podem ocorrer de dois fluxos anuais, em condições mais amenas, a até cinco fluxos, em condições mais quentes. Em regiões tropicais úmidas o crescimento de ramos ocorre ininterruptamente, ao longo do ano, sem fluxos distintos. O fluxo de primavera é o mais importante, contendo ramos tanto vegetativos quanto reprodutivos. Os fluxos de verão e demais são geralmente vegetativos (Spiegel Roy \& Goldschmidt, 1996). Inflorescências com folhas fixam uma porcentagem mais alta de flores do que inflorescências sem folhas. Geralmente ramos com uma alta razão folha/flor produzem e conduzem maiores porcentagens de frutos à maturidade, mas a árvore comumente produz mais inflorescências sem folhas e uma porcentagem mais alta de frutos produzidos resulta destas últimas (Lovatt et al., 1984; Davies \& Albrigo, 1994). A abundância relativa de inflorescências com e sem folhas parece se relacionar com temperatura. Safras com temperaturas altas de inverno conduzem ao desenvolvimento de mais inflorescências com folhas. Temperaturas baixas a moderadas durante o florescimento $\left(<20^{\circ} \mathrm{C}\right)$ produzem um florescimento prolongado, enquanto temperaturas de $25-30^{\circ} \mathrm{C}$ produzem um período de florescimento mais curto (Davies \& Albrigo, 1994).

Há evidências que a intensidade de floração é dependente do conteúdo de carboidratos (Goldschmidt \& Golomb, 1982; Lovatt et al., 1988) e de amônia nas folhas, e que a intensidade de floração e o conteúdo de amônia nas folhas aumentam com a severidade e duração do estresse (Lovatt et al., 1988). Porém, segundo Davies \& Albrigo (1994), o conteúdo de carboidratos em tronco, ramos e folhas nem sempre tem mostrado correlação com o florescimento. Níveis de carboidratos nas raízes, entretanto, são bem associados com florescimento em produção alternada de tangerinas, como murcote. Raízes são também uma fonte de carboidratos, portanto a correlação entre níveis de carboidratos e florescimento pode não ser casual. Além de carboidratos, outros fatores relacionados ao florescimento são hormônios, temperatura, relações hídricas e nutrição. 


\subsection{Fixação, crescimento e maturação do fruto}

A frutificação é o estádio de desenvolvimento que marca transição da flor (ovário) em fruto jovem, o qual crescerá até a maturidade. $\mathrm{O}$ crescimento do fruto constitui o aumento do tamanho do ovário/fruto. Ele depende do acúmulo de matéria seca, e embora na maioria das vezes assuma-se que ocorra após a fixação, começa antes do florescimento, no momento da flor se desenvolver (Guardiola, 1992).

Embora a floração da maioria das espécies de citros seja muito abundante - com produções entre 100.000 e 200.000 flores por planta em idade adulta - a quantidade de frutos fixados é muito pequena quando comparada com o número de flores. A porcentagem de fixação de flores em frutos maduros varia entre 0,1 e $3,5 \%$ do total de flores produzidas, estendendo-se o período de queda de poucas semanas antes da antese até aproximadamente 14 semanas após a mesma (Monselise, 1986). Daí a afirmação de Ben Mechlia \& Carrol (1989) de que a produção total depende realmente da fixação do fruto, não do número de flores.

O período de fixação dos frutos é bastante extenso, iniciando-se logo após a polinização (Davies \& Albrigo, 1994). Em diferentes momentos após a frutificação, de algumas semanas da abscisão das pétalas e dos estames até quando o ovário já possui um crescimento significativo, pode ocorrer abscisão do fruto (Guardiola, 1992). A abscisão pode ser condicionada por fatores que vão desde aspectos morfológicos, fisiológicos e fitossanitários até aspectos ambientais, como elevadas temperaturas, deficiência hídrica e chuvas e ventos intensos (Reuther, 1973; Doorenbos \& Kassam, 1979).

O primeiro ciclo de queda inicia-se no estádio de botões florais e alcança o pico no meio do período de florada, sendo chamado de queda de florada, quando há abscisão - na zona entre o pedicelo e o ramo - de flores fracas e frutinhos com estilos ou ovários defeituosos. Ao mesmo tempo em que muitos ovários crescem durante as primeiras semanas e desenvolvem uma coloração verde-escura, outros amarelecem e caem. Ocorre queda de frutos por mais dois ou três meses ainda e, no início do verão, novembro e dezembro nas condições do Estado de São Paulo, se dá uma grande queda - a chamada 'june drop' no hemisfério Norte, que se refere à abscisão de frutinhos quando eles se 
aproximam de 0,5 a $2,0 \mathrm{~cm}$ de diâmetro. Trata-se de uma desordem fisiológica provavelmente relacionada com a competição entre frutinhos por carboidratos, água, hormônios e outros metabólitos, sendo um mecanismo que ajusta o número de frutos ao potencial produtivo da árvore. O problema é acentuado por estresses, especialmente altas temperaturas e deficiência hídrica. Uma hipótese é que altas temperaturas e severo estresse hídrico causam fechamento estomatal com uma concomitante redução na assimilação de $\mathrm{CO}_{2}$. Abscisão do fruto ocorre então porque o fruto mantém um balanço negativo de carbono. A queda de frutos ocorre da zona de abscisão na base do fruto deixando o pedicelo ligado na árvore temporariamente (Volpe, 1992; Davies \& Albrigo, 1994; Spiegel Roy \& Goldschmidt, 1996). Após este período, praticamente não ocorre mais queda até a colheita, exceto aquelas que podem ser provocadas por condições climáticas ou sanitárias adversas (Volpe, 1992).

Segundo Guardiola (1992), o número de flores e as condições climáticas predominantes determinam a diminuição no número de flores por abscisão após a antese e a duração do período de queda. Quanto maior o número de flores, a maior parte delas cai antes da antese ou por volta da queda de pétalas; o número de ovários remanescentes após este período é pequeno relativamente ao número total de flores inicial. Contudo, quando o número de flores está baixo, um maior número de ovários evolui para frutinhos, sendo que a maioria dos ovários alcança o estádio de frutinho em árvores com baixo florescimento.

A influência do clima na abscisão é clara, uma vez que, geralmente, os principais picos de abscisão acontecem em seguida a um período de estresse temporário, o que pode ser causado por uma disponibilidade hídrica reduzida no solo ou por um período excessivamente quente e seco (Guardiola, 1992).

Ben Mechlia \& Carrol (1989) relatam que a fixação do fruto depende da produtividade do ano anterior, da temperatura do período pré-florada, e temperatura, precipitação e vento durante o período de florescimento. Altas temperaturas na fixação usualmente resultam em alta taxa de queda. Deficiência de água no solo é particularmente danosa na primavera, quando os frutos pequenos não podem tamponar o estresse. $\mathrm{O}$ efeito da chuva no florescimento e fixação dos frutos pode ser por danos 
diretos mecânicos para flores e limitação na polinização. Segundo Ginestar \& Castel (1996), estresse hídrico no primeiro estádio de desenvolvimento dos frutos afetou a produção principalmente pela redução do número de frutos devido a forte queda de frutinhos. No período de fixação, de acordo com Moreira (1985), altas temperaturas durante dias seguidos aumentam muito a queda natural dos frutos jovens.

O crescimento do fruto é um processo contínuo que se estende desde o florescimento até a maturação, embora numa taxa variável, seguindo um padrão sigmoidal, podendo ser subdividido em quatro fases: (i) divisão celular, (ii) diferenciação celular, (iii) expansão celular e (iv) maturação. A fase i é a fase de divisão celular, a qual se inicia na antese e se estende por poucas semanas, quando quase todas as células do fruto maduro são produzidas, sendo este número inicial de células determinante do tamanho final do fruto. A duração desta fase depende das condições climáticas após a florada e do cultivar, sendo sua taxa de crescimento pequena. Na fase ii ocorre a diferenciação celular em vários tipos de tecidos tais como albedo, flavedo, vesículas de suco, entre outras. A fase iii de expansão celular, vai até a quebra da cor verde intensa, ocorrendo rápido crescimento do fruto com alta respiração e mudanças morfológicas. Há um rápido aumento no tamanho do fruto e na porcentagem de sólidos solúveis, sendo a duração desta fase determinada pelas condições climáticas e pelo cultivar, chegando a mais de seis meses para laranjas doces. A fase de maturação (iv), é caracterizada por crescimento lento, decréscimo na respiração, mudança da cor da casca de verde para amarela, aumento gradual de sólidos solúveis e rápido decréscimo na acidez total, podendo atingir até oito a nove meses para laranja 'Valência' em condições subtropicais (Davies \& Albrigo, 1994; Fonfria et al., 1996).

A taxa de crescimento do fruto para diferentes regiões é função da temperatura durante cada estádio de desenvolvimento e da umidade do solo, principalmente durante as fases iii e iv. Temperaturas médias mais altas provém taxas mais rápidas de crescimento de frutos e temperaturas médias mais baixas, taxas mais lentas, o que é consistente com o conceito de unidades térmicas. Conteúdo de água do solo adequado via chuva ou irrigação aumenta significativamente o tamanho do fruto durante a fase iii mas resulta numa correspondente diluição de sólidos solúveis (Davies \& Albrigo, 1994). 
O crescimento do fruto é afetado por fatores que podem ser classificados dentro de duas categorias maiores: fatores da planta e fatores ambientais, sendo que na primeira categoria devem ser considerados o tamanho do fruto e o número de frutos e, na segunda, temperatura e estresse hídrico, sendo este último expresso em termos de demanda evapotranspiratória diária (Ben Mechlia \& Carrol, 1989). Assim, se os frutos são poucos, eles podem crescer mais, se eles são numerosos eles podem crescer menos, enquanto o produto do número e do peso de fruto tende a ser constante dentro de limites razoáveis. Há um efeito positivo no aumento de temperatura no crescimento do fruto. Sob condições frias ocorre crescimento lento, suportando a hipótese de crescimento limitado do fruto em temperaturas baixas. $\mathrm{O}$ efeito negativo de temperaturas muito altas não é claramente estabelecido, mas é fortemente sugerido pela supressão do nível de crescimento durante o verão onde temperaturas altas (acima de $35^{\circ} \mathrm{C}$ ) prevalecem.

O estresse hídrico pode resultar em crescimento mais lento do fruto ou retração diária do fruto. Geralmente o aumento no tamanho do fruto durante a estação chuvosa reflete o efeito de mais disponibilidade de água, menor demanda evaporativa, menor temperatura ou o conjunto de todas três condições. Ginestar \& Castel (1996) apontam que estresse hídrico durante o segundo estádio de desenvolvimento de frutos causa redução do tamanho dos mesmos.

Maturação de frutos compreende uma série de mudanças em suas características físicas, como textura e permeabilidade de tecidos, e químicas, como alterações nos teores de carboidratos, ácidos orgânicos, proteínas, fenóis, pigmentos e pectinas (Chitarra \& Chitarra, 1990). Rápidas mudanças fisiológicas caracterizam o período de maturação do fruto, principalmente aumento em sólidos solúveis totais (açúcares), decréscimo em ácidos e mudanças na quantidade de suco extraível. A relação entre sólidos solúveis totais e ácidos tituláveis é usada geralmente como índice de maturidade, sendo conhecida por 'ratio' (Soule \& Grierson, 1986). Os principais fatores que afetam a maturação dos fruto são porta-enxerto/variedade, idade da planta, estresses de água e de calor, localização do fruto na planta, radiação, práticas de manejo (principalmente nutrição) e densidade de plantio (Reuther, 1988). 
O ácido cítrico é o ácido mais acumulado na polpa da maioria dos frutos cítricos, e passa a ser acumulado no fruto logo após a formação do fruto, alcançando rapidamente um pico de concentração e de quantidade. Tal pico é correlacionado com estresse hídrico e temperatura. Em áreas mais quentes, o pico é alcançado mais rapidamente. Após o pico, ocorre uma queda gradual na concentração de ácidos, sendo esta queda relacionada com temperatura. O conteúdo de sólidos totais aumenta durante a estação de crescimento (Rasmussen et al., 1966).

Climas tropicais e quentes tornam o crescimento do fruto mais rápido. Em clima tropical, a laranjeira 'Valência' pode atingir a maturidade em torno de cinco meses e meio enquanto na região subtropical mediterrânea, precisa de 13 a 14 meses para amadurecer. A acidez cai mais rapidamente e volume, quantidade de suco e sólidos solúveis, se acumulam mais rapidamente, em clima tropical. Períodos extensos de chuva causam redução dos sólidos solúveis e períodos nublados podem reduzir a fotossíntese e o acúmulo de açúcar. A senescência do fruto é acelerada em condições mais quentes (Albrigo, 1992).

As cores interna e externa da fruta cítrica são condicionadas pelo clima, sobretudo a temperatura. Mudanças na cor da casca de frutas cítricas representam uma queda no conteúdo de clorofila da casca e uma ascensão da concentração de carotenóides. Cor da casca e maturidade do fruto não são necessariamente correlacionadas. A intensidade da cor da epiderme está associada às temperaturas baixas, principalmente menores que $13^{\circ} \mathrm{C}$. A amplitude térmica parece influenciar a pigmentação, sendo que maiores amplitudes resultam em mais carotenóides (Ben Mechlia \& Carrol, 1989).

Invernos mais rigorosos subtropicais são desfavoráveis ao acúmulo de sólidos solúveis. Climas intermediários são mais propícios para a produção máxima de sucos e teores de sólidos, mantendo um bom nível de acidez para o equilíbrio. Umidade excessiva no solo aumenta o tamanho do fruto, mas dilui os sólidos e os níveis de acidez. Já períodos de seca afetam o desenvolvimento do fruto aumentando sua queda, reduzindo o tamanho do mesmo e, também, a fotossíntese, diminuindo a produção de sólidos solúveis (Albrigo, 1992). 
O método cumulativo de unidades térmicas (graus-dia) parece se correlacionar razoavelmente bem com taxas de crescimento e desenvolvimento do fruto e tem sido comumente usado para estimar a quantidade de calor exigida para o crescimento e a maturação dos citros, permitindo predizer as datas de colheita (Kimball, 1984). Geralmente considera-se para cálculo dos graus-dia temperaturas basais mínima de $13^{\circ} \mathrm{C}$ e máxima de $32^{\circ} \mathrm{C}$ (Volpe, 1992) ou de $35^{\circ} \mathrm{C}$ (Ben Mechlia \& Carrol, 1989). Diferenças nas datas de maturação entre cultivares precoces e tardios refletem os diferentes requerimentos de soma térmica - cultivares tardios requerem maior soma de unidades térmicas (Albrigo, 1992). Ortolani et al. (1991) verificaram que para São Paulo, a maturação de variedades precoces, como a 'Hamlin', se completa com $2.500{ }^{\circ} \mathrm{C}$.dia, as médias, como a 'Pêra', com $3.100{ }^{\circ} \mathrm{C}$.dia e, as tardias, como 'Valência' com 3.600 ${ }^{\circ} \mathrm{C}$.dia.

\subsection{Modelos de previsão de produtividade de frutos cítricos}

Modelos de crescimento e desenvolvimento de plantas são úteis para planejamento e manejo da produção agrícola, sendo importantes também em pesquisa porque permitem estimar a importância e o efeito de certas variáveis, que poderiam ser mais estudadas em pesquisas futuras. Uma das importantes aplicações de modelos matemáticos em ciência agrícola é a previsão de respostas de plantas a certas condições climáticas e de manejo, como ferramenta para gerenciamento e tomada de decisão (Dourado Neto et al., 1998a).

Os modelos usados em ciência agrícola para quantificar o efeito do clima na produtividade podem ser classificados como matemático-empírico, matemáticomecanístico e conceitual (Acock \& Acock, 1991). O matemático-empírico faz relações entre variáveis sem se referir aos processos correlacionados, descrevendo o comportamento da planta, baseado diretamente em observações no nível de planta, tendo sido demonstradas restrições para extrapolação de resultados. O matemático-mecanístico descreve a performance da planta baseado no conhecimento dos processos que influem no seu crescimento e desenvolvimento, estabelecendo relações de causa e efeito entre as 
variáveis, apresentando menos restrições em relação à extrapolação de resultados que o anterior.

O modelo conceitual trata-se do mais complexo, envolve os processos físicos e biológicos relacionados com a produção, e pressupõe que a influência das variáveis meteorológicas em processos específicos como fotossíntese, respiração ou transpiração pode ser adequadamente simulada através de um conjunto de equações matemáticas. Seus coeficientes são derivados através de medições físicas e fisiológicas e não apresentam o inconveniente de restrição às condições climáticas específicas, tendo características de universalidade. Contudo, pela exigência de informações minuciosas e precisas da cultura e do ambiente de inserção da mesma, esses modelos têm difícil aplicação prática pela dificuldade de obtenção de informações detalhadas tanto de fisiologia das plantas como das condições ambientais (Berlato, 1987).

Os modelos matemático-mecanísticos são também criticados por serem semiempíricos, específicos de um local e incompletos, omitindo efeitos de outros fatores e suas interações com o clima. No entanto, apesar disso e embora sejam utilizados procedimentos convencionais de estatística para avaliação dos coeficientes que vinculam a resposta das plantas às variáveis meteorológicas, a estruturação desses modelos apresenta orientação fenológica, o que faz com que seus resultados tenham maior probabilidade de ser realistas do ponto de vista da teoria biológica e agronômica, sendo muito úteis como ferramenta de previsão sob dadas condições de clima (Vaux \& Pruitt, 1983; Berlato, 1987; Frizzone, 1998).

Principalmente para modelos matemático-empíricos, uma das técnicas estatísticas mais comuns de ajuste é a análise de regressão, sendo que para muitos propósitos analíticos e de previsão, a análise de regressão tem provido uma descrição matemática simples do crescimento e desenvolvimento da planta, sendo muito usada em ciência agrícola para modelar, por exemplo, o número de vários componentes de rendimento (como número de grãos ou frutos), produção de matéria seca, desenvolvimento fenológico e uso de recursos disponíveis. Quando gerado de uma série de dados longa, um modelo deste tipo pode ser suficientemente exato para ser usado em dada situação. No entanto, os modelos matemático-empíricos devem ser usados com 
ressalva para extrapolações, em condições similares àquelas em que foram gerados. Apesar da ressalva de extrapolação sem ajustes para diferentes condições daquelas de sua origem, um modelo obtido por análise de regressão, quando baseado no entendimento de processos de desenvolvimento de uma cultura, é mais valioso do que um complexo modelo mecanístico baseado somente no conhecimento de suas respostas (Dourado Neto et al., 1998b). Análises de regressão linear simples, quadrática e múltipla entre parâmetros culturais e meteorológicos, têm sido utilizadas na confecção de modelos de previsão de produção de frutos cítricos (Albisu, 1982; Du Plessis, 1983; Tubelis \& Salibe, 1988, 1989 e 1991; Di Giorgi et al., 1991; Pasqua, 2000).

Como o clima afeta o florescimento, fixação, queda e número de frutos por árvore, por conseqüência, afeta também a produtividade de frutos. Além disso, tamanho do fruto, outro componente da produtividade, é afetado pelo clima, principalmente pela disponibilidade de água e temperatura. Produtividades de importantes cultivares comerciais de citros variam consideravelmente de ano para ano, na mesma região, principalmente devido a fatores climáticos (Davies \& Albrigo, 1994).

Vários autores, em diferentes partes do mundo, têm tentado explicar as variações de produtividade de citros em função das condições climáticas, sendo que a maioria dos modelos desenvolvidos para citros são do tipo matemático-empírico (Ortolani et al., 1991), salvo raras exceções como o modelo conceitual de Ben Mechlia \& Carrol (1989) e o modelo matemático-mecanístico de Camargo et al. (1999). Para a variedade cultivada 'Washington Navel', 38 anos de dados na Califórnia demonstraram a irregularidade cíclica natural da produtividade relacionada ao clima (Jones \& Cree, 1965). Os principais fatores associados com esta variação incluíram temperatura durante a florada, queda fisiológica, e ao longo da safra. Em geral, temperaturas elevadas durante estes períodos reduziram a produtividade. Umidade do solo não foi um fator importante nesse caso já que a maioria dos pomares era irrigada.

Gallo et al. (1977), em Cordeirópolis, analisaram a relação entre deficiência e excedente hídrico com a produção da variedade cultivada 'Baianinha', não observando influências de tais variáveis em qualquer um dos bimestres do período junho a maio na 
produção. Concluíram empiricamente que a seca de inverno é benéfica à produção, sendo importante a presença de estação seca moderada para provocar o florescimento.

Pesquisa da África do Sul sugere que a maior parte da variação anual na produtividade de 'Washington Navel' é devida a fatores climáticos, em particular temperatura durante o período da queda fisiológica (Du Plessis, 1983). Segundo Albisu (1982), dentre os fatores que afetam a variação de produção de laranja de uma região, a idade dos pomares e o clima são tidos como os mais influentes. O primeiro tem uma forte influência de médio a longo prazo, mas um impacto marginal de safra para safra. Destaca a não disponibilidade de informações acuradas a respeito dos grupos de idade ao longo do tempo, devido à dificuldade de levantamento. O clima tem influência mais imediata, com efeito positivo ou negativo, seja no decorrer da safra, como na seguinte. Pino \& Amaro (1986) relatam que a previsão de produção de laranja pode se basear em levantamentos por faixas etárias combinadas com modelos agrometeorológicos de previsão.

Silva et al. (1986) estudaram o efeito da deficiência hídrica e de geadas na produção de laranja no Estado de São Paulo. A deficiência hídrica foi calculada via ponderação das deficiências hídricas de cada localidade, com base nas áreas cultivadas e representadas pelos postos meteorológicos, em relação à área total da cultura no Estado. Os resultados não indicaram influências da deficiência hídrica nos meses de junho a novembro do ano do florescimento, já a do mês de dezembro foi influente negativamente sobre a produção.

Tubelis \& Salibe (1988, 1989 e 1991) estudaram a produtividade da variedade 'Hamlin' sobre vários porta-enxertos, em Botucatu, SP, admitindo constantes os tratos culturais e os níveis de adubação. A produção seria determinada pela idade da planta e pelo regime de chuva durante o florescimento e a frutificação. Constataram que as chuvas que ocorrem no período de florescimento têm efeito depressivo na produção. De acordo com Fonfria et al. (1996), a quantidade e a qualidade da colheita começam a ser determinadas já mesmo no florescimento e, principalmente, durante as primeiras fases do desenvolvimento do fruto. 
Di Giorgi et al. (1991) encontraram os melhores modelos de previsão para a produtividade média do Estado de São Paulo com base nos elementos condicionantes do florescimento, como temperatura antes e deficiência hídrica por dois meses após o evento. Pasqua (2000) encontrou que a produtividade média da região de Limeira, entre as safras 1990/91 e 1997/98, para a variedade cultivada 'Pêra', sofreu influência negativa de temperaturas elevadas no período inicial do pré-florescimento e de precipitações e excedentes hídricos durante o florescimento, sendo que precipitações no início do período de desenvolvimento, a partir de dezembro, contribuíram para o aumento da produtividade.

Camargo et al. (1995) testaram seis modelos para estimativa de produtividade de citros no Estado de São Paulo, sendo quatro matemático-empíricos e dois matemáticomecanísticos. Os modelos matemático-empíricos tiveram desempenho de razoável a fraco, indicando limitação do uso de modelos dessa natureza para condições diferentes daquelas para as quais as relações foram estabelecidas. O modelo matemáticomecanístico de Doorenbos \& Kassam (1979) apresentou desempenho insatisfatório, enquanto que o modelo de penalização de produtividade de acordo com as condições hídricas nas fases fenológicas críticas à cultura proposto por Jensen (1968) apresentou melhor desempenho. Esse último modelo foi parametrizado e validado com dados independentes por Camargo et al. (1999), para pomares da região de Matão, apresentando bons resultados $\left(\mathrm{R}^{2}=0,70\right)$, com erros inferiores a 0,5 caixa por planta; sendo que a produtividade foi particularmente sensível ao estresse hídrico durante o florescimento.

O modelo conceitual de Ben Mechlia \& Carrol (1989) permite a previsão da produtividade e da qualidade dos frutos cítricos através da simulação do crescimento e do desenvolvimento das plantas. O modelo simula as fases fenológicas da planta e o índice de fixação dos frutos que servem de base para a determinação da produtividade final em função da temperatura do ar, radiação solar, vento, precipitação, densidade de plantio e idade da árvore. A partir daí, o modelo simula o crescimento do fruto, a curva de maturação e a coloração da casca, baseado nos dados de temperatura e balanço hídrico. 


\section{MATERIAL E MÉTODOS}

\subsection{Dados fitotécnicos}

Foram considerados dados de produção (número de frutos por planta) das variedades cultivadas 'Pêra', 'Valência' e 'Hamlin' de laranja doce (Citrus sinensis, L. Osbeck). Os dados foram colhidos de amostragens realizadas em 15 safras consecutivas (1990/91 a 2004/05) na região de Limeira, no sudeste do parque citrícola do Estado de São Paulo. Tais amostragens foram realizadas sempre em meados de abril de cada ano e fazem parte da estimação de produção anual realizada pela indústria de suco paulista.

A região é constituída por municípios circunvizinhos ao município de LimeiraSP, com desempenho fenológico de plantas semelhantes entre si. Em cada safra, utilizou-se o método de amostragem estratificada considerando três classes de idade (CI) de plantas: CI 1 (3 a 5 anos), CI 2 (6 a 10 anos) e CI 3 (maior que 10 anos), sendo o número de amostras para cada estrato determinado em função de sua variabilidade e de seu número de árvores (Tabela 1), de acordo com o procedimento descrito em Cochran (1965).

Cada amostra constituiu-se de todos os frutos da vigésima planta da décima linha do talhão, exceto para planta doente ou fora do estrato da idade. Nesse caso, a planta imediatamente posterior era amostrada. $\mathrm{O}$ talhão foi escolhido aleatoriamente via sorteio entre os talhões disponíveis daquele estrato. Os frutos derriçados foram contados. $\mathrm{O}$ número total de frutos por planta para cada classe de idade foi obtido pela média aritmética simples das amostras. 
Tabela 1. Número de amostras realizadas por cultivar, classe de idade $(\mathrm{CI})^{1}$ e safra. Limeira-SP

\begin{tabular}{|c|c|c|c|c|c|c|c|c|c|c|c|c|c|c|c|c|}
\hline \multirow[t]{2}{*}{ Cultivar } & \multirow{2}{*}{ CI } & \multicolumn{15}{|c|}{ Safra } \\
\hline & & 1990 & 1991 & 1992 & 1993 & 1994 & 1995 & 1996 & 1997 & 1998 & 1999 & 2000 & 2001 & 2002 & 2003 & 2004 \\
\hline \multirow[t]{3}{*}{ 'Pêra' } & 1 & 11 & 11 & 28 & 28 & 42 & 21 & 20 & 24 & 22 & 45 & 46 & 36 & 19 & 19 & 11 \\
\hline & 2 & 64 & 42 & 30 & 32 & 38 & 29 & 19 & 22 & 22 & 71 & 92 & 87 & 29 & 38 & 42 \\
\hline & 3 & 128 & 88 & 78 & 79 & 63 & 24 & 47 & 31 & 45 & 39 & 46 & 52 & 40 & 70 & 78 \\
\hline \multirow[t]{3}{*}{ 'Valência' } & 1 & 10 & 17 & 36 & 32 & 53 & 38 & 28 & 20 & 20 & 25 & 52 & 20 & 18 & 14 & 17 \\
\hline & 2 & 19 & 16 & 23 & 21 & 35 & 33 & 31 & 22 & 29 & 82 & 59 & 70 & 25 & 42 & 34 \\
\hline & 3 & 81 & 73 & 41 & 42 & 41 & 17 & 45 & 26 & 32 & 36 & 21 & 44 & 66 & 70 & 74 \\
\hline \multirow[t]{3}{*}{ 'Hamlin' } & 1 & 6 & 6 & 10 & 6 & 12 & 6 & 18 & 16 & 18 & 8 & 9 & 12 & 7 & 7 & 8 \\
\hline & 2 & 25 & 25 & 14 & 9 & 11 & 8 & 12 & 28 & 25 & 14 & 15 & 15 & 12 & 13 & 11 \\
\hline & 3 & 30 & 23 & 45 & 18 & 13 & 10 & 18 & 32 & 26 & 11 & 12 & 13 & 12 & 26 & 35 \\
\hline
\end{tabular}

${ }^{1}$ Classe de idade 1: 3 a 5 anos; 2: 6 a 10 anos; 3: superior a 10 anos

O rol de talhões disponíveis apresentavam tratos culturais e tipos de solos diferentes. O porta-enxerto também variou, sendo o limoeiro 'Cravo' (Citrus limonia, Osbeck) predominante para cerca de $95 \%$ dos casos.

As variedades cultivadas consideradas apresentam grande importância econômica no cenário de produção de frutas destinadas ao processamento industrial para extração de suco concentrado no Estado de São Paulo. Do total estadual estimado em 210,7 milhões de plantas, de acordo com o último censo citrícola, a 'Pêra' é a variedade cultivada mais plantada, com cerca de 38,2\% das plantas; a 'Valência' representa 17,32\% das plantas e a 'Hamlin', 6,79\% (Fundecitrus, 1999). Pertecem a grupos de maturação distintos, sendo a 'Pêra' uma variedade de meia estação, 'Valência' de maturação tardia e ‘Hamlin’ de maturação precoce (Davies \& Albrigo, 1994).

A laranjeira 'Pêra' provavelmente tem sua origem na Flórida, Estados Unidos; apresenta porte médio e densa folhagem. Sua produtividade é considerada muito boa, podendo atingir em média de 40 a 50 toneladas.ha $^{-1}$ em pomar adulto. Os frutos são médios, com cerca de 145 gramas cada, de forma ovalada, contendo cerca de três a quatro sementes. O suco é abundante ( $52 \%$ do peso do fruto) e de boa qualidade. A colheita principal é realizada entre julho e meados de novembro, sendo muito comum a ocorrência de floradas múltiplas nessa variedade cultivada (Figueiredo, 1991; Davies \& Albrigo, 1994). 
A laranjeira 'Valência' apresenta suposta origem espanhola, entretanto, sem confirmação. As árvores apresentam porte de médio a grande, com abundante folhagem. Trata-se da mais importante variedade tardia de laranja doce cultivada no mundo, com produtividades variando de moderada (40 a 50 toneladas.ha $^{-1}$ ) a alta (acima de 60 toneladas.ha ${ }^{-1}$ ) em algumas regiões. Os frutos são médios, com cerca de 150 gramas cada, com forma esférica a oblonga, e cinco a seis sementes. A qualidade para processamento é muito boa, principalmente pela forte coloração do suco e boa porcentagem de suco no fruto $(50 \%)$. A colheita ocorre entre meados de agosto a dezembro, nas condições do Estado de São Paulo (Figueiredo, 1991; Davies \& Albrigo, 1994).

A laranjeira 'Hamlin' é originária da Flórida, Estados Unidos. As árvores são grandes, com copa cônica e com densa folhagem. A produtividade é excelente, variando em média de 60 a 80 toneladas.ha ${ }^{-1}$. Os frutos são suavemente ovalados, com três a quatro sementes e peso médio de 130 gramas. Apresenta qualidade de suco inferior às duas primeiras variedades cultivadas descritas, principalmente em função da cor pobre e da menor porcentagem de suco do fruto $(41 \%)$. A colheita ocorre geralmente entre maio e meados de julho (Figueiredo, 1991; Davies \& Albrigo, 1994).

A amostragem para estimação de safra realizada pela indústria considera classes de idade definidas com o objetivo de diminuir o número de variáveis a serem levantadas em relação ao levantamento completo para cada idade, obviamente reduzindo o custo da amostragem. As classes foram definidas em função do comportamento produtivo das plantas com o aumento de idade. Assim, considera-se que até dois anos de idade as plantas são improdutivas, encontrando-se em fase de formação; com três anos as plantas começam a produzir, sendo que após o quinto ano passam a ocorrer rendimentos econômicos. A partir do décimo ano considera-se que as plantas entram em fase de produção plena. 


\subsection{Dados meteorológicos}

Foram utilizados dados diários de temperaturas máxima e mínima (Figura 2) e precipitação (Figura 3) entre os anos de 1989 e 2004, obtidos na Estação Meteorológica do Instituto Agronômico de Campinas (IAC), localizada em Limeira-SP (22³2’S, $47^{\circ} 27^{\prime} \mathrm{W}, 639$ metros). A temperatura média diária foi calculada através da média aritmética entre as temperaturas diárias máxima e mínima. Os dados foram utilizados para elaboração do balanço hídrico.

\subsection{Balanço hídrico}

O balanço hídrico foi elaborado com a finalidade de se estimar a deficiência e/ou excedente hídricos durante o ciclo da cultura dos citros. Foi utilizado o programa computacional Bhidrico (versão 3.21) (Dourado Neto et al., 1991), que permite elaborar o balanço hídrico para qualquer distribuição de dados climatológicos disponíveis, empregando o método de Thornthwaite \& Mather (1955) em escala diária, conforme descrito a seguir.

\subsubsection{Evapotranspiração de referência (ou potencial)}

Devido à disponibilidade de dados de precipitação e temperatura, a estimativa da evapotranspiração de referência foi realizada utilizando o procedimento proposto por Thornthwaite (1948). O método de Thornthwaite tem a vantagem de necessitar apenas dos dados de temperatura média dos períodos e da latitude local para o cálculo da evapotranspiração de referência, apresentando melhores resultados entre as latitudes $40^{\circ} \mathrm{N}$ e $40^{\circ} \mathrm{S}$.

Para Thornthwaite (1948), a evapotranspiração de referência (ou potencial) (ETo) é a perda total de água, na forma de vapor, de uma superfície natural bem suprida de água à atmosfera, ocorrendo quando a folhagem vegetal se mantém turgida e quando o processo decorre dependente de atributos do clima, não havendo restrição de água ou cobertura vegetal. Para o cálculo da mesma, o referido autor sugeriu a seguinte equação: 


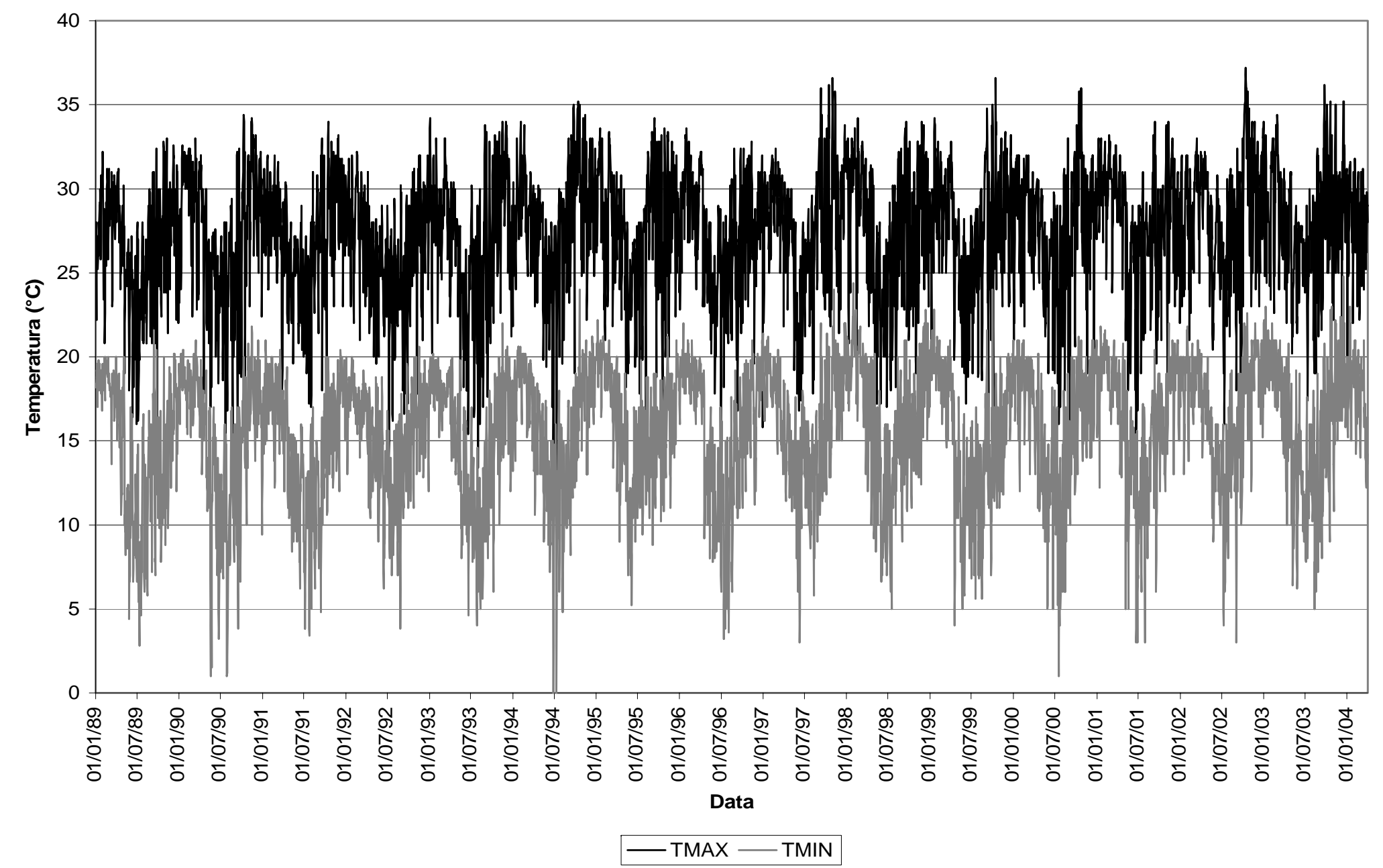

Figura 2 - Temperaturas máxima e mínima $\left({ }^{\circ} \mathrm{C}\right)$ diárias entre os anos de 1989 e 2004. Limeira-SP 


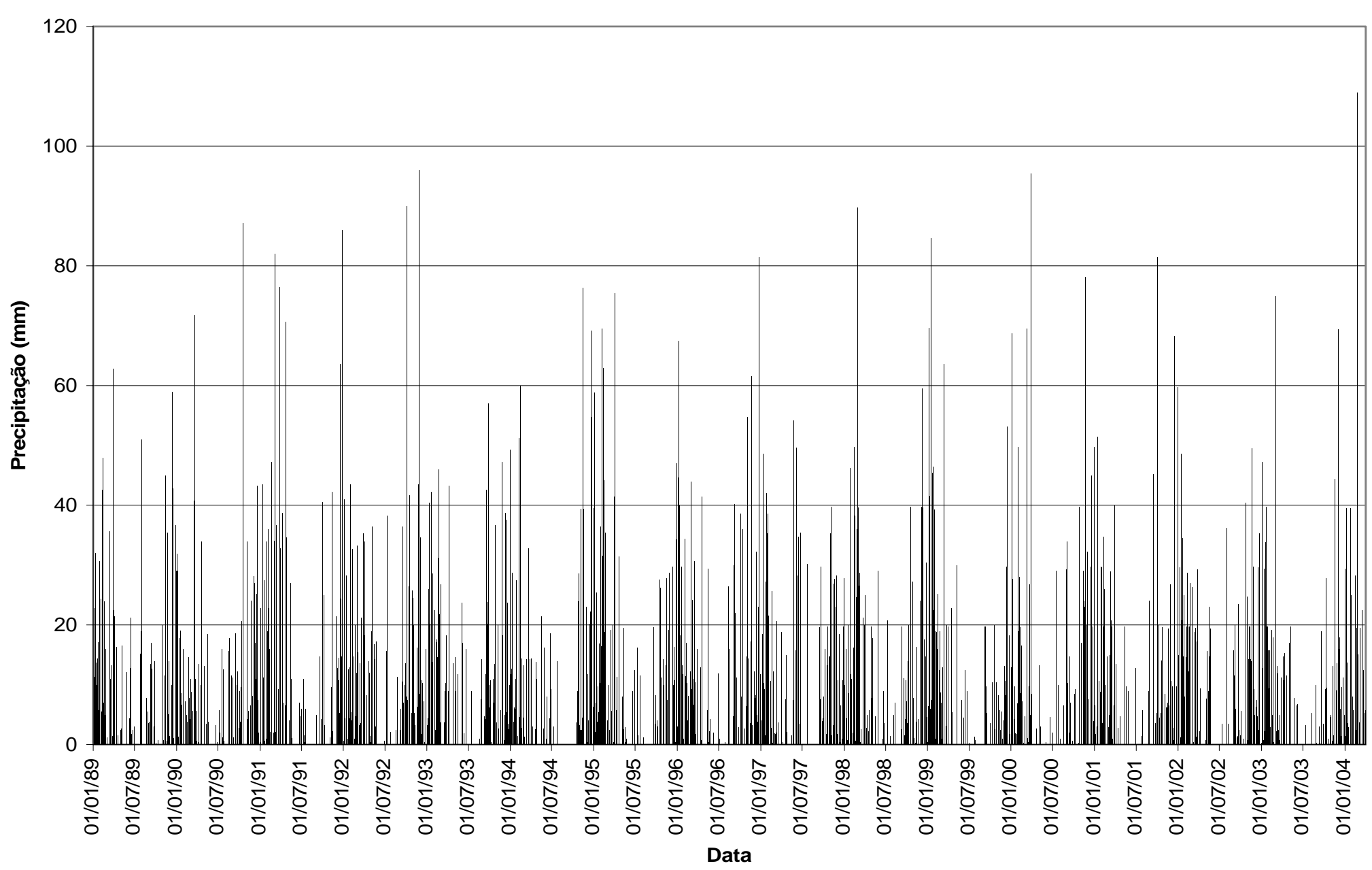

Figura 3 - Precipitação (mm) diária entre os anos de 1989 e 2004. Limeira-SP 


$$
E T o_{n}=0,53 \cdot\left(10 \frac{T_{n}}{I}\right)^{a} \frac{H_{n}}{12} N_{n}
$$

em que $\mathrm{ETo}_{\mathrm{n}}$ é a evapotranspiração de referência (mm/período) do n-ésimo período, $\mathrm{T}_{\mathrm{n}} \mathrm{a}$ temperatura média $\left({ }^{\circ} \mathrm{C}\right)$ referente ao n-ésimo período, ' $\mathrm{I}$ ' o índice térmico, ' $\mathrm{a}$ ' o coeficiente empírico composto, $\mathrm{H}_{\mathrm{n}}$ o número possível de horas de brilho solar no dia mediano do n-ésimo período, e $\mathrm{N}_{\mathrm{n}}$ o número de dias do n-ésimo período.

O índice térmico ou índice de calor anual (I) é assim calculado:

$$
I=0,08745 \sum_{j=1}^{12} T_{j}^{1.514}
$$

em que $\mathrm{T}_{\mathrm{j}}$ refere-se à temperatura $\left({ }^{\circ} \mathrm{C}\right)$ média diária do j-ésimo mês.

O coeficiente empírico composto (a) é calculado da seguinte maneira:

$$
a=\sum_{i=0}^{3} a_{i} I^{i}
$$

em que $a_{i}$ se refere aos coeficientes empíricos $\left(a_{0}=0,49239, a_{1}=0,01792\right.$, $a_{2}=-0,0000771$ e $\left.a_{3}=0,000000675\right)$.

$\mathrm{O}$ número de horas de brilho solar $\left(\mathrm{H}_{\mathrm{n}}\right.$, horas.dia $\left.{ }^{-1}\right)$ do dia mediano do n-ésimo período, necessário para o cálculo da evapotranspiração de referência, é calculado segundo a fórmula:

$$
H_{n}=\frac{24}{\pi} \operatorname{arcos}\left[-\operatorname{tg}\left(\alpha_{n}\right) \operatorname{tg}(\phi)\right]
$$

em que $\phi$ é a latitude do local (rad) e $\alpha_{\mathrm{n}}$ a declinação solar (rad) no dia mediano do nésimo período. A declinação solar foi calculada pela expressão proposta por Paltridge \& Platt (1976):

$$
\alpha_{n}=C_{0}+\sum_{i=1}^{3} C_{i} \operatorname{sen}\left(\frac{2 i \pi d_{n}}{365}\right)-D_{i} \cos \left(\frac{2 i \pi d_{n}}{365}\right)
$$

em que $d_{n}$ é o número de ordem (dia Juliano), defasado de 1 dia do dia mediano do nésimo período (número de ordem defasado do dia mediano 3 é 2, por exemplo), e $\mathrm{C}_{0}, \mathrm{C}_{\mathrm{i}}$ e $\mathrm{D}_{\mathrm{i}}$ são os parâmetros empíricos do modelo (Tabela 2). Considerou-se sempre que o ano possui 365 dias. 
Tabela 2. Parâmetros empíricos do modelo proposto por Paltridge \& Platt (1976) para estimativa da declinação solar

\begin{tabular}{cc}
\hline Parâmetro & Valor \\
\hline C0 & 0,006918 \\
C1 & 0,070257 \\
C2 & 0,000907 \\
C3 & 0,00148 \\
D1 & 0,399912 \\
D2 & 0,006758 \\
D3 & 0,002697 \\
\hline
\end{tabular}

\subsubsection{Evapotranspiração máxima}

Entende-se por evapotranspiração máxima (ou ótima) (ETm, mm.período $\left.{ }^{-1}\right)$ da cultura as perdas totais de água do solo à atmosfera, através de uma superfície vegetada pela cultura de interesse, pelos processos simultâneos de evaporação e transpiração. Essa evapotranspiração, por representar a maior troca de gases possível entre a cultura e a atmosfera, corresponde ao máximo rendimento da cultura. Estima-se a evapotranspiração ótima da cultura de interesse multiplicando-se a evapotranspiração de referência pelo coeficiente de cultura no n-ésimo período, conforme o procedimento proposto por Doorenbos \& Kassam (1979):

$$
\operatorname{ETm}_{n}=E \mathrm{To}_{n} \cdot \mathrm{KC}_{n}
$$

em que $\mathrm{Kc}_{\mathrm{n}}$ se refere ao coeficiente de cultura. Embora tenham sido consideradas três classes de idade de plantas, por falta de informações mais detalhadas para cada uma delas, adotou-se para citros $\mathrm{Kc}=1$, conforme sugerido por Camargo et al. (1999).

\subsubsection{Saldo e negativo acumulado}

Entende-se por saldo a diferença entre chuva e evapotranspiração máxima:

$$
S_{n}=C_{n}-E m_{n}
$$

em que $S_{n}$ é o saldo $(\mathrm{mm}), C_{n}$ a chuva $(\mathrm{mm})$ e $\mathrm{ETm}_{\mathrm{n}}$ a evapotranspiração ótima $(\mathrm{mm})$ da cultura, referentes ao n-ésimo período. 
O negativo acumulado pode ser entendido como o módulo da diferença acumulada das chuvas e evapotranspiração ótima da cultura até o período em questão, o qual é estimado utilizando o seguinte procedimento:

Se $\mathrm{S}_{\mathrm{n}}<0$

$$
L_{n}=L_{n-1}+\left|S_{n}\right|
$$

$\mathrm{e}$

$$
A r m_{n}=C A D_{n} e^{\frac{-L_{n}}{C A D_{n}}}
$$

Se $\mathrm{S}_{\mathrm{n}}>0$

$$
\operatorname{Arm}_{n}=\operatorname{Arm}_{n-1}+S_{n}
$$

$\mathrm{e}$

$$
L_{n}=-C A D_{n} \ln \left(\frac{A r m_{n}}{C A D_{n}}\right)
$$

em que $\mathrm{L}_{\mathrm{n}}$ é o negativo acumulado $(\mathrm{mm}), \mathrm{Arm}_{\mathrm{n}}$ o armazenamento e $\mathrm{CAD}_{\mathrm{n}}$ a capacidade de água disponível no n-ésimo período.

\subsubsection{Critério de iniciar o balanço hídrico}

O critério de iniciar o balanço hídrico cíclico (Thornthwaite \& Mather, 1955) é o de que o solo se encontra na capacidade de campo no final da estação úmida $(\mathrm{L}=0$; Arm=CAD). Caso isso não se verifique, o procedimento é repetido até que haja coerência no balanço hídrico em termos de armazenamento de água disponível no solo e negativo acumulado.

Para os autores a perda de água pelo processo de evapotranspiração é diretamente proporcional ao conteúdo de água no solo, assumindo-se que a evapotranspiração varia linearmente com o armazenamento de água no solo, conseqüentemente, esse armazenamento varia exponencialmente com o negativo acumulado:

$$
\operatorname{Arm}_{n}=C A D_{n} e^{\frac{-L_{n}}{C A D_{n}}}
$$




\subsubsection{Capacidade de água disponível}

Capacidade de água disponível $(\mathrm{CAD}, \mathrm{mm})$ é o armazenamento máximo de água disponível à cultura, pondendo ser calculada pela seguinte expressão:

$$
C A D_{n}=10\left(\theta_{c c}-\theta_{p m p}\right) Z e_{n}
$$

em que $\mathrm{Ze}_{\mathrm{n}}$ é a profundidade efetiva do sistema radicular $(\mathrm{cm})$ no n-ésimo período, $\theta_{\mathrm{cc}}$ a capacidade de campo $\left(\mathrm{cm}^{3} \cdot \mathrm{cm}^{-3}\right)$ e $\theta_{\text {pmp }}$ o ponto de murchamento permanente $\left(\mathrm{cm}^{3} \cdot \mathrm{cm}^{-3}\right)$. Para citros, foi considerada uma profundidade efetiva de $100 \mathrm{~cm}$, já que de acordo com Moreira (1983), para laranjeiras 'Pêra', por exemplo, cerca de $80 \%$ das radicelas se encontram em profundidade de $90 \mathrm{~cm}$. Por falta de informações mais detalhadas para cada uma das três classes de idades de plantas consideradas e visando-se maior operacionalização dos cálculos, adotou-se a mesma Ze para todas as classes. Ford (1954) encontrou que, com o aumento da idade (de 5 a 16 anos), variavam as proporções das raízes nas diversas profundidades estudadas, mas que, de um modo geral, as raízes absorventes estavam um pouco mais profundas nas plantas mais velhas, com a maior concentração delas até $76,2 \mathrm{~cm}$. Camargo et al. (1999) adotou Ze padrão de $100 \mathrm{~cm}$ para laranjeiras 'Valência' entre 5 e 17 anos de idade. Foi considerada CAD de 100mm $\left(1 \mathrm{~mm} . \mathrm{cm}^{-1}\right)$ para Limeira em função do tipo de solo regional predominante (Latossolos) (Prado, 1997).

\subsection{6 Água disponível}

Armazenamento de água disponível (Arm, mm) é a quantidade de água armazenada no perfil do solo, da superfície à profundidade efetiva do sistema radicular, do conteúdo de água correspondente ao ponto de murcha permanente à umidade atual, assumindo que os valores de umidade atual $\left(\theta_{\mathrm{a}}, \mathrm{cm}^{3} . \mathrm{cm}^{-3}\right)$ e os correspondentes ao ponto de murcha permanente em todo o perfil de solo explorado pelo sistema radicular podem ser representados pelos valores médios de umidade:

$$
\operatorname{Arm}_{n}=10\left(\theta_{a}-\theta_{p m p}\right) Z e_{n}
$$


em que $A_{\mathrm{n}}$ é a quantidade de água disponível referente ao n-ésimo período, e $\theta_{\mathrm{a}}$ é a umidade atual no dia mediano do n-ésimo período.

\subsubsection{Estimativa do armazenamento inicial}

Como a umidade do solo no início do período de interesse não era conhecida, fez-se o balanço hídrico cíclico a partir dos dados de temperatura e de chuva referente ao ano de 1989 (primeiro ano da série), usando a profundidade efetiva do sistema radicular de $100 \mathrm{~cm}$ (valor constante).

Sendo assim, utilizou-se o armazenamento correspondente ao último dia de 1989 para iniciar o balanço hídrico seqüencial para o ano subseqüente (1990). Utilizou-se o armazenamento correspondente ao último dia de 1990 para iniciar o balanço hídrico seqüencial para o ano subseqüente (1991). Esse procedimento foi repetido até o ano de 2004.

\subsubsection{Evapotranspiração real}

Estimou-se a evapotranspiração real $(\mathrm{ETr}, \mathrm{mm})$ para todos os períodos pelo método proposto por Thornthwaite \& Mather (1955):

$$
\operatorname{ETr}_{n}=\operatorname{ETm}_{n}\left(\operatorname{se~C~}_{\mathrm{n}} \geq \mathrm{ETm}_{\mathrm{n}}\right)
$$

$\mathrm{e}$

$$
\operatorname{ETr}_{n}=C_{n}+\left|V A_{n}\right|\left(\text { se } C_{\mathrm{n}}<\mathrm{ETm}_{\mathrm{n}}\right)
$$

em que $\mathrm{C}_{\mathrm{n}}$ é a chuva e $\mathrm{VA}_{\mathrm{n}}$ a variação de armazenamento ocorrida no n-ésimo período, sendo que:

$$
V A_{n}=A r m_{n}-A r m_{n-1}
$$

\subsubsection{Deficiência hídrica}

Deficiência hídrica (DH) é definida como a diferença entre a ETm e a ETr:

$$
D H_{n}=E \operatorname{Tm}_{n}-\operatorname{ETr}_{n}\left(\text { se } \mathrm{C}_{\mathrm{n}}<\mathrm{ETm}_{\mathrm{n}}\right)
$$


Existe deficiência hídrica nos períodos em que a ETr é menor que a ETm, em conseqüência do total de chuva e da variação de água armazenada no perfil de solo não suprirem a demanda evapotranspiratória. Se $C_{n} \geq E m_{n}$, a deficiência hídrica é nula $\left(\mathrm{DH}_{\mathrm{n}}=0\right)$.

\subsubsection{Excedente hídrico}

Excedente hídrico $(\mathrm{EH})$ é definido como a diferença entre a quantidade de chuva de um período e a evapotranspiração real mais a variação do armazenamento:

$$
E H_{n}=C_{n}-E T r_{n}-\left|V A_{n}\right|\left(\operatorname{se~C}_{\mathrm{n}} \geq \operatorname{ETm}_{\mathrm{n}}\right)
$$

Existe excedente hídrico quando a chuva excede a soma da evapotranspiração real e a quantidade de água que falta no solo para atingir a sua capacidade de armazenamento máximo (CAD). Se $\mathrm{C}_{\mathrm{n}}<\mathrm{ETm}_{\mathrm{n}}$, o excedente hídrico é nulo $\left(\mathrm{EH}_{\mathrm{n}}=0\right)$.

\subsection{Análise estatística}

Considerou-se a hipótese de que o número de frutos por planta de uma cultura pode ser predito satisfatoriamente a partir das variáveis componentes do balanço hídrico e da temperatura do ar, nas diferentes fases do ciclo da cultura, além da produção de frutos do ano anterior.

Foram avaliados períodos desde o ano do florescimento, ou seja, o ano anterior à safra, até janeiro do ano da safra. Assim, períodos denominados 1, 2, ... 12, correspondem, respectivamente, aos meses de janeiro, fevereiro, ... e dezembro do ano do florescimento; e o período denominado de 13 corresponde ao mês de janeiro da safra corrente. Combinações de meses consecutivos também foram testadas, sendo que, períodos como 1 a 2 e 1 a 3 indicam, respectivamente, os períodos entre janeiro a fevereiro e janeiro a março do ano do florescimento. Ao todo, foram analisados 46 períodos diferentes.

Inicialmente, foram calculados coeficientes de correlação linear (r) entre o componente de produtividade em estudo, número de frutos por planta da safra, e 
variáveis agrometeorológicas dos vários períodos anteriores à amostragem, visando a avaliação do efeito individual das mesmas em períodos distintos do ciclo da cultura. As correlações foram calculadas separadamente para cada um dos estratos resultantes das combinações da classe de idade da planta e cultivar ( 9 estratos). O teste $\mathrm{F}$ de Fisher foi usado para testar a significância das correlações (Weiss, 1982).

As variáveis agrometeorológicas testadas para todos os períodos foram: temperatura média (TMED), máxima (TMAX) e mínima (TMIN), expressas em ${ }^{\circ} \mathrm{C}$; e totais de precipitação (PREC), evapotranspiração máxima (ETM), evapotranspiração real (ETR), deficiência hídrica (DEF) e excedente hídrico (EXC), expressas em mm, número de dias com deficiência hídrica (NDH) e a relação ETR/ETM. O valor de ETR/ETM indica o grau de suprimento de água à cultura: valor unitário indica ausência de restrição hídrica; valor próximo a zero indica deficiência hídrica extrema no período. A inclusão de variáveis correlatas, tais como DEF e NDH, deriva da tentativa de se encontrar a expressão que melhor capte uma possível correlação com a variável dependente (número de frutos por planta).

A influência da classe de idade no número de frutos por planta de cada cultivar, sem considerar as variáveis agrometeorológicas, foi avaliada mediante regressão linear, considerando-se o número de frutos por planta como variável dependente e a classe de idade como variável independente. Os coeficientes de determinação foram calculados e o teste $\mathrm{F}$ de Fisher foi usado para testar a significância das correlações.

A influência do número de frutos produzidos por planta na safra anterior foi avaliada utilizando o seguinte modelo autoregressivo de primeira ordem (Shumway, 1988):

$$
Y_{i j t}=\alpha_{i j 0}+\alpha_{i j 1} \cdot Y_{i j(t-1)}+\varepsilon_{i j t}
$$

em que $Y_{i j t}$ é o número de frutos por planta na variedade cultivada $i$ ( $i=P$ : 'Pêra', $V$ : 'Valência', H: 'Hamlin'), na classe de idade $j(j=1,2,3)$ e na safra $t,(t=1990, \ldots, 2004)$, $\alpha_{i j 0}$ é o intercepto de cada modelo e $\alpha_{i j 1}$ o coeficiente que representa o efeito do número de frutos da safra anterior $Y_{i j t(t-1)}$, e $\varepsilon_{i j t}$ o erro aleatório associado a cada observação. Os modelos autoregressivos foram ajustados utilizando o procedimento ARIMA do 
‘software' SAS (Statistical Analysis System) (SAS, 1998). A significância do parâmetro $\alpha_{i j 1}$ foi avaliada utilizando o teste t de Student.

Com base nos coeficientes de correlação e nos coeficientes $\alpha_{\mathrm{ij} 1}$, escolheram-se subconjuntos de variáveis preditoras a serem usadas em cada modelo de regressão, sendo que prioritariamente foram escolhidas aquelas com as maiores correlações com o número de frutos por planta, embora esse critério não tenha sido exclusivo, considerando também questões fitotécnicas como o período de ocorrência vinculado à fase fenológica da cultura, procurando-se contemplar as diferentes fases do ciclo da cultura. Outro fator considerado foi, em primeira instância, a consistência do efeito da variável para as diferentes classes de idade de cada variedade cultivada, e, em segundo caso, entre as diferentes variedades cultivadas.

Foram ajustados, então, modelos de regressão linear múltipla para predição do número de frutos por planta em função das variáveis selecionadas para cada um dos estratos, representados por:

$$
Y_{i j t}=\beta_{i j 0}+\sum_{k=1}^{n} \beta_{i j k} \cdot X_{i j t}+\varepsilon_{i j t}
$$

em que $Y_{i j t}$ é o número de frutos por planta na variedade cultivada $i$ ( $i=P$ : 'Pêra', $V$ : 'Valência', H: 'Hamlin'), na classe de idade $j(j=1,2,3)$ e na safra $t,(t=1990, \ldots, 2004)$, $\beta_{i j 0}$ é o intercepto de cada modelo e $\beta_{i j k}$ o coeficiente que representa o efeito de cada variável preditora $X_{i j t}$ sobre $Y_{i j t}$ e $\varepsilon_{i j t}$ o erro aleatório associado a cada observação. Um importante pressuposto desse tipo de modelo é a ausência de correlação entre os erros $\varepsilon_{i j t}$ (Draper \& Smith, 1981).

Utilizando o método "stepwise" do procedimento REG do 'software' SAS (SAS, 1998), os modelos foram reduzidos utilizando os seguintes critérios: (i) valores $p$ associados aos testes t para avaliação da significância dos parâmetros correspondentes a cada variável preditora inferiores a 0,20 ; (ii) entre os modelos onde o critério (i) foi satisfeito, escolheu-se aquele com o maior coeficiente de determinação.

Utilizando os modelos selecionados, foram estimados valores de número de frutos por planta para cada safra com respectivos intervalos de confiança de $95 \%$. A 
qualidade do ajuste de cada modelo foi avaliada com base nos erros padrão relativos dos valores preditos (erro padrão/valor predito), resíduos padronizados (resíduo/erro padrão do resíduo) e coeficientes de determinação $\left(\mathrm{R}^{2}\right.$, soma de quadrados do modelo/soma de quadrados total) (Draper \& Smith, 1981).

O pressuposto de ausência de correlação entre os erros $\varepsilon_{i j t}$ foi avaliado ajustandose modelos autoregressivos para os resíduos dos modelos finais para cada estrato, descritos por:

$$
r_{i j t}=\theta_{i j 0}+\theta_{i j 1} \cdot r_{i j(t-1)}+\varepsilon_{i j t}
$$

onde $r_{i j t}$ é a diferença entre o valor observado $Y_{i j t}$ e o correspondente valor predito para o número de frutos por planta na variedade i (i=P: 'Pêra', V: 'Valência', H: 'Hamlin'), na classe de idade $j(j=1,2,3)$ e na safra $t,(t=1990, \ldots, 2004), \theta_{i j 0}$ o intercepto de cada modelo e $\theta_{i j 1}$ o coeficiente que representa o grau de autocorrelação entre os resíduos. Os modelos autoregressivos foram ajustados utilizando o procedimento ARIMA do ‘software' SAS (SAS, 1998). A significância do parâmetro $\theta_{i j 1}$ foi avaliada utilizando o teste $\mathrm{t}$ de Student. 


\section{RESULTADOS E DISCUSSÃO}

\subsection{Condições meteorológicas entre 1989 e 2004}

Os dados médios mensais de temperaturas média, máxima e mínima, precipitação e os componentes do balanço hídrico observados durante os anos considerados no estudo para a localidade de Limeira se encontram em ANEXO (Tabelas 12 a 21). Cabe salientar que os cálculos referentes ao balanço hídrico foram efetuados na escala diária.

A temperatura média anual variou de $20,4^{\circ} \mathrm{C}$ (valor mínimo), em 1989 , a $22,4^{\circ} \mathrm{C}$ (valor máximo), em 2002, com média geral, para a série de anos, de $21,4^{\circ} \mathrm{C}$. A temperatura média mensal ficou entre $16,4^{\circ} \mathrm{C}$ (valor mínimo), em julho de 1990 , e 25,6 $6^{\circ} \mathrm{C}$ (valor máximo), em outubro de 2002 (ANEXO: Tabela 12). Os meses de verão, janeiro e fevereiro, seguidos por dezembro, foram sempre os mais quentes de cada ano, com média de $23,8^{\circ} \mathrm{C}$. A temperatura média de junho e julho (meses mais frios) variou

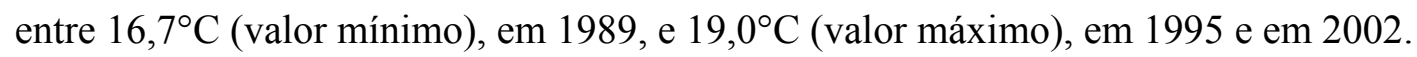

A temperatura máxima média anual variou de $26,4^{\circ} \mathrm{C}$ (valor mínimo) a $28,4^{\circ} \mathrm{C}$ (valor máximo), respectivamente, nos anos de 1989 e 2002, com média no período todo de $27,4^{\circ} \mathrm{C}$, sendo que os meses com as maiores temperaturas máximas foram outubro de $2000\left(31,6^{\circ} \mathrm{C}\right)$ e outubro de $2002\left(32,7^{\circ} \mathrm{C}\right)$. Os meses mais frios apresentaram médias de $24,4^{\circ} \mathrm{C}$ (valores mínimos) e $29,0^{\circ} \mathrm{C}$ (valores máximos) (ANEXO: Tabela 13).

A temperatura mínima média anual foi de $15,4^{\circ} \mathrm{C}$, e variou de $14,5^{\circ} \mathrm{C}$ (valor mínimo), em 1989 , a $16,5^{\circ} \mathrm{C}$ (valor máximo), em 2002 . O mês que apresentou a maior temperatura média mínima foi fevereiro de $1998\left(20,2^{\circ} \mathrm{C}\right)$ e a menor temperatura média 
mínima ocorreu em julho de $1996\left(9,5^{\circ} \mathrm{C}\right)$. A média da temperatura mínima nos meses mais frios foi de $11,5^{\circ} \mathrm{C}$ e, nos meses mais quentes, de $18,6^{\circ} \mathrm{C}$ (ANEXO: Tabela 14).

Assim, em Limeira, no período de pré-florescimento, aproximadamente entre maio e julho, a planta cítrica é submetida a temperaturas mais amenas, com médias mínimas menores que $13,0^{\circ} \mathrm{C}$, e médias máximas abaixo de $25,0^{\circ} \mathrm{C}$. De agosto a novembro, entre o final do pré-florescimento e a fixação dos frutos, as temperaturas encontram-se em elevação, com médias mínimas de $12,3^{\circ} \mathrm{C}$ a $17^{\circ} \mathrm{C}$, e médias máximas de $26,4^{\circ} \mathrm{C}$ a $28,9^{\circ} \mathrm{C}$. De dezembro, mês em que geralmente a fixação dos frutos das floradas principais está se estabilizando, até março, fase de crescimento, os valores de temperatura média mínima encontram-se acima de $18^{\circ} \mathrm{C}$ e os de média máxima acima de $28,9^{\circ} \mathrm{C}$.

A análise conjunta da Figura 3 com a distribuição de precipitação (ANEXO: Tabela 15) e da Figura 4, com os componentes do balanço hídrico (ANEXO: Tabelas 16 a 21), permite uma visão da disponibilidade hídrica no período. Em Limeira, o ano de menor precipitação foi 2003, com $1129 \mathrm{~mm}$, e o mais chuvoso foi 1996, com 1734mm, sendo de 1419mm a média dos 15 anos analisados (ANEXO: Tabela 15). Os meses com a menor ocorrência de chuvas foram junho, julho e agosto - período entre o préflorescimento e o início do florescimento. Dezembro e janeiro têm maior ocorrência de chuvas, quando a fixação se estabiliza e o crescimento está acontecendo. A evapotranspiração máxima anual (ANEXO: Tabela 16) variou de 965mm (1989) a $1128 \mathrm{~mm}$ (2002) e a evapotranspiração real (ANEXO: Tabela 17) anual variou de $759 \mathrm{~mm}$ (1999) a $905 \mathrm{~mm}$ (2002).

Com relação à deficiência hídrica anual (ANEXO: Tabela 18), a média dos 15 anos considerados foi de 210mm. As maiores deficiências foram alcançadas em 1999 (270mm) e 2003 (291 mm), e as menores, em 1992 (121mm) e 1996 (136mm). Os meses em que ocorre maior deficiência são agosto e setembro, com aproximadamente $28 \mathrm{~mm}$ cada, e os meses de menor deficiência são janeiro e fevereiro, com cerca de $8 \mathrm{~mm}$ cada. 


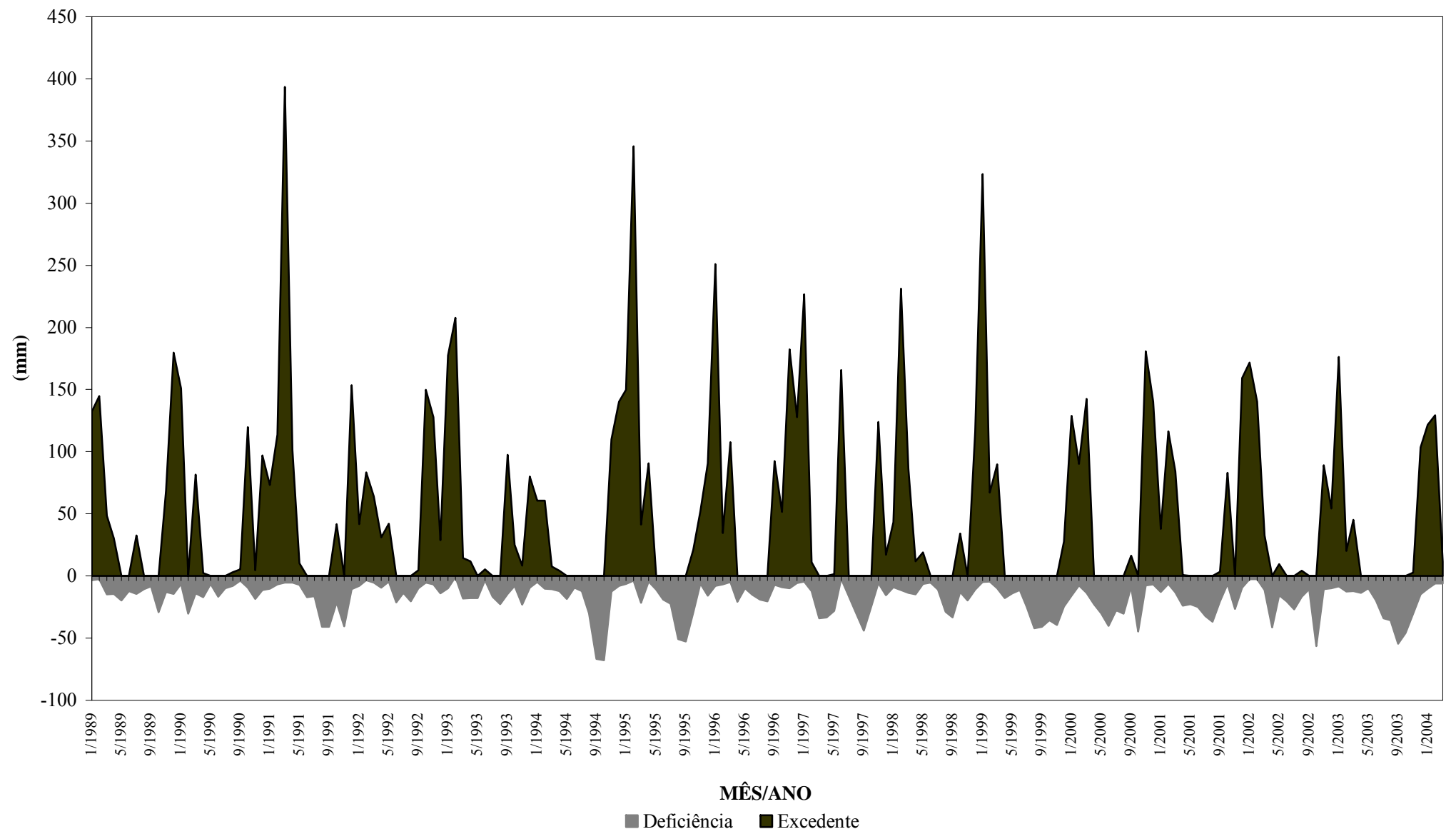

Figura 4 - Componentes do balanço hídrico, para CAD de 100 mm, entre os anos de 1989 e 2004. Limeira-SP 
O excedente hídrico anual (ANEXO: Tabela 19) médio do anos estudados foi de $590 \mathrm{~mm}$, sendo o ano de 2003 o de menor excedente $(348 \mathrm{~mm}$ ) e o de 1991, o de maior (888mm). Os meses de janeiro e fevereiro são aqueles onde mais excedentes acontecem, enquanto em julho e agosto eles praticamente não ocorrem. Nos meses de outubro e novembro, no florescimento e início da fixação dos frutos, quando do início da estação chuvosa, foram verificados anos com grandes precipitações e, por conseguinte, excedentes, como os anos de 1992, com $278 \mathrm{~mm}$ de excedente, e o de 1996, com $234 \mathrm{~mm}$. Nesses meses, também houve anos com excedente nulo (1999) ou próximo a zero (2003).

A média anual de dias com alguma deficiência hídrica (ANEXO: Tabela 20) foi de 267 dias, sendo 1990 o ano com menor número de dias com deficiência (248) e 1999 o ano com maior número de dias com deficiência (292). Os meses que, em média, apresentam maior número de dias com deficiência são julho e agosto (28 cada) e os com menor número de dias são fevereiro (15) e janeiro (16).

A deficiência hídrica $(\mathrm{mm})$ e o número de dias com deficiência são decorrentes do método utilizado para cálculo do balanço hídrico (vide equações 15, 16 e 18) (Thornthwaite \& Mather, 1955) em escala diária, o qual considera que sempre que o armazenamento for inferior à capacidade de água disponível e, concomitantemente, a chuva for inferior à evapotranspiração máxima ocorre deficiência. Thornthwaite \& Mather (1955) sugerem que a evapotranspiração real só se equivale à evapotranspiração máxima quando o solo se encontra na capacidade de campo. Assim, por exemplo, dias com $0,1 \mathrm{~mm}$ (diferença entre a chuva e a evapotranspiração máxima) de deficiência são considerados dias secos, o que ocorre com freqüência nos meses de verão, a exemplo de janeiro, em que a média de deficiência é 8mm, com 16 dias sob deficiência.

A relação entre a evapotranspiração real e a máxima (ETR/ETM) média anual do período foi de 0,80 , indicando bom suprimento médio de água à cultura na localidade. $\mathrm{O}$ ano de maior restrição hídrica foi $2003(0,73)$ e os de menor foram 1992 e $1996(0,87)$. O mês de maior restrição hídrica é agosto, com ETR/ETM de 0,56, e o mês de menor restrição hídrica é janeiro, com ETR/ETM de 0,94. 


\subsection{Números de frutos por planta observados}

Para a variedade cultivada 'Pêra', classe de idade 1 (3 a 5 anos), os valores observados variaram de 184 frutos por planta, em 1993, a 407 frutos por planta, em 2002 (Tabela 3). Para a idade 2 (6 a 10 anos), os valores observados variaram de 310 frutos por planta, em 2001, a 735 frutos por planta, em 1999, e, para a idade 3 (maior que 10 anos), variaram de 382 frutos por planta, em 2001, a 973 frutos por planta, em 1999. Constata-se, portanto, a influência da idade no número de frutos por planta, com valores crescentes a medida que a idade aumenta.

Tabela 3. Números de frutos por planta observados da variedade cultivada 'Pêra' por safra e classe de idade $^{1}$. Limeira-SP

\begin{tabular}{lccc}
\hline Safra & \multicolumn{3}{c}{ Classe de Idade } \\
& 1 & 2 & 3 \\
\hline 1990 & 367 & 637 & 700 \\
1991 & 242 & 452 & 635 \\
1992 & 239 & 544 & 706 \\
1993 & 184 & 419 & 470 \\
1994 & 235 & 488 & 631 \\
1995 & 286 & 493 & 724 \\
1996 & 401 & 541 & 639 \\
1997 & 367 & 590 & 589 \\
1998 & 332 & 554 & 700 \\
1999 & 403 & 735 & 973 \\
2000 & 315 & 728 & 902 \\
2001 & 186 & 310 & 382 \\
2002 & 407 & 646 & 786 \\
2003 & 193 & 473 & 780 \\
2004 & 281 & 453 & 599 \\
\hline
\end{tabular}

${ }^{1}$ Classe de idade 1: 3 a 5 anos; 2: 6 a 10 anos; 3 : superior a 10 anos

De um modo geral, para laranjeira 'Pêra', a safra 1999, seguida pela safra 2000, tiveram os melhores resultados em número de frutos por planta, e 2001 e 1993, os menores resultados. 
Os valores observados na classe de idade 1 da variedade cultivada 'Valência' variaram de 156 frutos por planta, em 2003, a 492 frutos por planta, em 1990 (Tabela 4). Para a classe de idade 2, a amplitude foi de 416 frutos por planta, em 2001, a 877 frutos por planta, em 1999, e, para a classe de idade 3, a amplitude foi de 603, em 1993, a 1398 frutos por planta, em 1999. Novamente, a influência crescente da idade no número de frutos por planta é observada. No conjunto das idades, as safras de menores valores observados foram 2001 e 2003, e as de maiores foram 1999 e 2000.

Tabela 4. Números de frutos por planta observados da variedade cultivada 'Valência' por safra e classe de idade ${ }^{1}$. Limeira-SP

\begin{tabular}{cccc}
\hline Safra & \multicolumn{3}{c}{ Classe de Idade } \\
& 1 & 2 & 3 \\
\hline 1990 & 492 & 592 & 711 \\
1991 & 207 & 545 & 856 \\
1992 & 266 & 627 & 980 \\
1993 & 297 & 583 & 603 \\
1994 & 289 & 490 & 637 \\
1995 & 330 & 583 & 1044 \\
1996 & 403 & 660 & 850 \\
1997 & 300 & 607 & 897 \\
1998 & 234 & 582 & 675 \\
1999 & 434 & 877 & 1398 \\
2000 & 374 & 787 & 1223 \\
2001 & 225 & 416 & 707 \\
2002 & 460 & 788 & 867 \\
2003 & 156 & 480 & 640 \\
2004 & 317 & 699 & 1049 \\
\hline
\end{tabular}

${ }^{1}$ Classe de idade 1: 3 a 5 anos; 2: 6 a 10 anos; 3: superior a 10 anos

Os valores referentes ao número de frutos por planta observados entre 1990 e 2004 para a variedade cultivada 'Hamlin' apresentam uma amplitude de 233 frutos por planta, em 2001, a 689 frutos por planta, em 1999, para a classe de idade 1 (Tabela 5). Para a classe de idade 2, os valores variaram de 673 frutos por planta, em 1995, a 1723 frutos por planta, em 1999 e, para a classe de idade 3, os valores observados variaram de 973 frutos por planta, em 1998, a 2120 frutos por planta, em 2004. Considerando o 
conjunto das idades, as safras de menores valores de número de frutos por planta foram 2001 e 2003 e as de maiores valores foram 1999 e 2004.

Tabela 5. Números de frutos por planta observados da variedade cultivada 'Hamlin' por safra e classe de idade ${ }^{1}$. Limeira-SP

\begin{tabular}{cccc}
\hline Safra & \multicolumn{3}{c}{ Classe de Idade } \\
& 1 & 2 & 3 \\
\hline 1990 & 441 & 1122 & 1513 \\
1991 & 287 & 1023 & 1739 \\
1992 & 478 & 1325 & 2016 \\
1993 & 379 & 929 & 1135 \\
1994 & 513 & 733 & 1110 \\
1995 & 295 & 673 & 1689 \\
1996 & 595 & 724 & 1996 \\
1997 & 618 & 1351 & 2053 \\
1998 & 394 & 809 & 973 \\
1999 & 689 & 1723 & 1887 \\
2000 & 587 & 1301 & 1733 \\
2001 & 233 & 698 & 1163 \\
2002 & 384 & 1325 & 1843 \\
2003 & 492 & 676 & 1094 \\
2004 & 615 & 1419 & 2120 \\
\hline
\end{tabular}

${ }^{1}$ Classe de idade 1: 3 a 5 anos; 2: 6 a 10 anos; 3: superior a 10 anos

Constata-se que 'Hamlin' é a variedade cultivada que apresenta maior produção de frutos por planta e 'Pêra' a que apresenta a menor, identificando a diferença de potencial genético produtivo vinculado a cada cultivar estudado.

De fato, a laranjeira 'Hamlin' apresenta porte grande e é conhecida como a mais produtiva das variedades cultivadas nacionais de laranja doce; já a 'Valência' apresenta porte médio a grande, com produção muito boa, intermediária entre 'Pêra' e 'Hamlin'; e a variedade cultivada 'Pêra' tem porte médio, apresentando também boa produtividade (Figueiredo, 1991; Donadio et al., 1995). 


\subsection{Influência da classe de idade}

Na Tabela 6 são apresentados os resultados da influência da classe de idade no número de frutos por planta de cada cultivar, sem considerar as variáveis agrometeorológicas.

Tabela 6. Coeficientes das equações de regressão linear entre número de frutos por planta $(\mathrm{Y})$ por cultivar e classe de idade $(\mathrm{x})^{*}$, coeficiente de determinação $\left(\mathrm{R}^{2}\right)$ e valor $\mathrm{p}^{* *}$

\begin{tabular}{ccccc}
\hline Cultivar & \multicolumn{2}{c}{$\mathrm{Y}=\mathrm{a}+\mathrm{b} \cdot \mathrm{x}+\varepsilon$} & $\mathrm{R}^{2}$ & Valor $\mathrm{p}$ \\
& $\mathrm{A}$ & $\mathrm{b}$ & & \\
\hline 'Pêra' & 119,622 & 192,600 & 0,65 & 0,0001 \\
'Valência' & 48,400 & 278,433 & 0,68 & 0,0001 \\
'Hamlin' & $-95,489$ & 568,800 & 0,70 & 0,0001 \\
\hline *x = 1: 3 a 5 anos, 2: 6 a 10 anos, 3: superior a 10 anos \\
** Valores p associados aos testes F para investigar a significância do modelo
\end{tabular}

Todos os coeficientes de determinação entre a classe de idade e o número de frutos por planta foram significativos ao nível de $1 \%$ de probabilidade. Assim, a medida que as variedades cultivadas mudam de classe de idade, há acréscimo no potencial produtivo de uma classe para outra.

A influência da idade da planta cítrica em seus componentes de produção vem sendo citada (Reuther, 1973; Nogueira, 1979; Albisu, 1982). As plantas cítricas normalmente começam a produzir frutos no terceiro ano após o plantio, mas rendimentos econômicos são geralmente obtidos apenas após o quinto ano de idade do pomar (Doorenbos \& Kassam, 1979).

Tubelis \& Salibe (1988) verificaram uma relação linear crescente entre idade (em anos) da variedade cultivada 'Hamlin' e produtividade (em kg/planta) entre 7 e 17 anos $\left(\mathrm{R}^{2}=0,61\right)$. Do mesmo modo, Ben Mechlia \& Carrol (1989) relatam uma produtividade crescente linearmente até os 25 anos de idade do pomar para a variedade cultivada 'Valência'. 
Analisando-se o coeficiente angular referente à relação funcional linear entre número de frutos por planta e classe de idade (b) (Tabela 6), verifica-se que o acréscimo entre classes é mais pronunciado para 'Hamlin', com cerca de 569 frutos por planta, seguida por 'Valência', com 278 frutos por planta e 'Pêra', com 193 frutos por planta. Tais diferenças encontram-se relacionadas aos distintos potenciais genéticos produtivos vinculados a cada cultivar estudado (Figueiredo, 1991; Donadio et al., 1995), conforme já discutido no item anterior.

Dada sua influência na produção de frutos por planta e o fato dos dados amostrais terem sido coletados estratificadamente por classe de idade, os modelos agrometeorológicos para estimação do número de frutos por planta foram desenvolvidos por classe de idade, conforme sugerido por Albisu (1982) e Pino \& Amaro (1986).

\subsection{Influência do número de frutos do ano anterior}

A Tabela 7 apresenta os resultados dos modelos autoregressivos de primeira ordem utilizados para avaliar a influência do número de frutos do ano anterior por cultivar e por classe de idade.

Não foram detectadas influências significativas $(p>0,10)$ do número de frutos por planta do ano anterior no número de frutos por planta da safra seguinte para todas as variedades cultivadas e classes de idade estudadas, exceto para a variedade cultivada 'Valência' na classe de idade 1.

O padrão de dispersão aleatório nos dados para cada estrato de cultivar e classe de idade também ilustra bem este fato (Figura 5). Analisando-se o conjunto dos dados por cultivar, aparentemente, observa-se correlação positiva entre a produção de frutos de uma safra com sua anterior, mas o efeito observado deriva apenas do padrão crescente de produção entre as classes de idade.

Do ponto de vista fitotécnico, seria de se esperar uma correlação negativa entre a produção de frutos com sua anterior e não positiva como o mascaramento dos dados gerado pelo agrupamento de idades proporciona (quando a produtividade é alta num ano, espera-se baixa produtividade no ano seguinte e vice-versa). 
Tabela 7. Estimativas do parâmetros $\alpha_{\mathrm{ij} 1}$ (equação 20) dos modelos autoregressivos usados para investigar presença de correlação entre o número de frutos produzidos na safra anterior $\left(Y_{t-1}\right)$ e na corrente safra $\left(Y_{t}\right)$ por cultivar $(\mathrm{P}$ : 'Pêra', V: 'Valência', H: 'Hamlin') e por classe de idade (CI - 1: 3 a 5 anos, 2: 6 a 10 anos, 3: superior a 10 anos)

\begin{tabular}{ccccccc}
\hline Cultivar & CI & Parâmetro & Estimativa & Erro padrão & Estatística t & Valor p* \\
\hline 'Pêra' & 1 & $\alpha_{\mathrm{P} 11}$ & 0,0430 & 0,2775 & 0,16 & 0,8792 \\
'Pêra' & 2 & $\alpha_{\mathrm{P} 21}$ & $-0,1720$ & 0,2789 & $-0,62$ & 0,5482 \\
'Pêra' & 3 & $\alpha_{\mathrm{P} 31}$ & $-0,0774$ & 0,2798 & $-0,28$ & 0,7863 \\
'Valência' & 1 & $\alpha_{\mathrm{V} 11}$ & 0,5500 & 0,2316 & $-2,37$ & 0,0337 \\
'Valência' & 2 & $\alpha_{\mathrm{V} 21}$ & 0,2847 & 0,2702 & $-1,05$ & 0,3113 \\
'Valência' & 3 & $\alpha_{\mathrm{V} 31}$ & 0,0447 & 0,2832 & $-0,16$ & 0,8771 \\
'Hamlin' & 1 & $\alpha_{\mathrm{H} 11}$ & $-0,0853$ & 0,2895 & $-0,29$ & 0,7730 \\
'Hamlin' & 2 & $\alpha_{\mathrm{H} 21}$ & $-0,2438$ & 0,2827 & $-0,86$ & 0,4046 \\
'Hamlin' & 3 & $\alpha_{\mathrm{H} 31}$ & $-0,3602$ & 0,2788 & $-1,29$ & 0,2190 \\
\hline
\end{tabular}

* Valor aproximado da probabilidade de erro tipo I associada ao teste $\mathrm{t}$ para contrastes utilizado para a hipótese de ausência de correlação entre $\mathrm{Y}_{\mathrm{t}}$ e $\mathrm{Y}_{\mathrm{t}-1}$

De acordo com Ben Mechlia \& Carrol (1989), a produtividade do ano anterior influi na fixação de frutos. Como a produtividade é tratada como massa de frutos por planta, os resultados não são comparáveis, já que, apenas um componente da produtividade - o número de frutos por planta - está aqui sendo considerado, não conjuntamente com a massa unitária de cada fruto. 
(A)

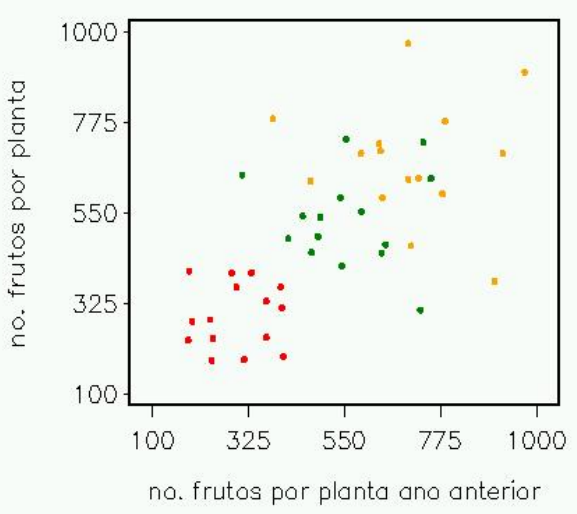

idade $\because 1 \cdots 2$

(B)

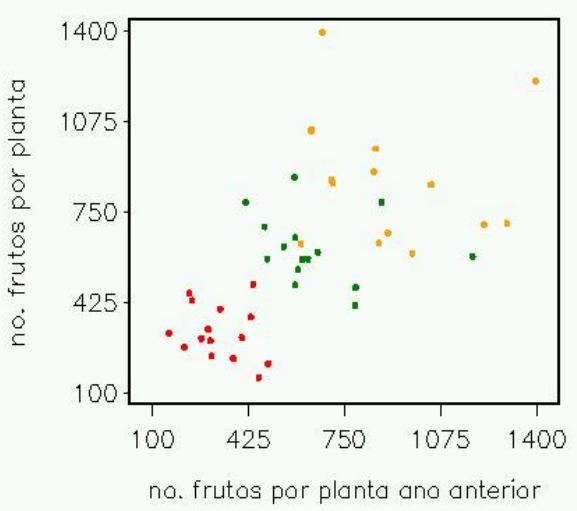

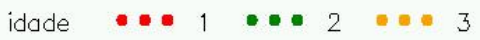

(c)

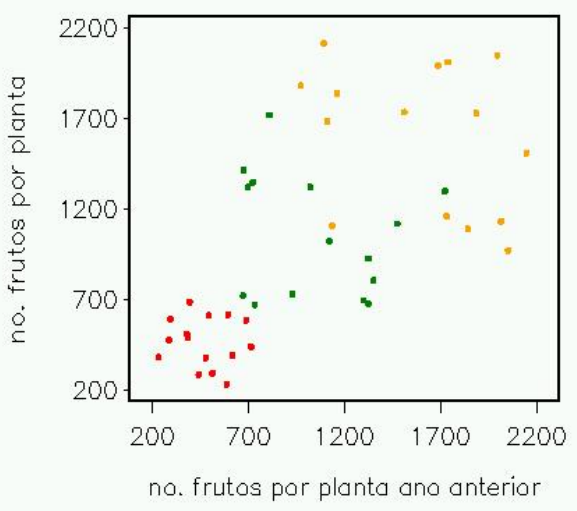

idade $1 \cdots 2=0.3$

Figura 5 - Relações entre o número de frutos produzidos por planta numa safra e na safra imediatamente anterior. Cultivares 'Pêra' (A), 'Valência' (B) e 'Hamlin' (C) 
No entanto, à semelhança dos resultados aqui obtidos, em estudo conduzido por Tubelis \& Salibe (1988), não se constatou a influência da produtividade (kg por planta), de determinado ano na produtividade do ano seguinte para a laranjeira 'Hamlin'. Do mesmo modo, ajustando-se um modelo autoregressivo, igual ao aqui considerado, para os valores de produtividade relativa e sua anterior publicados por Camargo et al. (1999) para a laranjeira 'Valência', não foi encontrada autocorrelação significativa $(p=0,28)$. Pasqua (2000) relata que a produção do ano anterior não explica significativamente as variações na produção do ano corrente para laranjeira 'Pêra'.

Grandes influências de produção de um ano no ano posterior têm sido relatadas para cultivares e híbridos de tangerinas, a exemplo do tangor 'Murcote' (Citrus reticulata Blanco x C. sinensis Osbeck), com claro padrão de alternância de altas e baixas produções (Goldschmidt \& Golomb, 1982; Davies \& Albrigo, 1994; Syvertsen \& Lloyd, 1994), fato aqui não constatado para as variedades cultivadas em questão.

Assim, a ausência de significância entre a produção de número de frutos por planta com a produção anterior vem justificar o uso de modelos de análise de regressão múltipla neste estudo e não o uso de modelos autoregressivos ou de séries temporais (Shumway, 1988).

\subsection{Influência das variáveis agrometeorológicas no ciclo da cultura}

De acordo com as condições meteorológicas prevalescentes, geralmente, a maioria das variedades cultivadas de citros fixam entre uma ou duas colheitas principais e uma ou duas colheitas menores por safra, em condições como as do sudeste do Brasil (Reuther, 1973; Ortolani et al., 1991). As fases fenológicas da cultura podem variar de safra para safra na mesma região, sendo que datas de florada principal, por exemplo, podem variar acima de seis ou oito semanas (Reuther, 1973).

Deste modo, quando não se dispõe de dados exatos sobre a ocorrência das fases fenológicas, não se pode estabelecer rigorosamente, entre safras, os meses em que as fases fenológicas estão ocorrendo, mas apenas adotar a ocorrência mais freqüente delas ao longo do tempo. Neste estudo, adotou-se como referência a seqüência fenológica 
apresentada por Sentelhas (2005), assumindo as épocas mais usuais de ocorrência das fases fenológicas nas condições do Estado de São Paulo (Figura 1).

\subsubsection{Cultivar 'Pêra'}

As Tabelas 22 a 24 (ANEXO) apresentam os resultados dos coeficientes de correlação linear (r) entre o número de frutos por planta de cada safra e variáveis agrometeorológicas dos 46 períodos anteriores à amostragem testados para as classes de idade 1, 2 e 3, respectivamente, para a variedade cultivada 'Pêra'.

De um modo geral, correlações significativas ocorreram distribuídas ao longo do ano do florescimento e no início do ano de colheita, em quatro momentos principais, para todas as classes de idade: nos meses de verão (janeiro e fevereiro), nos meses de pré-florescimento (abril a setembro), nos meses de florescimento (outubro a novembro) e nos meses de fixação e crescimento inicial dos frutos (dezembro a janeiro).

As magnitudes das correlações e dos níveis de significância (valores p) variaram entre as classes de idade para as mesmas variáveis agrometeorológicas e períodos, mantendo, contudo, coerência de épocas de ocorrência e de efeito (negativo ou positivo) no número de frutos por planta.

Para a classe de idade 1 (ANEXO: Tabela 22), nos períodos relacionados aos meses de janeiro e fevereiro do ano do florescimento, coincidentes com a época de fluxo de crescimento vegetativo de verão das plantas cítricas, foram verificadas correlações significativas para as variáveis temperaturas máxima, mínima e média e evapotranspiração máxima e evapotranspiração real, todas correlacionadas positivamente com o número de frutos por planta. As correlações significativas observadas nos períodos 1 a 3 e 1 a 4 são devidas à influência dos meses 1 e 2 , já que nos meses 3 e 4 não se observou o mesmo para tais variáveis. As maiores correlações $(\mathrm{p}<0,01)$ ocorreram no período 1 a 2 para a evapotranspiração máxima e a evapotranspiração real, respectivamente, com $r$ de 0,75 e 0,84 . $O$ fato da evapotranspiração real apresentar maior valor $r$ que a evapotranspiração máxima indica o efeito conjunto da temperatura e do suprimento hídrico na primeira. Para as classes de 
idade 2 (ANEXO: Tabela 23) e idade 3 (ANEXO: Tabela 24), nos meses de janeiro e fevereiro do ano do florescimento, as variáveis temperatura e evapotranspiração máxima e real também foram positivamente correlacionadas com o número de frutos por planta. As maiores correlações foram obtidas para a evapotranspiração real no período 1 a 2 , com $r$ de $0,73(p<0,01)$ e $0,57(p<0,05)$, respectivamente, para as classes de idade 2 e 3 .

Assim, nesse período, geralmente marcado por bom suprimento de água, típico da estação chuvosa, quanto maior a demanda evapotranspiratória, maior será o efeito na safra do ano seguinte no número de frutos por planta, provavelmente, em função do maior crescimento vegetativo, relacionado, por exemplo, com aumento de área fotossintética. Para seu crescimento vegetativo, a planta cítrica depende dos fluxos de crescimento de verão (Spiegel Roy \& Goldschmidt, 1996). De acordo com Davies \& Albrigo (1994), a distribuição e a extensão do crescimento dos ramos são afetadas pela temperatura, sendo que o acúmulo de matéria seca é geralmente maior em condições de dias longos e altas temperaturas médias diurnas e noturnas. Segundo Gat et al. (1997), temperaturas mais baixas reduzem o crescimento potencial, resultando em menores incrementos anuais de crescimento vegetativo e, sobretudo, do tamanho da árvore e, portanto, de seu potencial produtivo.

Observa-se que as correlações foram mais altas para as classes de idade mais jovens (idade 1: 3 a 5 anos e idade 2: 6 a 10 anos), o que pode indicar um efeito mais marcante da fase de crescimento vegetativo na formação das plantas mais jovens com reflexo na produção de frutos por planta, do que nas plantas mais velhas (idade 3: acima de 10 anos). De acordo com Doorenbos \& Kassam (1979), crescimento vegetativo em um ano é influenciado pelo efeito residual de crescimento em anos anteriores. Assim, o crescimento vegetativo de árvores jovens determina o tamanho e a capacidade da árvore em produzir frutos.

Para a classe de idade 1 (ANEXO: Tabela 22), nos meses iniciais do préflorescimento (abril a junho) foram detectadas influências negativas das variáveis temperaturas máxima, mínima e média e da evapotranspiração máxima no número de frutos por planta, sendo a evapotranspiração máxima nos períodos 5 a 6 e 6 , a variável que apresentou maior coeficiente de correlação, respectivamente, $-0,68(p<0,01)$ e $-0,60$ 
$(\mathrm{p}<0,05)$. Para as idades 2 (ANEXO: Tabela 23) e 3 (ANEXO: Tabela 24), nesses mesmos meses (abril a junho) foi observado o mesmo efeito, encontrando-se correlações negativas entre as variáveis temperatura, evapotranspiração máxima e deficiência hídrica e o número de frutos por planta. A evapotranspiração máxima nos períodos 5 a 6 e 6 foi a variável que apresentou maior coeficiente de correlação nesses meses, tanto para a idade $2(-0,70$ e $-0,67, p<0,01)$ quanto para a $3(-0,53$ e $-0,59, \mathrm{p}<0,05)$.

Portanto, maiores temperaturas e, conseqüentemente, demandas evapotranspiratórias, e deficiência hídrica nesses períodos contribuem para diminuição do número de frutos por planta. Pasqua (2000) também encontrou para esses meses influências negativas de temperatura e evapotranspiração altas na produção de frutos de laranjeira 'Pêra', na região de Limeira. Segundo Ben Mechlia \& Carrol (1989), as condições climáticas do período de pré-florescimento influi sobre a fixação do fruto, já que determina quando ocorre o florescimento (precoce ou tardio), bem como sua duração (prolongado ou concentrado). Desta forma, pode-se inferir que a ocorrência de estresses por deficiência hídrica, altas temperaturas e demandas evapotranspiratórias em tais meses (muito anteriores à época normal de florescimento - outubro/novembro) provavelmente leva a uma antecipação da fase de florescimento para um momento em que as condições meteorológicas são menos apropriadas para a polinização e a fixação do fruto (Lomas \& Burd, 1983).

Para a idade 1 (3 a 5 anos), nos meses finais do pré-florescimento (julho a setembro), influências positivas na produção de frutos por planta das variáveis temperaturas máxima e média e evapotranspiração máxima foram detectadas. A temperatura máxima no período 7 a 8 e a evapotranspiração máxima nos períodos 7 a 9 e 8 a 9, apresentaram, de modo geral, as maiores correlações positivas nesses meses. Para a idade 2, a temperatura máxima dos períodos 7 a 8 e 7 a 9 foram positivamente correlacionadas com o número de frutos por planta. Para a idade 3 , a temperatura máxima nos períodos 7,7 a 8,7 a 9 e 8 a 9 também se mostraram diretamente relacionadas com o número de frutos por planta.

Assim, ao contrário do ocorrido para os meses abril a junho, altas temperaturas e demandas evapotranspiratórias antes do florescimento (julho a setembro) se relacionam 
com maiores produções de frutos por planta. O pré-florescimento se trata do período em que ocorre a indução floral, que pode ser promovida por estresse hídrico em regiões tropicais com período de seca no inverno ou por baixas temperaturas em regiões subtropicais (Reuther, 1988). Para Gat et al. (1997), qualquer redução ou parada de crescimento vegetativo (comum tanto para estresse hídrico como para baixas temperaturas), pode ser assumido como o estímulo necessário para indução floral em citros. Segundo Lovatt et al. (1988), quanto maior a intensidade do estresse, maior o acúmulo de reservas (carboidratos e amônia) que serão direcionadas ao desenvolvimento de estruturas reprodutivas. Os resultados aqui obtidos vêm ao encontro de tais afirmações, embora não tenham ocorrido correlações significativas para a deficiência hídrica, uma vez que os fatores geradores do estresse (temperaturas máximas e demandas evapotranspiratórias elevadas) no período resultaram em maior produção de frutos por planta, provavelmente, pelo maior acúmulo de reservas dado pelo maior estresse.

Em períodos relacionados aos meses 10 e 11, quando florescimento e início de fixação dos frutos estão ocorrendo, para a idade 1 (3 a 5 anos) (ANEXO: Tabela 22), as variáveis temperatura e evapotranspiração máxima apresentaram efeito negativo sobre a produção de frutos, sendo que altas temperaturas e evapotranspiração máxima nesses meses diminuíram o número de frutos por planta. A maior correlação foi observada para a evapotranspiração máxima no período 10 , com $\mathrm{r}$ de $-0,63(\mathrm{p}<0,01)$. Para a idade 2 (ANEXO: Tabela 23), nos meses 10 e 11, além das correlações negativas significativas das variáveis temperatura e evapotranspiração (à semelhança do ocorrido para idade 1), as variáveis precipitação e excedente hídrico também se mostraram negativamente relacionadas com a produção de frutos por planta. Assim, precipitações e excedentes hídricos altos nesse período diminuem a produção de frutos. Nos mesmos meses, para a idade 3 (ANEXO: Tabela 24), as correlações significativas ocorreram para precipitação e excedente hídrico, também negativamente relacionados à produção de frutos. As correlações positivas observadas da variável deficiência hídrica e da variável número de dias com deficiência hídrica no período 11 a 12 para as idades 2 (6 a 10 anos) e 3 (superior a 10 anos), advém, portanto, não no sentido de efeito benéfico de deficiência 
hídrica propriamente dita, mas da menor incidência de precipitações e excedentes hídricos vinculada à mesma.

Temperaturas e evapotranspiração potencial elevadas, bem como severo estresse hídrico, contribuem para aumentar a queda de flores e frutinhos em citros (Volpe, 1992). Temperaturas elevadas e baixa umidade relativa do ar levam à formação de camada de abscisão na base do pedúnculo das flores, resultando em queda (Rodrigues, 1991). Di Giorgi et al. (1991) encontraram influência negativa de temperaturas altas nos meses de florescimento e fixação de frutos na produtividade de 'Pêra'.

A fixação do fruto depende da precipitação durante o período de florescimento, sendo que o efeito da chuva no florescimento e fixação dos frutos pode ser por danos diretos mecânicos para flores e limitação na polinização (Ben Mechlia \& Carrol, 1989). A abertura das anteras e a polinização são prejudicadas por umidade relativa do ar excessiva; estresses térmicos por temperaturas elevadas ou muito baixas também afetam a polinização, danificando e destruindo o grão de pólen, prejudicando o tubo polínico e causando atrofia floral, sendo a abertura floral mais favorecida com temperaturas moderadas e ar atmosférico relativamente seco (Nogueira, 1979). Além disso, a coincidência do florescimento com épocas de precipitações e umidade relativa do ar elevada tem contribuído para aumentar a severidade de sintomas de doenças como a podridão floral dos citros, que afeta flores e frutos recém-formados causando-lhes queda (Prates \& Rodrigues, 1995). Tubelis \& Salibe (1988, 1989 e 1991) encontraram que a precipitação nos meses de florescimento é inversamente correlacionada com a produção de laranjeira 'Hamlin', nas condições de Botucatu, SP, associando-a posteriormente com a ocorrência da podridão floral dos citros (Tubelis, 1995). Pasqua (2000), em Limeira, encontrou a mesma resposta para laranjeira 'Pêra'.

Já a partir dos meses 12 e 13 (janeiro do ano da colheita), fase de fixação e início do crescimento dos frutos, para a idade 1 (ANEXO: Tabela 22), variáveis relacionadas ao suprimento hídrico foram significativamente correlacionadas com a produção de frutos por planta, sendo que nos períodos 12 a 13 e 13, precipitações e excedentes hídricos contribuíram para maiores produções de frutos por planta, e deficiência hídrica e o número de dias com deficiência, por conseqüência, tiveram o efeito contrário. 
Também para a idade 2 (ANEXO: Tabela 23), nos períodos 12 a 13 e 13, as variáveis precipitação e excedente hídrico foram positivamente correlacionadas à produção. $\mathrm{O}$ mesmo efeito foi verificado para a classe de idade 3 (ANEXO: Tabela 24) no mês 13, quando a precipitação e o excedente hídrico apresentaram correlação positiva com o número de frutos por planta.

Do mesmo modo, Pasqua (2000) encontrou influência positiva de precipitação e excedente hídrico na produção de frutos de laranjeira 'Pêra' no período final de fixação e início do crescimento do fruto, associando-a ao efeito benéfico de bom suprimento hídrico em tal período. De acordo com Ginestar \& Castel (1996), a produção de frutos é afetada por deficiência hídrica na fase inicial do crescimento dos frutos principalmente pela redução de seu número devido à forte queda de frutinhos.

\subsubsection{Cultivar 'Valência'}

Nas Tabelas 25 a 27 (ANEXO), encontram-se os resultados dos coeficientes de correlação linear (r) entre o número de frutos por planta de cada safra e variáveis agrometeorológicas dos 46 períodos anteriores à amostragem testados para as classes de idade 1, 2 e 3, respectivamente, para a variedade cultivada 'Valência'.

De modo semelhante ao ocorrido com a variedade cultivada 'Pêra', foram observadas correlações significativas distribuídas ao longo do ano do florescimento e no início do ano de colheita, em quatro momentos distintos, para todas as três classes de idade: nos meses de verão (janeiro e fevereiro), no pré-florescimento (abril a setembro), no florescimento (outubro a novembro) e na fixação e crescimento inicial dos frutos (dezembro a janeiro).

Como para laranjeira 'Pêra', as magnitudes das correlações e dos níveis de significância (valores p) variaram entre as classes de idades para as mesmas variáveis agrometeorológicas e períodos, mas mantendo coerência de épocas de ocorrência e de efeito (negativo ou positivo) no número de frutos por planta.

Foram verificadas correlações positivas significativas entre o número de frutos por planta e as variáveis temperaturas mínima e média e evapotranspiração máxima e 
evapotranspiração real, para a classe de idade 1 (ANEXO: Tabela 25), nos períodos relacionados aos meses de janeiro e fevereiro do ano do florescimento. A maior correlação deu-se no período 1 a 2 para a evapotranspiração real, com $r$ de 0,71 $(\mathrm{p}<0,01)$. A precipitação de fevereiro também foi positivamente correlacionada com o número de frutos por planta. Para as idades 2 (ANEXO: Tabela 26) e 3 (ANEXO: Tabela 27) também ocorreram correlações positivas entre as variáveis temperaturas máxima, mínima e média e evapotranspiração máxima e real nos períodos relacionados a janeiro e fevereiro, sendo que as maiores correlações se deram no período 1 a 2 para evapotranspiração real na idade 2 , com $r$ de $0,79(\mathrm{p}<0,01)$ e para evapotranspiração máxima na idade 3 , com $r$ de $0,69(\mathrm{p}<0,01)$.

Desse modo, em tais períodos, coincidentes com a época de fluxo de crescimento vegetativo de verão das plantas cítricas, bom suprimento de água e altas demandas evapotranspiratórias repercutem positivamente na produção de frutos da safra seguinte, em função, provavelmente, conforme já discutido para laranjeira 'Pêra', do aumento de área fotossintética proporcionado pelo maior crescimento vegetativo. Para Nogueira (1979), a taxa de crescimento vegetativo é maior em plantas expostas a temperaturas mais elevadas, dentro da faixa ótima de crescimento de $22^{\circ} \mathrm{C}$ a $33^{\circ} \mathrm{C}$. Quanto maior a temperatura, maior o crescimento vegetativo, sendo que deficiência hídrica crescente resulta em menor crescimento vegetativo (Chaikiattiyos et al., 1994).

Para laranjeira 'Valência' não houve distinção de magnitude de correlações observadas nesses períodos entre as idades mais jovens ( 1 e 2) e a mais velha (3), ocorrendo as correlações em faixas mais similares que para 'Pêra', de onde se infere que para esse cultivar, geralmente de porte e níveis de produtividade maiores que 'Pêra' (Figueiredo, 1991), o crescimento vegetativo é igualmente importante nas diferentes classes de idade para a produção de frutos.

Para alguns períodos relacionados aos meses iniciais do pré-florescimento (abril a junho) as variáveis temperaturas máxima e média e evapotranspiração máxima se mostraram inversamente relacionadas com a produção de frutos por planta para idade 1 (ANEXO: Tabela 25), sendo a maior correlação observada para temperatura máxima no período 5 a 6 , com $\mathrm{r}$ de $-0,54(\mathrm{p}<0,05)$. A variável deficiência hídrica no período 4 se 
mostrou inversamente correlacionada com a produção $(\mathrm{r}=-0,45, \mathrm{p}<0,10)$ e a variável relação ETR/ETM, por conseguinte, se mostrou positivamente relacionada com a produção no mesmo período $(\mathrm{r}=0,47, \mathrm{p}<0,10)$. Para a classe de idade 2 (ANEXO: Tabela 26), a temperatura máxima do período 5 e a evapotranspiração máxima no período 5 a 6 (ambas com $r=-0,51, p<0,10$ ), também se mostraram negativamente relacionadas com o número de frutos por planta. Para a idade 3 (ANEXO: Tabela 27), nos períodos 5 a 6 e 6 , a temperatura mínima e a evapotranspiração máxima apresentaram-se inversamente correlacionadas com o número de frutos por planta, o mesmo ocorrendo para a variável deficiência hídrica nos períodos 3 a $6(\mathrm{r}=-0,48, \mathrm{p}<0,10)$ e 4 a $6(\mathrm{r}=-0,46, \mathrm{p}<0,10)$. Assim, altas temperaturas, demandas evapotranspiratórias e deficiências hídricas entre os meses de abril a junho têm efeito depressivo sobre a produção de frutos por planta para laranjeira 'Valência', à semelhança do detectado e discutido para laranjeira 'Pêra'.

Com relação aos meses finais do pré-florescimento (julho a setembro), foi observada correlação negativa entre precipitação $(r=-0,44 ; p<0,10)$ e excedente hídrico $(\mathrm{r}=-0,58, \mathrm{p}<0,05)$ e produção de frutos por planta no período 8 para a idade 1 (ANEXO: Tabela 25). Para a idade 2, foram observadas correlações positivas para as variáveis temperaturas máxima e média e evapotranspiração máxima nos períodos 7, 7 a 8 e 7 a 9 . A deficiência hídrica nos períodos 7 a 9,8 e 8 a 9 também foi diretamente relacionada com o número de frutos por planta. A precipitação apresentou correlação negativa com o número de frutos por planta nos períodos 6 a 9 e 7 a $9(\mathrm{r}=-0,47, \mathrm{p}<0,10)$ (ANEXO: Tabela 26). No caso da idade 3 , a temperatura máxima e a deficiência hídrica nos períodos 7 a 9,8 a 9 e 9 se mostraram positivamente relacionadas com o número de frutos por planta, e a precipitação apresentou o efeito inverso nos períodos 7 a 8,7 a 9 e 8 a 9 (ANEXO: Tabela 27).

Portanto, altas temperaturas, demandas evapotranspiratórias e deficiência hídrica nos meses finais do pré-florescimento resultam em maiores produções de frutos por planta, e, por conseqüência, precipitações e excedentes hídricos resultam em menores produções de frutos por planta, respostas similares às detectadas para laranjeira 'Pêra'. Quanto maior a intensidade do estresse ambiental (nesse caso, deficiência hídrica, temperaturas e demandas evapotranspiratórias elevadas) que leva à redução de 
crescimento associada à indução floral no período de pré-florescimento, maior será o acúmulo de reservas direcionadas ao desenvolvimento reprodutivo (Lovatt et al., 1988; Davies \& Albrigo, 1994; Gat et al., 1997).

Em períodos relacionados aos meses 10 e 11, no florescimento e início de fixação dos frutos, para a idade 1 (ANEXO: Tabela 25), as variáveis temperatura e evapotranspiração máxima e real foram inversamente correlacionadas à produção de frutos, encontrando-se a maior correlação no período 10 a 11 para a evapotranspiração máxima $(r=-0,78, p<0,01)$. Para a idade 2 (ANEXO: Tabela 26), além das variáveis temperatura e evapotranspiração, precipitação e excedente hídrico também foram negativamente relacionadas com o número de frutos por planta. A maior correlação se deu para precipitação do período 11 , com $r$ de $-0,67$ ( $p<0,01)$. Para a idade 3 (ANEXO: Tabela 27), as variáveis evapotranspiração real, precipitação e excedente hídrico apresentaram efeito negativo sobre a produção de frutos, sendo que a maior correlação ocorreu no período 10 a 11 para a evapotranspiração real $(r=-0,61, p<0,05)$. As correlações positivas encontradas para as variáveis deficiência hídrica e número de dias com deficiência hídrica no período 11 , por exemplo, para as idades 2 e 3 , advém da menor incidência de precipitações e excedentes hídricos vinculada às mesmas. Assim, no florescimento e início da fixação dos frutos, altas temperaturas e demandas evapotranspiratórias, bem como precipitações e excedentes hídricos, diminuem a produção de frutos por planta da variedade cultivada 'Valência'.

Em geral, temperaturas elevadas durante a florada e a fixação de frutos reduzem a produtividade (Jones \& Cree, 1965). Temperaturas altas durante o florescimento e na fixação do fruto podem resultar em perda completa de produção (Reuther, 1973). O efeito das precipitações pode ocorrer via dano mecânico direto às flores e frutinhos em fase de estabelecimento e limitação de polinização (Ben Mechlia \& Carrol, 1989). Precipitações contínuas e alta umidade relativa do ar no período do florescimento podem contribuir para o aumento da incidência do fungo Colletotrichum gloeosporioides causador da podridão floral dos citros, provocando a queda de flores e frutos jovens (Agostini et al., 1995). 
$\mathrm{Na}$ fase de fixação e início do crescimento dos frutos, para a idade 1 (ANEXO: Tabela 25), as variáveis temperatura máxima e evapotranspiração real foram negativamente correlacionadas à produção no período 12. As precipitações nos períodos $12(\mathrm{r}=0,45, \mathrm{p}<0,10)$ e 12 a $13(\mathrm{r}=0,60, \mathrm{p}<0,05)$, e os excedentes hídricos nos períodos 12 a $13(\mathrm{r}=0,65, \mathrm{p}<0,01)$ e $13(\mathrm{r}=0,53, \mathrm{p}<0,05)$ contribuíram para maiores produções de frutos por planta. Para a idade 2 (ANEXO: Tabela 26), nos períodos 12 a 13 e 13, as variáveis precipitação e excedente hídrico foram diretamente correlacionadas à produção. Para a classe de idade 3 (ANEXO: Tabela 27), tal efeito ocorreu nos mesmos períodos (12 a 13 e 13), quando a precipitação apresentou correlação positiva com o número de frutos por planta $(\mathrm{r}=0,52, \mathrm{p}<0,05 \mathrm{e} \mathrm{r}=0,44, \mathrm{p}<0,10$, respectivamente). Portanto, altas demandas evapotranspiratórias na fase de fixação e início do crescimento dos frutos são depressivas à produção de frutos de 'Valência', enquanto bom suprimento hídrico é favorável à produção dos mesmos.

Moss \& Muirhead (1971) também encontraram correlação significativa entre taxas de evapotranspiração e produtividade de frutos cítricos na fase de fixação e crescimento inicial dos frutos, sendo que altas demandas evapotranspiratórias apresentaram efeito limitante à produtividade. De acordo com Rodrigues (1991), a ocorrência de dias quentes e secos na fase de fixação dos frutos causa aumento de queda de frutos, havendo efeito positivo de temperaturas amenas e bom suprimento hídrico.

Nota-se claramente, portanto, que, salvo as magnitudes das correlações e dos níveis de significância, tanto para laranjeira 'Pêra' quanto para laranjeira 'Valência', nas diferentes classes de idade, houve coerência de épocas de ocorrência e de efeitos das variáveis que demonstraram correlações significativas com o número de frutos por planta.

\subsubsection{Cultivar 'Hamlin'}

Os resultados para a variedade cultivada 'Hamlin' dos coeficientes de correlação linear (r) entre o número de frutos por planta de cada safra e variáveis 
agrometeorológicas dos períodos anteriores à amostragem testados para as classes de idade 1, 2 e 3, encontram-se, respectivamente, nas Tabelas 28 a 30 (ANEXO).

Conforme ocorrido para as variedades cultivadas 'Pêra' e 'Valência', observaram-se correlações significativas distribuídas ao longo do ano do florescimento e no início do ano de colheita, em quatro momentos distintos, para as três classes de idade: nos meses de verão (janeiro e fevereiro), no pré-florescimento (abril a setembro), no florescimento (outubro a novembro) e na fixação e crescimento inicial dos frutos (dezembro a janeiro). Mais uma vez, entre as idades variaram as magnitudes das correlações e dos valores p para as variáveis agrometeorológicas e períodos, mantendose, contudo, a coerência de épocas de ocorrência e de efeito (negativo ou positivo) no número de frutos por planta.

Para a classe de idade 1 (ANEXO: Tabela 28), nos períodos relacionados aos meses de janeiro e fevereiro do ano do florescimento, foram verificadas correlações positivas entre as variáveis temperatura mínima e média, evapotranspiração máxima e evapotranspiração real e a variável número de frutos por planta. Precipitação e excedente hídrico também foram positivamente correlacionados com a produção de frutos. No período 1 a 2, a relação ETR/ETM mostrou-se diretamente relacionada com o número de frutos por planta. As maiores correlações ocorreram no período 1 a 2 com $r$ de 0,66 $(\mathrm{p}<0,01)$ para a evapotranspiração real e $\mathrm{r}$ de $0,65(\mathrm{p}<0,01)$ para a precipitação.

Para as idades 2 (ANEXO: Tabela 29) e 3 (ANEXO: Tabela 30) correlações positivas ocorreram entre as variáveis temperaturas máxima, mínima e média e evapotranspiração máxima e real nos períodos relacionados a janeiro e fevereiro, sendo que as maiores correlações se deram no período 1 a 2 para evapotranspiração máxima com $r$ de $0,60(p<0,05)$ para a idade 2 e $r$ de $0,63(p<0,05)$ para a idade 3 . Portanto, à semelhança do obtido para laranjeiras 'Pêra' e Valência, nos períodos coincidentes com a época de fluxo de crescimento vegetativo de verão das plantas cítricas, bom suprimento de água e altas demandas evapotranspiratórias são positivas para a produção de frutos da safra seguinte, em função, conforme já discutido, do maior crescimento vegetativo alcançado. 
Sob condições de bom suprimento hídrico, plantas expostas a temperaturas mais elevadas apresentam uma taxa de crescimento vegetativo mais rápida (Nogueira, 1979). Temperaturas mais amenas diminuem o crescimento potencial, resultando em incrementos anuais menores de crescimento vegetativo, bem como, em menor porte, com reflexos no potencial produtivo da planta (Gat et al., 1997). O crescimento vegetativo pode ser diminuído substancialmente por disponibilidade hídrica deficiente (Ginestar \& Castel, 1996).

Do mesmo modo que para 'Valência', para laranjeira 'Hamlin' não houve tanta distinção de magnitude de correlações observadas nesses períodos entre as idades mais jovens (1 e 2) e a mais velha (3), ocorrendo as correlações em faixas mais similares que para 'Pêra', de onde se infere que para esse cultivar, de porte e níveis de produtividade maiores (Figueiredo, 1991), como observado na apresentação dos resultados para produção de frutos ao longo das safras avaliadas (Tabela 5), o crescimento vegetativo é igualmente importante nas diferentes classes de idade para a produção de frutos.

Para alguns períodos relacionados aos meses iniciais do pré-florescimento (abril a junho), as variáveis deficiência hídrica e relação ETR/ETM foram significativamente correlacionadas com a produção de frutos por planta para idade 1 (ANEXO: Tabela 28), sendo que, no período 5 a 6 , quando ocorreram as maiores correlações, a deficiência hídrica apresentou correlação negativa com $\mathrm{r}$ de $-0,57(\mathrm{p}<0,05)$ e a variável relação ETR/ETM, consequentemente, se mostrou positivamente relacionada com a produção de frutos $(\mathrm{r}=0,56, \mathrm{p}<0,05)$. Para a idade 2 (ANEXO: Tabela 29), no período 5, as variáveis temperatura máxima $(\mathrm{r}=-0,63, \mathrm{p}<0,05)$, evapotranspiração máxima $(\mathrm{r}=-0,65, \mathrm{p}<0,01)$ e deficiência hídrica, também se mostraram negativamente relacionadas com o número de frutos por planta. Para a idade 3 (ANEXO: Tabela 30), ocorreram muitas correlações significativas para períodos relacionados aos meses 4,5 e 6 , principalmente para as variáveis deficiência hídrica e número de dias com deficiência hídrica (NDH), as quais se mostraram negativamente relacionadas com o número de frutos por planta, sendo que a variável que apresentou maior correlação foi a NDH no período 3 a 4, com r=-0,71 $(\mathrm{p}<0,01)$. 
Portanto, altas temperaturas, demandas evapotranspiratórias e deficiências hídricas entre abril e junho têm efeito depressivo sobre a produção de frutos por planta, conforme ocorrido para as outras variedades cultivadas em estudo. Tal efeito provavelmente ocorre porque o estresse nesses períodos resulta em florescimento em época menos adequada à polinização e à fixação de frutos (Lomas \& Burd, 1983; Ben Mechlia \& Carrol, 1989).

Nos meses finais do pré-florescimento (julho a setembro), para a idade 1 (ANEXO: Tabela 28), foram observadas correlações negativas entre precipitação (períodos 7, 6 a 8 e 7 a 8) e produção de frutos por planta. O NDH no período 7 foi positivamente relacionado com o número de frutos por planta. Para a idade 2 (ANEXO: Tabela 29), a precipitação do período 6 a 8 foi negativamente correlacionada com a produção de frutos $(\mathrm{r}=-0,44, \mathrm{p}<0,10)$. Já para a idade 3 (ANEXO: Tabela 30), a variável precipitação apresentou correlações negativas $(\mathrm{p}<0,05)$ com a produção de frutos para os períodos 5 a $8(\mathrm{r}=-0,60), 6$ a $8(\mathrm{r}=-0,62)$ e 6 a $9(\mathrm{r}=-0,61)$. O excedente hídrico também apresentou correlações negativas para esses mesmos períodos. Assim, de um modo geral, nos meses finais do pré-florescimento maiores precipitações e excedentes hídricos resultam em menores produções de frutos por planta. Tais resultados provavelmente se relacionam ao menor estresse ambiental vinculado às precipitações e aos excedentes hídricos, gerando um menor estímulo ao acúmulo de reservas a serem direcionadas ao desenvolvimento reprodutivo (Lovatt et al., 1988; Davies \& Albrigo, 1994; Gat et al., 1997).

Nos períodos relacionados aos meses 10 e 11, no florescimento e início de fixação dos frutos, para a idade 1 (ANEXO: Tabela 28), as variáveis temperatura máxima, evapotranspiração máxima e real, precipitação e excedente hídrico apresentaram-se inversamente correlacionadas à produção de frutos, encontrando-se a maior correlação no período 11 para a evapotranspiração real $(r=-0,49, p<0,10)$. Para a idade 2 (ANEXO: Tabela 29), as variáveis já listadas para idade 1 foram também negativamente relacionadas com o número de frutos por planta. A maior correlação se deu para evapotranspiração real do período 11 , com $r$ de $-0,64(p<0,01)$. Para a idade 3 (ANEXO: Tabela 30), as variáveis precipitação e evapotranspiração real foram 
negativamente relacionadas com o número de frutos por planta, sendo que a maior correlação ocorreu no período 11 para a evapotranspiração real $(\mathrm{r}=-0,54, \mathrm{p}<0,05)$. Conforme já colocado para laranjeiras 'Pêra' e 'Valência', as correlações positivas encontradas para as variáveis deficiência hídrica e número de dias com deficiência hídrica, por exemplo, no período 11, para as idades 2 e 3, decorrem da menor incidência de precipitações vinculada às mesmas.

Altas precipitações no período de florescimento e fixação dos frutos podem ser prejudiciais por danos diretos mecânicos causados às flores e frutinhos em formação, bem como por limitação à polinização (Nogueira, 1979), estando também associadas à ocorrência de doenças como a podridão floral dos citros que leva à queda prematura de flores e frutos recém-formados (Prates \& Rodrigues, 1995). Di Giorgi et al. (1991), à semelhança de Tubelis \& Salibe (1988), também encontraram efeito depressivo de maiores precipitações nos meses de florescimento para a variedade cultivada 'Hamlin'. Tubelis (1995) sugere que a razão pela qual a produtividade se encontra inversamente correlacionada com a precipitação na florada, embora pareça contra-senso, já que a água é necessária à fixação do fruto, é o favorecimento da multiplicação do fungo causador da podridão floral dos citros, conforme já colocado. Altas temperaturas durante o período de florescimento e fixação dos frutos cítricos são muito depressivas à produtividade ( $\mathrm{Du}$ Plessis, 1983), e se relacionam com a formação de uma camada de abcisão na base do pedúnculo das flores, resultando em sua queda (Rodrigues, 1991).

$\mathrm{Na}$ fase de fixação e início do crescimento dos frutos (dezembro a janeiro), para a idade 1 (ANEXO: Tabela 28), a variável temperatura máxima foi negativamente correlacionada à produção no período 13 . A precipitação $(r=0,56, p<0,05)$ e o excedente hídrico $(\mathrm{r}=0,59, \mathrm{p}<0,05)$, também no período 13 , foram diretamente correlacionadas com o número de frutos por planta. Para a idade 2 (ANEXO: Tabela 29), no período 12 a 13, as variáveis precipitação $(r=0,50, p<0,10)$ e excedente hídrico $(r=0,45, p<0,10)$ foram positivamente correlacionadas à produção de frutos. Para a classe de idade 3 (ANEXO: Tabela 30), o mesmo efeito ocorreu nos períodos 12 e 12 a 13, quando a precipitação (respectivamente, $\mathrm{r}=0,53$ e $\mathrm{r}=0,60, \mathrm{p}<0,05)$ e o excedente hídrico $(\mathrm{r}=0,48, \mathrm{p}<0,10$ e $\mathrm{r}=0,58, \mathrm{p}<0,05$, respectivamente) apresentaram correlações positivas com o número de 
frutos por planta. Em concordância com as observações realizadas para as variedades cultivadas 'Pêra' e 'Valência', temperaturas mais amenas e bom suprimento hídrico na fase de fixação e início do crescimento dos frutos contribuem para aumentar o número de frutos fixados por planta (Moreira, 1985; Rodrigues, 1991; Pasqua, 2000).

Portanto, salienta-se que, para as três variedades cultivadas analisadas, nas diferentes classes de idade, exceto pelas magnitudes das correlações e dos níveis de significância, foi mantida coerência de épocas de ocorrência e de efeitos das variáveis que se apresentaram significativamente correlacionadas com o número de frutos por planta.

O desenvolvimento dos modelos agrometeorológicos por classe de idade é importante também para não se perder informações a respeito da influência das variáveis agrometeorológicas individualmente para cada idade, fato que ocorreria em caso da inclusão dessa como variável independente nas regressões múltiplas.

\subsection{Modelos agrometeorológicos}

\subsubsection{Descrição dos modelos obtidos}

Após a análise da influência das variáveis agrometeorológicas dos diferentes períodos sobre a produção de frutos por planta, foram ajustados modelos de regressão linear múltipla considerando os subconjuntos de potenciais variáveis preditoras préselecionados por estrato de cultivar e classe de idade. Utilizando-se o procedimento "stepwise" para escolha dos melhores preditores, foram obtidos modelos reduzidos para cada estrato, detalhados a seguir.

Salienta-se que, embora todas as variáveis dos subconjuntos iniciais de potenciais preditoras apresentassem correlações significativas com o número de frutos por planta, permanecem nos modelos, após aplicação dos critérios de redução, apenas aquelas que, conjuntamente, apresentam melhor ajuste preditivo. Pelo mesmo motivo, verificou-se que nem sempre as variáveis de maior correlação individual permaneceram nos modelos finais. 
Como o significado fitotécnico das correlações entre as variáveis agrometeorológicas com o número de frutos por planta foram previamente discutidos no item 4.5, no presente item apenas se faz breve menção sobre o efeito observado de cada variável preditora selecionada no modelo final sobre o número de frutos por planta.

\subsubsection{Cultivar 'Pêra'}

Para a variedade cultivada 'Pêra' (Tabela 8), todos os modelos obtidos foram significativos $(\mathrm{p}<0,01)$, apresentando $\mathrm{R}^{2}$ satisfatórios da ordem de 0,88, 0,76 e 0,75, respectivamente, para as classes de idades 1,2 e 3 .

As variáveis que permaneceram no modelo como preditoras para a classe de idade 1, foram a evapotranspiração real no período 1 a 2 (ETR1a2) e a evapotranspiração máxima nos períodos 5 a 6 (ETM5a6), 8 a 9 (ETM8a9) e 10 (ETM10), correspondendo a efeitos nas fases de crescimento vegetativo de verão, préflorescimento e florescimento. A magnitude dos parâmetros revela a contribuição de cada variável sobre a produção de frutos por planta. Assim, a ETR1a2 e a ETM8a9 apresentam contribuição positiva e a ETM5a6 e a ETM10 apresentam contribuição negativa sobre o número de frutos por planta, conforme já discutido no item 4.5.1 quando da discussão fitotécnica de tais efeitos.

Para a classe de idade 2, as variáveis integrantes finais do modelo foram a evapotranspiração real no período 1 a 2 (ETR1a2), a evapotranspiração máxima no período 6 (ETM6) e a precipitação no período 10 a 11 (PREC10a11), representando efeitos nas fases de crescimento vegetativo, pré-florescimento, florescimento e início da fixação de frutos. Analisando-se a magnitude dos parâmetros, a ETR1a2 apresenta contribuição positiva e a ETM6 e PREC10a11 apresentam contribuição negativa sobre o número de frutos por planta. 
Tabela 8. Estimativas dos parâmetros dos modelos de regressão múltipla que descrevem o padrão de variação do número de frutos por planta em função de variáveis agrometeorológicas, coeficientes de determinação $\left(\mathrm{R}^{2}\right)$ e valores $\mathrm{p}$ associados aos testes F para a variedade cultivada 'Pêra' em três classes de idade (CI)*

\begin{tabular}{cccccccc}
\hline CI & Preditor & Parâmetro & Estimativa & Erro padrão & $\mathrm{p}_{1}{ }^{* *}$ & $\mathrm{p}_{2}{ }^{* *}$ & $\mathrm{R}^{2}$ \\
\hline 1 & Intercepto & $\beta_{\mathrm{P} 10}$ & $-47,19$ & 264,11 & 0,8618 & 0,0001 & 0,88 \\
1 & ETR1a2 & $\beta_{\mathrm{P} 11}$ & 2,54 & 1,06 & 0,0369 & & \\
1 & ETM5a6 & $\beta_{\mathrm{P} 12}$ & $-2,18$ & 1,32 & 0,1288 & & \\
1 & ETM8a9 & $\beta_{\mathrm{P} 13}$ & 1,55 & 0,79 & 0,0784 & & \\
1 & ETM10 & $\beta_{\mathrm{P} 14}$ & $-1,80$ & 0,81 & 0,0504 & & \\
2 & Intercepto & $\beta_{\mathrm{P} 20}$ & 48,73 & 395,06 & 0,9041 & 0,0009 & 0,76 \\
2 & ETR1a2 & $\beta_{\mathrm{P} 21}$ & 4,28 & 1,46 & 0,0139 & & \\
2 & ETM6 & $\beta_{\mathrm{P} 22}$ & $-6,67$ & 2,99 & 0,0477 & & \\
2 & PREC10a11 & $\beta_{\mathrm{P} 23}$ & $-0,32$ & 0,19 & 0,1188 & & \\
3 & Intercepto & $\beta_{\mathrm{P} 30}$ & 1112,44 & 200,70 & 0,0002 & 0,0015 & 0,75 \\
3 & ETM6 & $\beta_{\mathrm{P} 31}$ & $-7,53$ & 3,86 & 0,0773 & & \\
3 & PREC10a11 & $\beta_{\mathrm{P} 32}$ & $-0,85$ & 0,25 & 0,0056 & & \\
3 & PREC13 & $\beta_{\mathrm{P} 33}$ & 0,70 & 0,26 & 0,0219 & & \\
\hline
\end{tabular}

* Classe de idade 1: 3 a 5 anos; idade 2: 6 a 10 anos; idade 3: superior a 10 anos

**Valores $\mathrm{p}$ associados aos testes $\mathrm{F}$ para investigar a significância de cada um dos parâmetros do modelo, isoladamente $\left(\mathrm{p}_{1}\right)$, e teste de significância do modelo, considerando todos os parâmetros conjuntamente $\left(\mathrm{p}_{2}\right)$

Com relação à classe de idade 3 , permaneceram no modelo final as variáveis evapotranspiração máxima no período 6 (ETM6) e precipitação no período 10 a 11 (PREC10a11) e no período 13 (PREC13), correspondendo a efeitos nas fases de préflorescimento, florescimento e início de crescimento dos frutos, apresentando as duas primeiras contribuição negativa e a última contribuição positiva sobre o número de frutos por planta. 
Nota-se que, apenas na classe de idade 3, não permaneceu no modelo variável referente aos meses de crescimento vegetativo (janeiro e fevereiro), reforçando a inferência anteriormente discutida de maior influência do mesmo nas classes de idade mais jovens para a variedade cultivada 'Pêra'. Também apenas para a idade 3, variável representativa do período de crescimento inicial de frutos (mês 13 - janeiro do ano da colheita) foi mantida, indicando esta proporcionar melhor ajuste no conjunto das variáveis preditoras para a classe em questão.

\subsubsection{Cultivar 'Valência'}

Todos os modelos foram significativos ao nível de $1 \%$ de probabilidade, apresentando $\mathrm{R}^{2}$ satisfatórios da ordem de $0,81,0,81$ e 0,85 , respectivamente, para as classes de idade 1, 2 e 3 da variedade cultivada 'Valência' (Tabela 9).

Para a classe de idade 1 de 'Valência', as variáveis preditoras no modelo final foram a evapotranspiração real no período 1 a 2 (ETR1a2), a evapotranspiração máxima no período 10 (ETM10) e o excedente hídrico no período 12 a 13 (EXC12a13), correspondendo a efeitos nas fases de crescimento vegetativo de verão, florescimento e crescimento inicial de frutos. As variáveis ETR1a2 e EXC12a13 apresentam contribuição positiva e a ETM10 apresenta contribuição negativa sobre o número de frutos por planta.

As variáveis que permaneceram como preditoras no modelo para a classe de idade 2 de laranjeira 'Valência' foram a evapotranspiração máxima no período 1 a 2 (ETM1a2) e a precipitação nos períodos 11 (PREC11) e 13 (PREC13), representando, à semelhança da idade 1 do mesmo cultivar, efeitos nas fases de crescimento vegetativo de verão, florescimento e fixação e crescimento inicial de frutos. A ETM1a2 e a PREC13 têm contribuição positiva e a PREC11 tem contribuição negativa sobre a produção de frutos por planta. 
Tabela 9. Estimativas dos parâmetros dos modelos de regressão múltipla que descrevem o padrão de variação do número de frutos por planta em função de variáveis agrometeorológicas, coeficientes de determinação $\left(\mathrm{R}^{2}\right)$ e valores $\mathrm{p}$ associados aos testes $\mathrm{F}$ para a variedade cultivada 'Valência' em três classes de idade $(\mathrm{CI})^{*}$

\begin{tabular}{cccccccc}
\hline CI & Preditor & Parâmetro & Estimativa & Erro padrão & $\mathrm{p}_{1}^{* *}$ & $\mathrm{p}_{2} * *$ & $\mathrm{R}^{2}$ \\
\hline 1 & Intercepto & $\beta_{\mathrm{V} 10}$ & 82,16 & 297,91 & 0,7878 & 0,0003 & 0,81 \\
1 & ETR1a2 & $\beta_{\mathrm{V} 11}$ & 2,37 & 1,28 & 0,0921 & & \\
1 & ETM10 & $\beta_{\mathrm{V} 12}$ & $-3,32$ & 0,94 & 0,0047 & & \\
1 & EXC12a13 & $\beta_{\mathrm{V} 13}$ & 0,27 & 0,16 & 0,1261 & & \\
2 & Intercepto & $\beta_{\mathrm{V} 20}$ & $-248,01$ & 330,89 & 0,4693 & 0,0003 & 0,81 \\
2 & ETM1a2 & $\beta_{\mathrm{V} 21}$ & 3,85 & 1,49 & 0,0250 & & \\
2 & PREC11 & $\beta_{\mathrm{V} 22}$ & $-0,71$ & 0,21 & 0,0068 & & \\
2 & PREC13 & $\beta_{\mathrm{V} 23}$ & 0,41 & 0,21 & 0,0819 & & \\
3 & Intercepto & $\beta_{\mathrm{V} 30}$ & 2779,32 & 366,58 & 0,0000 & 0,0001 & 0,85 \\
3 & ETM5a6 & $\beta_{\mathrm{V} 31}$ & $-15,71$ & 3,04 & 0,0003 & & \\
3 & PREC6a9 & $\beta_{\mathrm{V} 32}$ & $-2,05$ & 0,40 & 0,0003 & & \\
3 & PREC13 & $\beta_{\mathrm{V} 33}$ & 0,48 & 0,32 & 0,1612 & & \\
\hline
\end{tabular}

* Classe de idade 1: 3 a 5 anos; 2: 6 a 10 anos; 3: superior a 10 anos

**Valores $\mathrm{p}$ associados aos testes $\mathrm{F}$ para investigar a significância de cada um dos parâmetros do modelo, isoladamente $\left(\mathrm{p}_{1}\right)$, e teste de significância do modelo, considerando todos os parâmetros conjuntamente $\left(\mathrm{p}_{2}\right)$

Para o estrato de laranjeira 'Valência' classe de idade 3 permaneceram no modelo as variáveis preditoras evapotranspiração máxima no período 5 a 6 (ETM5a6) e precipitação nos períodos 6 a 9 (PREC6a9) e 13 (PREC13), se reportando a efeitos nas fases de pré-florescimento e início de crescimento de frutos. O efeito das duas primeiras variáveis sobre a produção de frutos por planta é negativo e o da última é positivo. 


\subsubsection{Cultivar 'Hamlin'}

Para a variedade cultivada 'Hamlin' todos os modelos foram significativos ao nível de $1 \%$ de probabilidade, apresentando $\mathrm{R}^{2}$ satisfatórios de $0,83,0,72$ e 0,87 , respectivamente, para as classes de idade 1,2 e 3 (Tabela 10).

Tabela 10. Estimativas dos parâmetros dos modelos de regressão múltipla que descrevem o padrão de variação do número de frutos por planta em função de variáveis agrometeorológicas, coeficientes de determinação $\left(\mathrm{R}^{2}\right)$ e valores $\mathrm{p}$ associados aos testes F para a variedade cultivada 'Hamlin' em três classes de idade $(\mathrm{CI})^{*}$

\begin{tabular}{cccccccc}
\hline CI & Preditor & Parâmetro & Estimativa & Erro padrão & $\mathrm{p}_{1}{ }^{* *}$ & $\mathrm{p}_{2}{ }^{* *}$ & $\mathrm{R}^{2}$ \\
\hline 1 & Intercepto & $\beta_{\mathrm{H} 10}$ & $-271,61$ & 221,84 & 0,2489 & 0,0007 & 0,83 \\
1 & PREC1a2 & $\beta_{\mathrm{H} 11}$ & 0,35 & 0,18 & 0,0779 & & \\
1 & DEF5a6 & $\beta_{\mathrm{H} 12}$ & $-4,10$ & 1,44 & 0,0173 & & \\
1 & NDH7 & $\beta_{\mathrm{H} 13}$ & 22,03 & 8,49 & 0,0268 & & \\
1 & EXC13 & $\beta_{\mathrm{H} 14}$ & 0,57 & 0,24 & 0,0372 & & \\
2 & Intercepto & $\beta_{\mathrm{H} 20}$ & 3221,38 & 807,27 & 0,0021 & 0,0023 & 0,72 \\
2 & ETM5 & $\beta_{\mathrm{H} 21}$ & $-33,14$ & 13,80 & 0,0351 & & \\
2 & ETR11 & $\beta_{\mathrm{H} 22}$ & $-8,84$ & 3,81 & 0,0407 & & \\
2 & PREC12a13 & $\beta_{\mathrm{H} 23}$ & 1,12 & 0,50 & 0,0487 & & \\
3 & Intercepto & $\beta_{\mathrm{H} 30}$ & 2381,80 & 1694,0 & 0,1900 & 0,0002 & 0,87 \\
3 & ETM1a2 & $\beta_{\mathrm{H} 31}$ & 10,66 & 4,58 & 0,0420 & & \\
3 & NDH3a4 & $\beta_{\mathrm{H} 32}$ & $-36,71$ & 11,32 & 0,0088 & & \\
3 & ETM5 & $\beta_{\mathrm{H} 33}$ & $-23,26$ & 14,80 & 0,1472 & & \\
3 & PREC6a8 & $\beta_{\mathrm{H} 34}$ & $-2,16$ & 1,26 & 0,1182 & & \\
\hline
\end{tabular}

* Classe de idade 1: 3 a 5 anos; 2: 6 a 10 anos; 3: superior a 10 anos

**Valores p associados aos testes $\mathrm{F}$ para investigar a significância de cada um dos parâmetros do modelo, isoladamente $\left(\mathrm{p}_{1}\right)$, e teste de significância do modelo, considerando todos os parâmetros conjuntamente $\left(\mathrm{p}_{2}\right)$ 
Permaneceram no modelo como variáveis preditoras para a classe de idade 1 de 'Hamlin', a precipitação no período 1 a 2 (PREC1a2), a deficiência hídrica no período 5 a 6 (DEF5a6), o número de dias com deficiência hídrica no período 7 (NDH7) e o excedente hídrico no período 13 (EXC13), respondendo por efeitos nas fases de crescimento vegetativo de verão, pré-florescimento e crescimento inicial dos frutos. A produção de frutos por planta apresenta resposta positiva para as variáveis PREC1a2, NDH7 e EXC13 e negativa para a DEF5a6.

Para a classe de idade 2 de laranjeira 'Hamlin', o modelo final ficou composto pelas variáveis evapotranspiração máxima no período 5 (ETM5), evapotranspiração real no período 11 (ETR11) e precipitação no período 12 a 13 (PREC12a13), que atuam nas fases de pré-florescimento, florescimento e fixação e crescimento inicial dos frutos. As variáveis ETM5 e ETR11 influem negativamente na produção de frutos e a PREC12a13 influi positivamente.

As variáveis preditoras para a classe de idade 3 de 'Hamlin' foram a evapotranspiração máxima no período 1 a 2 (ETM1a2), o número de dias com deficiência hídrica no período 3 a 4 (NDH3a4), a evapotranspiração máxima no período 5 (ETM5) e a precipitação no período 6 a 8 (PREC6a8), atuantes nas fases de crescimento vegetativo de verão e de pré-florescimento. A variável ETM1a2 tem efeito positivo e NDH3a4, ETM5 e PREC6a8 têm efeito negativo sobre a produção de frutos por planta.

Para as três variedades cultivadas consideradas, com relação aos períodos que entraram na composição dos modelos, observa-se que, de um modo geral, envolvem meses até pelo menos o florescimento e início de fixação dos frutos (até os meses 10 e 11) ou fixação e início do crescimento do fruto (até os meses 12 e 13). A exceção ocorreu para o estrato laranjeira 'Hamlin' classe de idade 3, que apresenta entrada de dados apenas até o pré-florescimento (até agosto).

Os modelos obtidos constaram de no mínimo três (geralmente) e no máximo quatro variáveis preditoras, mantendo uma boa relação com o número de observações (15 safras). A adição de muitas variáveis regressoras no modelo induz a um aumento nem sempre coerente de $\mathrm{R}^{2}$ (Werkema \& Aguiar, 1996). 


\subsubsection{Ajuste dos modelos}

\subsubsection{Cultivar 'Pêra'}

Os valores estimados de número de frutos por planta para cada safra usando os modelos selecionados com os respectivos intervalos de confiança de 95\% para a variedade cultivada 'Pêra' por classe de idade constam na Figura 6. Os erros padrão relativos e resíduos padronizados utilizados para avaliar a qualidade do ajuste dos modelos se encontram na Tabela 31 (ANEXO).

De um modo geral, os valores de número de frutos observados mantiveram-se dentro dos intervalos de confiança de $95 \%$ para as três classes de idade (Figura 6), sendo que para a idade 1 o comportamento foi superior aos das idades 2 e 3 , em função do maior coeficiente de determinação obtido para o primeiro modelo, conforme já apresentado no item anterior, sendo o $\mathrm{R}^{2}$ de 0,88 para a idade 1 , e 0,76 e 0,75 para as idades 2 e 3 , respectivamente.

$\mathrm{O}$ erro padrão relativo $\left(\mathrm{Ep}_{\mathrm{r}}\right)$ (ANEXO: Tabela 31) variou de 0,03 a 0,14 , com valor médio de 0,07 , sendo que o maior $\mathrm{E}_{\mathrm{r}}$ ocorreu na safra 2003 da idade 1, a qual foi uma safra de baixa produção de frutos para o estrato. Contudo, pode-se dizer que a qualidade da predição foi boa, já que o valor estimado nessa safra (178,7 frutos por planta) acompanhou muito bem a tendência de baixa real do estrato, a qual foi de 407 frutos em 2002 para 193 frutos por planta em 2003.

$\mathrm{O}$ resíduo padronizado $(\mathrm{Rp})$ deve se manter entre valores de -2 e 2 para indicar bons níveis de ajuste dos modelos (Draper \& Smith, 1981). Nos modelos obtidos para laranjeira 'Pêra' os valores de Rp situaram-se todos dentro desta faixa, com exceção apenas de um caso para a idade 1 (safra 2000) e de dois casos para a idade 3 (safra 1998 e 2003), indicando que, em geral, os modelos se apresentaram satisfatórios. 
(A)

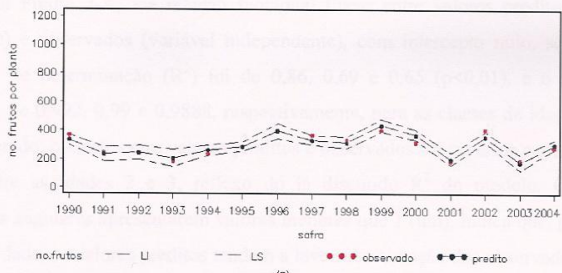

(B)

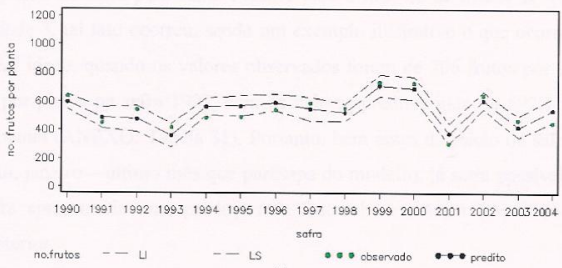

(c)

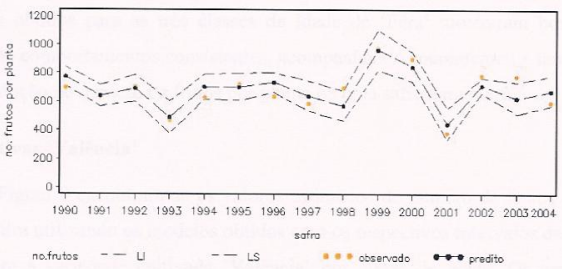

Figura 6 - Valores observados e preditos do número de frutos por planta com respectivos limites inferior (LD) e superior (LS) dos intervalos de confiança de 95\%. 'Pêra', idades 1 (A), 2 (B) e 3 (C) 
Para complementar a análise dos ajustes dos modelos foi feita comparação, ilustrada na Figura 7-A, via relação funcional linear entre valores preditos (variável dependente) e observados (variável independente), com intercepto nulo, sendo que o coeficiente de determinação $\left(\mathrm{R}^{2}\right)$ foi de $0,86,0,69$ e $0,65(\mathrm{p}<0,01)$, e o coeficiente angular foi de 0,992, 0,99 e 0,9888, respectivamente, para as classes de idade 1, 2 e 3. Como esperado, o ajuste entre valores preditos e observados foi superior para a idade $1 \mathrm{e}$ similar entre as idades 2 e 3 , reflexo do já discutido $\mathrm{R}^{2}$ do modelo. $\mathrm{O}$ fato dos coeficientes angulares apresentarem valores menores que 1 (um), indica que, para as três classes de idade, os valores preditos tendem a leve subestimação dos observados.

Os modelos foram capazes de acompanhar as grandes variações de produção de frutos por planta de safra para safra. Mesmo para o modelo de menor $\mathrm{R}^{2}(0,75)$, o da classe de idade 3, tal fato ocorreu, sendo um exemplo ilustrativo o que ocorreu na safra 1992 para tal idade, quando os valores observados foram de 706 frutos por planta para 470 frutos por planta na safra 1993, com os valores preditos indo de 692,1 para 490,1 frutos por planta (ANEXO: Tabela 31). Portanto, bem antes do início da safra (no caso desse estrato, janeiro - último mês que participa do modelo), já seria possível saber que a nova safra apresentaria uma produção de frutos bem inferior (cerca de 30\%) em relação à anterior.

Assim, o conjunto dos índices $E p_{r}$, $R p$ e $R^{2}$, além da análise dos valores estimados em relação aos observados no tempo, permitem dizer que, de maneira geral, os modelos obtidos para as três classes de idade de 'Pêra' mostraram bons ajustes, apresentando comportamentos consistentes, acompanhando coerentemente tendências de aumento/redução no número de frutos por planta de uma safra para outra.

\subsubsection{Cultivar 'Valência'}

Na Figura 8 encontram-se os valores estimados de número de frutos por planta para cada safra utilizando os modelos obtidos com os respectivos intervalos de confiança de $95 \%$ para a variedade cultivada 'Valência' por classe de idade. Os erros padrão relativos e resíduos padronizados utilizados para avaliar a qualidade do ajuste dos modelos são apresentados na Tabela 32 (ANEXO). 
(A)

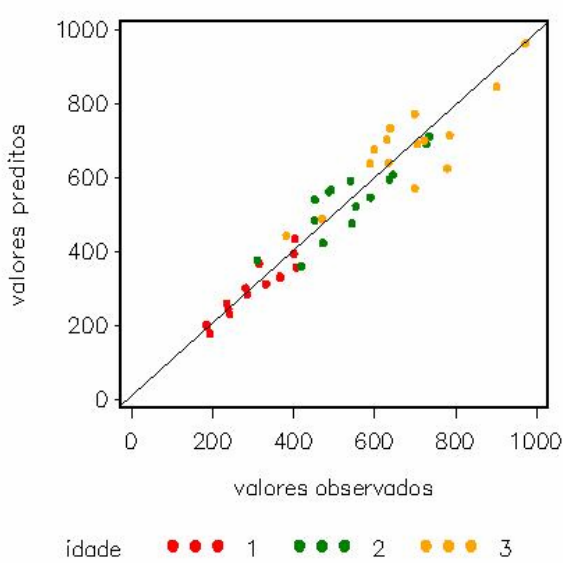

(B)

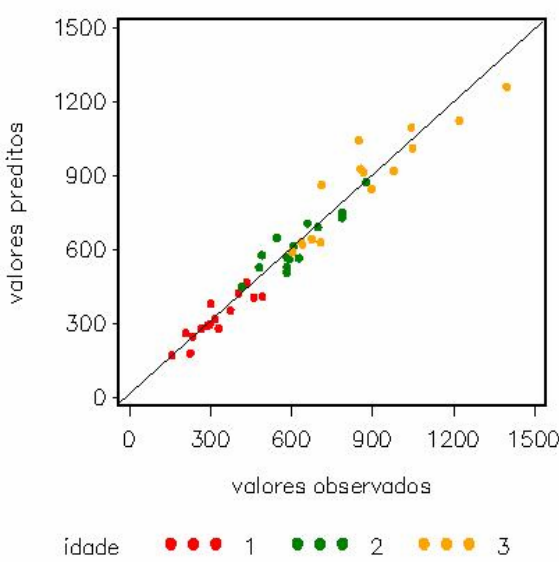

(c)

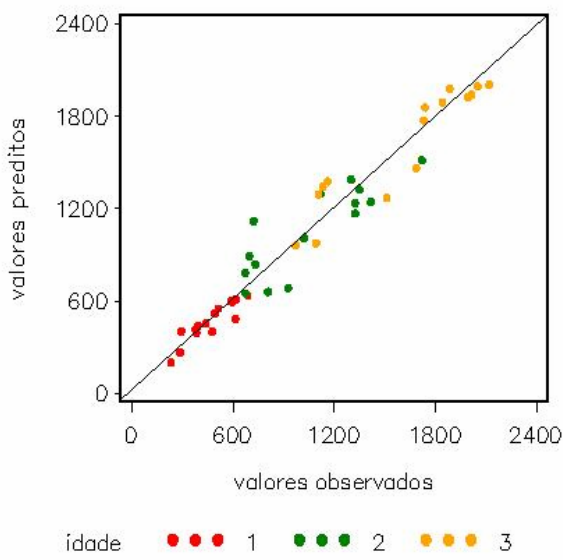

Figura 7 - Relação entre valores preditos do número de frutos por planta e valores observados pelos modelos agrometeorológicos para as variedades cultivadas 'Pêra' (A), 'Valência' (B) e 'Hamlin' (C) em três classes de idades 
Em geral, os valores de número de frutos observados situaram-se dentro dos intervalos de confiança de 95\% para as três classes de idade (Figura 8). Os coeficientes de determinação, apresentados na Tabela 9 , foram de 0,81 para as idade 1 e 2 e de 0,85 , para a idade 3 .

$\mathrm{O}$ erro padrão relativo $\left(\mathrm{Ep}_{\mathrm{r}}\right)$ (ANEXO: Tabela 32) variou de 0,03 a 0,20 , com valor médio de 0,07. Do mesmo modo como ocorrido para 'Pêra', o maior Ep $p_{\mathrm{r}}$ ocorreu na safra 2003 da idade 1, a qual foi uma safra de baixa produção de frutos para o estrato. Apesar disso, a qualidade da predição foi muito boa, uma vez que foi capaz de acompanhar bem a grande tendência de queda na produção de frutos de 2002 para 2003.

Com relação aos resíduos padronizados (Rp), nos modelos obtidos para 'Valência', os valores de Rp se situaram na grande maioria dentro da faixa de bom ajuste de -2 a 2 (Draper \& Smith, 1981), exceções ocorrendo apenas para dois casos nas idades 1 (safras 1990 e 1997) e 3 (safras 1996 e 1999) e em um caso na idade 2 (safra 1991), indicando que os modelos apresentam ajustes satisfatórios.

Nota-se que os modelos foram capazes de acompanhar as grandes variações de produção de frutos por planta de safra para safra. Um exemplo bem ilustrativo é o que ocorreu na safra 1999 para a idade 3, quando os valores observados foram de 675 frutos por planta, na safra 1998, para 1398 frutos por planta, na safra 1999 (aproximadamente o dobro), com os valores preditos indo de 643,9 para 1262,3 frutos por planta (ANEXO: Tabela 32). Assim, num momento muito anterior ao início da safra (no caso desse estrato, janeiro - último mês que participa do modelo), já seria possível saber que a nova safra apresentaria uma produção de frutos muito superior em relação à anterior.

A comparação via relação funcional linear entre valores preditos (variável dependente) e observados (variável independente), com intercepto nulo, para laranjeira 'Valência' apresentou coeficientes de determinação $\left(R^{2}\right)$ de $0,76,0,76$ e $0,82(p<0,01)$, e coeficientes angulares de 0,9844, 0,993 e 0,9907, respectivamente, para as classes de idade 1,2 e 3 . Os coeficientes angulares menores que um, indicam que, os valores preditos tendem a leve subestimação dos observados, para as três classes de idade (Figura 7-B). 


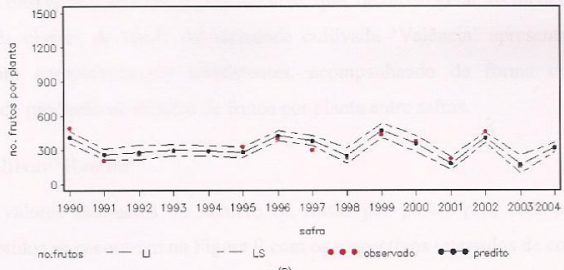

(B)

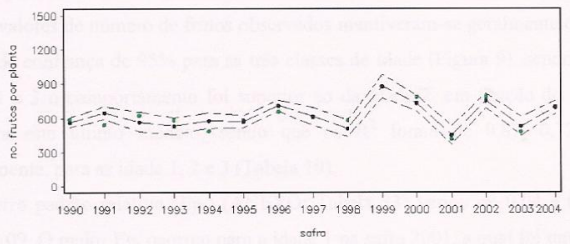

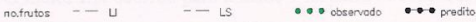

(c)

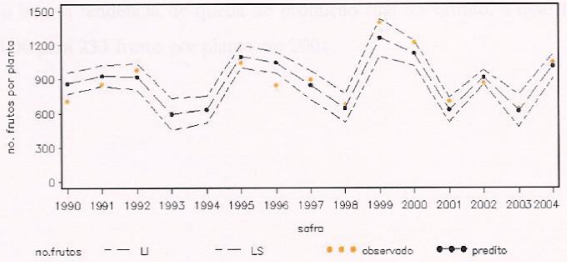

Figura 8 - Valores observados e preditos do número de frutos por planta com limites inferior (LI) e superior (LS) dos intervalos de confiança de 95\%. 'Valência', idades 1 (A), 2 (B) e 3 (C) 
Do conjunto dos índices $\mathrm{Ep}_{\mathrm{r}}, \mathrm{Rp}$ e $\mathrm{R}^{2}$ e da análise dos valores estimados em relação aos observados no tempo, pode-se dizer que, de modo geral, os modelos obtidos para as três classes de idade da variedade cultivada 'Valência' apresentaram bons ajustes, com comportamentos consistentes, acompanhando de forma coerente as tendências de produção de número de frutos por planta entre safras.

\subsubsection{Cultivar 'Hamlin'}

Os valores estimados de número de frutos por planta para cada safra pelos modelos obtidos se encontram na Figura 9 com os respectivos intervalos de confiança de 95\% para a variedade cultivada 'Hamlin' por classe de idade. Os erros padrão relativos e os resíduos padronizados são apresentados na Tabela 33 (ANEXO).

Os valores de número de frutos observados mantiveram-se geralmente dentro dos intervalos de confiança de 95\% para as três classes de idade (Figura 9), sendo que para as idades 1 e 3 o comportamento foi superior ao da idade 2, em função do menor $\mathrm{R}^{2}$ obtido para este último modelo, sendo que os $\mathrm{R}^{2}$ foram de $0,83,0,72$ e 0,87 , respectivamente, para as idade 1,2 e 3 (Tabela 10).

$\mathrm{O}$ erro padrão relativo $\left(\mathrm{Ep}_{\mathrm{r}}\right)$ (ANEXO: Tabela 33) variou de 0,04 a 0,28, com média de 0,09. O maior Ep $p_{\mathrm{r}}$ ocorreu para a idade 1 na safra 2001, a qual foi uma safra de baixa produção de frutos para o estrato. Entretanto, pode-se dizer que a qualidade da predição foi boa, já que o valor estimado nessa safra (204,9 frutos por planta) acompanhou bem a tendência de queda de produção real do estrato, a qual foi de 587 frutos em 2000 para 233 frutos por planta em 2001. 


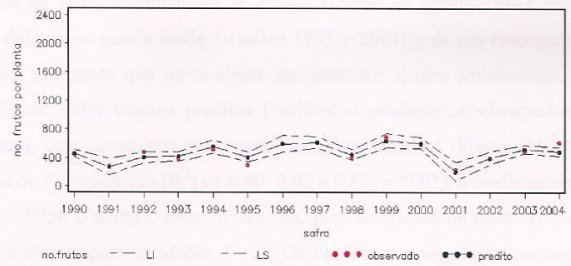

(B)

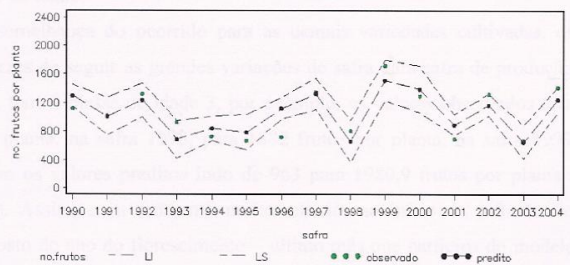

(c)

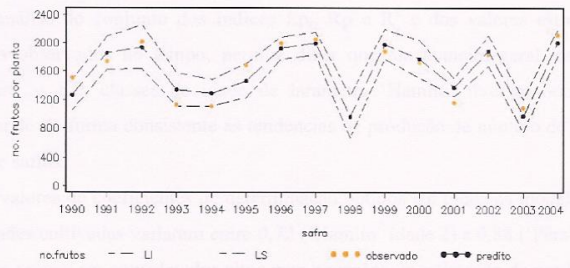

Figura 9 - Valores observados e preditos do número de frutos por planta com respectivos limites inferior (LI) e superior (LS) dos intervalos de confiança de 95\%. 'Hamlin', idades 1 (A), 2 (B) e 3 (C) 
Nos modelos obtidos para laranjeira 'Hamlin' os valores de Rp permaneceram todos dentro da faixa recomendada de -2 a 2 (Draper \& Smith, 1981), com exceção apenas de dois casos para a idade 1 (safras 1995 e 2004) e de um caso para a idade 2 (safra 1996), indicando que os modelos apresentaram ajustes satisfatórios. A relação funcional linear entre valores preditos (variável dependente) e observados (variável independente), com intercepto nulo, para laranjeira 'Hamlin' (Figura 7-C) apresentou coeficientes de determinação $\left(\mathrm{R}^{2}\right)$ de $0,80,0,62$ e $0,85(\mathrm{p}<0,01)$, e coeficientes angulares de 0,9872, 0,9756 e 0,9927, respectivamente, para as classes de idade 1, 2 e 3, sendo melhores os ajustes para as idades 1 e 3 . Os coeficientes angulares menores que um, indicam que, os valores preditos tendem a leve subestimação dos observados, para as três classes de idade.

À semelhança do ocorrido para as demais variedades cultivadas, os modelos foram capazes de seguir as grandes variações de safra para safra de produção de frutos por planta. Para a classe de idade 3, por exemplo, os valores observados foram de 973 frutos por planta, na safra 1998, para 1887 frutos por planta, na safra 1999 (quase o dobro), com os valores preditos indo de 963 para 1980,9 frutos por planta (ANEXO: Tabela 33). Assim, num momento muito anterior ao início da safra (no caso desse estrato, agosto do ano do florescimento - último mês que participa do modelo), já seria possível saber que a nova safra apresentaria uma produção de frutos muito superior em relação à anterior.

A análise do conjunto dos índices $E p_{r}, R p$ e $R^{2}$ e dos valores estimados em relação aos observados no tempo, permite dizer que, de maneira geral, os modelos obtidos para as três classes de idade de laranjeira 'Hamlin' tiveram bons ajustes, acompanhando de forma consistente as tendências de produção de número de frutos por planta entre safras.

Os valores de coeficientes de determinação obtidos em todos os modelos para as três variedades cultivadas variaram entre 0,72 ('Hamlin' idade 2) e 0,88 ('Pêra' idade 1). Tais valores podem ser considerados altos para equações de estimação de produtividade, de acordo com Albisu (1982), o qual obteve modelos agrometeorológicos para as condições de clima mediterrâneo com $\mathrm{R}^{2}$ variando de 0,77 a 0,85 . 
Fazendo uma análise integral dos ajustes dos modelos para as três variedades cultivadas, pode-se dizer que os modelos apresentaram desempenhos satisfatórios e podem ser utilizados com fins de previsão de produção de frutos por planta para a região de Limeira, desde que os valores das variáveis utilizadas estejam na faixa (entre os valores mínimo e máximo) correspondente aos valores utilizados na análise de regressão.

\subsubsection{Análise de resíduos}

A Tabela 11 apresenta os resultados obtidos para os modelos autoregressivos utilizados para verificar a presença de autocorrelações nos resíduos dos modelos agrometeorológicos por cultivar e classe de idade.

Não foram detectadas autocorrelações de primeira ordem significativas $(p>0,10)$ entre os resíduos dos modelos agrometeorológicos para estimação do número de frutos por planta de nenhum estrato considerado, corroborando o uso de modelos de regressão múltipla nesse estudo.

A ausência dessas autocorrelações é o principal pressuposto para adoção de análise de regressão linear múltipla pelo fato de ele influenciar a qualidade dos estimadores dos parâmetros da equação e os intervalos de confiança. Além disso, os testes de hipóteses baseados nas distribuições $\mathrm{t}$ e $\mathrm{F}$ tornam-se inapropriados nesses casos. A presença de autocorrelações nos resíduos inviabiliza o uso de regressão linear múltipla, devendo-se adotar outro tipo de modelo, no qual sejam consideradas estruturas de autocorrelação (Draper \& Smith, 1981). 
Tabela 11. Estimativas dos parâmetros $\theta_{\mathrm{ij} 1}$ (equação 22) dos modelos autoregressivos utilizados para investigar a presença de autocorrelação de ordem um entre os resíduos $(\varepsilon)$ em cada modelo que escreve a relação entre o número de frutos por planta e variáveis agrometeorológicas por cultivar (P: 'Pêra', V: 'Valência' e H: 'Hamlin') e classe de idade (CI)*

\begin{tabular}{ccccccc}
\hline Cultivar & CI & Parâmetro & Estimativa & Erro padrão & $\mathrm{T}$ & Valor $\mathrm{p}^{* *}$ \\
\hline 'Pêra' & 1 & $\theta_{\mathrm{P} 11}$ & 0,3488 & 0,2671 & 1,31 & 0,2143 \\
'Pêra' & 2 & $\theta_{\mathrm{P} 21}$ & $-0,0417$ & 0,3064 & $-0,14$ & 0,8938 \\
'Pêra' & 3 & $\theta_{\mathrm{P} 31}$ & $-0,1588$ & 0,2858 & $-0,56$ & 0,5879 \\
'Valência' & 1 & $\theta_{\mathrm{V} 11}$ & 0,0091 & 0,2774 & 0,03 & 0,9744 \\
'Valência' & 2 & $\theta_{\mathrm{V} 21}$ & $-0,4383$ & 0,2495 & $-1,76$ & 0,1025 \\
'Valência' & 3 & $\theta_{\mathrm{V} 31}$ & 0,3431 & 0,2628 & 1,31 & 0,2143 \\
'Hamlin' & 1 & $\theta_{\mathrm{H} 11}$ & $-0,1184$ & 0,3568 & $-0,33$ & 0,7452 \\
'Hamlin' & 2 & $\theta_{\mathrm{H} 21}$ & 0,1329 & 0,2858 & 0,47 & 0,6495 \\
'Hamlin' & 3 & $\theta_{\mathrm{H} 31}$ & $-0,0278$ & 0,2840 & $-0,10$ & 0,9236 \\
\hline
\end{tabular}

* Classe de idade 1: 3 a 5 anos; 2: 6 a 10 anos; 3: superior a 10 anos

** Valor aproximado da probabilidade de erro tipo I associada ao teste t para contrastes utilizado para testar a hipótese de ausência de correlação entre $\varepsilon_{\mathrm{t}} \mathrm{e} \varepsilon_{\mathrm{t}-1}$

\subsection{Considerações gerais}

Na cultura de citros é notória a dificuldade de condução de estudos controlados de longo prazo para obtenção de dados precisos sobre produtividade, início e duração de fases fenológicas e processos fisiológicos envolvidos.

Nesse contexto, para as condições do Estado de São Paulo, o processo de modelagem para previsões de safra de citros com base em dados agrometeorológicos tem sido restrito à construção de modelos matemático-empíricos (Ortolani et al., 1991), salvo raras exceções (Camargo et al., 1999). 
Em função da disponibilidade da série de dados de quinze anos de previsão de safra da indústria de suco paulista para diferentes cultivares na região de Limeira, no presente estudo procurou-se utilizar os mesmos para estabelecer, então, modelos matemático-empíricos, procurando-se imprimir orientação fitotécnica na busca por variáveis agrometeorológicas correlacionadas com a produção de frutos em diferentes fases do ciclo da cultura, visando se antecipar a estimação da época normal realizada pela indústria (abril).

Há que se considerar, portanto, que os dados aqui utilizados não foram coletados para fins específicos de modelagem, não se tratando de dados controlados de um determinado pomar, mas sim de amostragens com vistas à previsão de safra, sendo compostos por dados de produção de pomares sob diferentes condições edáficas e de manejo. Fica claro, então, que os modelos aqui obtidos não retratam a resposta de um pomar em questão, mas a resposta média dos pomares regionais às condições climáticas, prestando-se à previsões de safra em escala macro-regional.

Como tais dados são coletados sempre em meados de abril, eles se resumem a apenas um componente de produtividade - o número de frutos por planta, não se reportando ao componente tamanho de frutos, o qual, a essa época, ainda não se encontra estabilizado por estar o fruto em pleno processo de crescimento (Albrigo, 1992). No entanto, a determinação de tendência de alta ou baixa produção de frutos por planta já no período inicial de crescimento dos frutos (janeiro do ano da colheita) proporcionada pelos modelos obtidos nesse estudo é de grande valia para indústria e citricultores, trazendo consideráveis vantagens econômicas, possibilitando sobretudo antecipar transações operacionais e comerciais meses antes do início da safra.

Não foram realizados procedimentos para validação dos modelos pelo fato de se dispor de apenas quinze anos de dados. A exclusão de algumas safras do conjunto de dados utilizado para ajuste dos modelos comprometeria a investigação da presença de autocorrelações, aspecto fundamental na modelagem (Draper \& Smith, 1981). Além disso, a capacidade previsiva dos modelos não pode ser adequadamente avaliada com observações de apenas algumas safras. O que se espera é que os modelos aqui obtidos 
acompanhem, a longo prazo, a tendência de variação da produção de frutos por planta na região de Limeira.

Foi utilizado o procedimento clássico de Thornthwaite \& Mather (1955) para realização do balanço hídrico na escala diária para correlacionar variáveis agrometeorológicas com produção de frutos por planta. Não foi utilizado o fator de depleção de água no solo em função da dificuldade de obtenção dessa informação na literatura. A rigor, sabe-se que a evapotranspiração real é igual a evapotranspiração máxima quando o conteúdo de água no solo se encontra na faixa ótima de umidade (entre a umidade crítica e a capacidade de campo). Sendo assim, o procedimento preconizado por Thornthwaite \& Mather tende a superestimar a deficiência hídrica.

Para o cálculo da capacidade de água disponível (CAD), leva-se em consideração as umidades referentes à capacidade de campo e ao ponto de murcha permanente, bem como a profundidade efetiva do sistema radicular. Na natureza, em função dos teores de argila e de matéria orgânica, a CAD por unidade de profundidade efetiva do sistema radicular varia de 0,5 (baixo teor de argila e matéria orgânica) a 2,0 mm.cm ${ }^{-1}$. Em Latossolos, esse valor está em torno de $1 \mathrm{~mm} . \mathrm{cm}^{-1}$, valor adotado neste trabalho, em função da necessidade de determinar a ordem de grandeza da evapotranspiração real, da deficiência hídrica e do excedente hídrico para a região de Limeira.

A profundidade efetiva do sistema radicular foi considerada constante e o coeficiente de cultura $(\mathrm{Kc})$ foi considerado unitário por se tratar de procedimento para obtenção de estimativas (ordem de grandeza) de variáveis agrometeorológicas para uma região. No caso de considerar a variação temporal da profundidade efetiva do sistema radicular dever-se-ia conhecer o modelo de crescimento bem como a profundidade de molhamento para realização do cálculo na forma seqüencial, no intuito de não haver aumento de armazenamento, devido ao aumento da profundidade efetiva do sistema radicular, sem ter havido chuva. Além disso, esse procedimento dificulta o balanço hídrico cíclico, o qual foi utilizado no primeiro ano (1989) para o cálculo da umidade para início da realização do balanço hídrico seqüencial.

A título de sugestão, a indústria deve se preocupar com a formação de um banco de dados de longo prazo utilizando, para suas áreas próprias de produção (devido à 
maior facilidade de controle de informações), talhões com eventos documentados e controlados, como características de solo, de clima (posto meteorológico automatizado) de manejo (adubação, controle fitossanitário e irrigação, principalmente) e de planta (cultivar, idade, época de ocorrência de florescimento, produtividade final e parâmetros de maturação), para prover subsídios a um processo de modelagem menos empírico. Tal controle, além da importância para modelagem, também é importante para adiantar tendências futuras como a rastreabilidade da produção de frutas e de suco, sendo, por conseguinte, de grande valia também para a área de marketing. 


\section{CONCLUSÕES}

De acordo com os resultados obtidos, pode-se concluir que, na região de Limeira: (i) a produção de frutos por planta aumenta com altas demandas evapotranspiratórias e adequado suprimento de água nos períodos coincidentes com o fluxo de crescimento vegetativo de verão (janeiro e fevereiro). Estresses por deficiência hídrica, altas temperaturas e demandas evapotranspiratórias entre abril e junho diminuem a produção e, entre julho e setembro, aumentam a produção. Altas demandas evapotranspiratórias, precipitações e excedentes hídricos, no florescimento e fixação, reduzem a produção de frutos por planta. Precipitações e excedentes hídricos na fase inicial do crescimento dos frutos (dezembro e janeiro) contribuem para aumentar a produção de frutos; (ii) para as três variedades cultivadas, nas diferentes classes de idade, houve coerência de épocas de ocorrência e de efeitos das variáveis significativamente correlacionadas com o número de frutos por planta; e (iii) os modelos agrometeorológicos obtidos para estimação de número de frutos por planta para todas as variedades cultivadas e classes de idade apresentaram desempenhos satisfatórios, possibilitando adiantar em pelo menos três meses (janeiro) a estimação da época normal (abril) realizada pela indústria. 
ANEXO 
Tabela 12. Temperatura média mensal $\left({ }^{\circ} \mathrm{C}\right)$ entre os anos de 1989 e 2004 , em LimeiraSP

\begin{tabular}{lccccccccccccc}
\hline \multirow{2}{*}{ Ano } & \multicolumn{10}{c}{ Mês } & \multicolumn{10}{c}{ Média } \\
\cline { 2 - 12 } & Jan & Fev & Mar & Abr & Mai & Jun & Jul & Ago & Set & Out & Nov & Dez & \\
\hline 1989 & 23,3 & 23,5 & 23,3 & 22,0 & 17,9 & 16,8 & 16,5 & 18,3 & 19,4 & 20,1 & 21,4 & 22,6 & 20,4 \\
1990 & 24,3 & 24,1 & 23,6 & 22,7 & 17,8 & 17,3 & 16,4 & 17,9 & 18,4 & 22,3 & 24,3 & 23,3 & 21,0 \\
1991 & 22,9 & 23,1 & 21,9 & 20,9 & 18,7 & 18,1 & 16,7 & 19,4 & 19,5 & 21,6 & 22,8 & 23,5 & 20,8 \\
1992 & 23,2 & 22,9 & 22,4 & 20,7 & 19,8 & 19,2 & 17,6 & 18,1 & 19,0 & 21,7 & 22,0 & 22,4 & 20,8 \\
1993 & 24,0 & 22,7 & 23,7 & 21,9 & 18,9 & 17,3 & 18,2 & 17,0 & 19,6 & 21,8 & 23,7 & 23,0 & 21,0 \\
1994 & 22,9 & 25,2 & 22,7 & 21,5 & 20,0 & 16,9 & 18,7 & 19,1 & 22,1 & 23,9 & 23,6 & 24,4 & 21,8 \\
1995 & 25,1 & 23,5 & 23,2 & 21,3 & 18,9 & 18,4 & 19,6 & 21,8 & 21,5 & 21,0 & 22,1 & 23,1 & 21,6 \\
1996 & 24,2 & 24,5 & 23,6 & 21,9 & 18,2 & 17,7 & 16,6 & 19,0 & 20,1 & 22,2 & 22,4 & 23,6 & 21,2 \\
1997 & 23,7 & 24,2 & 22,7 & 21,4 & 18,8 & 17,5 & 18,8 & 19,6 & 22,3 & 22,7 & 24,1 & 24,5 & 21,7 \\
1998 & 24,9 & 25,0 & 24,4 & 22,1 & 18,4 & 16,7 & 18,3 & 21,1 & 21,5 & 21,1 & 22,3 & 23,9 & 21,6 \\
1999 & 24,5 & 24,2 & 23,8 & 20,9 & 18,1 & 17,3 & 18,7 & 18,7 & 21,1 & 21,7 & 21,7 & 23,9 & 21,2 \\
2000 & 23,5 & 23,7 & 23,2 & 21,4 & 18,8 & 19,4 & 16,7 & 19,8 & 20,9 & 24,7 & 22,8 & 23,4 & 21,5 \\
2001 & 24,7 & 25,0 & 24,5 & 23,0 & 18,8 & 18,0 & 19,1 & 20,0 & 21,0 & 21,9 & 23,8 & 23,1 & 21,9 \\
2002 & 23,6 & 22,9 & 24,7 & 24,1 & 20,1 & 20,2 & 17,7 & 21,5 & 19,9 & 25,6 & 24,1 & 24,5 & 22,4 \\
2003 & 24,1 & 25,2 & 23,6 & 22,0 & 18,4 & 19,7 & 19,0 & 18,9 & 21,6 & 22,9 & 23,3 & 24,6 & 21,9 \\
2004 & 23,2 & 23,0 & 22,4 & & & & & & & & & & \\
Média & 23,9 & 23,9 & 23,4 & 21,9 & 18,8 & 18,0 & 17,9 & 19,3 & 20,5 & 22,3 & 23,0 & 23,6 & 21,4 \\
\hline
\end{tabular}

Tabela 13. Temperatura máxima mensal $\left({ }^{\circ} \mathrm{C}\right)$ entre os anos de 1989 e 2004, em LimeiraSP

\begin{tabular}{lccccccccccccc}
\hline \multirow{2}{*}{ Ano } & \multicolumn{10}{c}{ Mês } & \multicolumn{10}{c}{ Média } \\
\cline { 2 - 12 } & Jan & Fev & Mar & Abr & Mai & Jun & Jul & Ago & Set & Out & Nov & Dez & \\
\hline 1989 & 28,0 & 28,0 & 28,6 & 27,9 & 24,4 & 22,8 & 23,0 & 25,4 & 24,9 & 27,7 & 27,6 & 28,1 & 26,4 \\
1990 & 29,6 & 30,1 & 29,0 & 28,4 & 24,0 & 24,1 & 22,7 & 24,5 & 25,0 & 28,4 & 30,3 & 29,4 & 27,1 \\
1991 & 28,3 & 28,6 & 26,3 & 26,6 & 25,1 & 24,1 & 23,7 & 26,7 & 27,3 & 27,9 & 29,4 & 28,9 & 26,9 \\
1992 & 28,5 & 28,5 & 27,9 & 26,4 & 24,8 & 25,3 & 23,6 & 24,7 & 23,7 & 27,4 & 27,4 & 28,3 & 26,4 \\
1993 & 29,5 & 27,5 & 29,4 & 27,7 & 24,6 & 22,9 & 25,3 & 24,2 & 26,1 & 28,7 & 30,6 & 28,7 & 27,1 \\
1994 & 28,2 & 31,1 & 28,1 & 27,5 & 25,8 & 23,4 & 25,5 & 27,0 & 30,2 & 30,9 & 29,3 & 29,8 & 28,1 \\
1995 & 30,2 & 27,5 & 28,8 & 27,3 & 24,7 & 24,6 & 25,3 & 28,8 & 28,4 & 26,9 & 27,7 & 28,6 & 27,4 \\
1996 & 29,3 & 29,8 & 28,6 & 28,1 & 24,3 & 24,2 & 23,8 & 26,4 & 25,8 & 28,0 & 27,8 & 28,3 & 27,0 \\
1997 & 28,2 & 30,0 & 28,7 & 27,8 & 25,0 & 22,5 & 25,3 & 26,8 & 29,2 & 28,7 & 29,3 & 29,9 & 27,6 \\
1998 & 30,0 & 29,8 & 29,8 & 27,7 & 23,8 & 22,7 & 25,1 & 27,3 & 27,7 & 26,3 & 28,7 & 28,8 & 27,3 \\
1999 & 29,1 & 29,2 & 29,5 & 27,4 & 24,9 & 23,4 & 25,3 & 26,5 & 28,2 & 28,3 & 28,6 & 29,6 & 27,5 \\
2000 & 29,0 & 28,4 & 28,5 & 28,3 & 25,6 & 26,0 & 23,3 & 26,3 & 26,4 & 31,6 & 28,4 & 28,2 & 27,5 \\
2001 & 30,5 & 30,5 & 30,2 & 29,2 & 24,5 & 24,1 & 26,3 & 27,1 & 27,2 & 28,1 & 29,5 & 27,8 & 27,9 \\
2002 & 28,6 & 27,6 & 30,5 & 30,7 & 26,0 & 27,2 & 24,4 & 27,8 & 25,9 & 32,7 & 29,7 & 29,7 & 28,4 \\
2003 & 28,0 & 30,8 & 29,0 & 27,8 & 24,9 & 26,5 & 25,7 & 26,1 & 28,6 & 29,4 & 29,0 & 29,9 & 28,0 \\
2004 & 28,0 & 27,9 & 28,0 & & & & & & & & & & \\
Média & 28,9 & 29,1 & 28,8 & 27,9 & 24,8 & 24,3 & 24,6 & 26,4 & 27,0 & 28,7 & 28,9 & 28,9 & 27,4 \\
\hline
\end{tabular}


Tabela 14. Temperatura mínima mensal $\left({ }^{\circ} \mathrm{C}\right)$ entre os anos de 1989 e 2004, em LimeiraSP

\begin{tabular}{|c|c|c|c|c|c|c|c|c|c|c|c|c|c|}
\hline \multirow[t]{2}{*}{ Ano } & \multicolumn{12}{|c|}{ Mês } & \multirow[t]{2}{*}{ Médi } \\
\hline & Jan & $\mathrm{Fev}$ & Mar & Abr & Mai & Jun & Jul & Ago & Set & Out & Nov & Dez & \\
\hline 1989 & 18,7 & 19,0 & 18,0 & 16,1 & 11,4 & 10,8 & 9,9 & 11,2 & 13,8 & 12,5 & 15,2 & 17,0 & 14,5 \\
\hline 1990 & 18,9 & 18,1 & 18,3 & 17,0 & 11,7 & 10,6 & 10,1 & 11,2 & 11,8 & 16,2 & 18,2 & 17,2 & 14,9 \\
\hline 1991 & 17,5 & 17,5 & 17,5 & 15,2 & 12,4 & 12,1 & 9,6 & 12,0 & 11,7 & 15,2 & 16,1 & 18,0 & 14,6 \\
\hline 1992 & 17,8 & 17,3 & 17,0 & 15,0 & 14,7 & 13,1 & 11,5 & 11,5 & 14,3 & 16,0 & 16,7 & 16,5 & 15,1 \\
\hline 1993 & 18,5 & 17,8 & 18,0 & 16,0 & 13,2 & 11,7 & 11,1 & 9,8 & 13,1 & 14,9 & 16,9 & 17,4 & 14,9 \\
\hline 1994 & 17,7 & 19,3 & 17,3 & 15,5 & 14,1 & 10,3 & 12,0 & 11,2 & 14,0 & 17,0 & 17,8 & 19,0 & 15,4 \\
\hline 1995 & 19,9 & 19,6 & 17,7 & 15,2 & 13,1 & 12,2 & 13,8 & 14,8 & 14,7 & 15,1 & 16,5 & 17,7 & 15,9 \\
\hline 1996 & 19,1 & 19,2 & 18,6 & 15,7 & 12,1 & 11,2 & 9,5 & 11,5 & 14,5 & 16,4 & 16,9 & 19,0 & 15,3 \\
\hline 1997 & 19,3 & 18,4 & 16,7 & 15,1 & 12,7 & 12,5 & 12,4 & 12,4 & 15,4 & 16,7 & 18,9 & 19,2 & 15,8 \\
\hline 1998 & 19,8 & 20,2 & 18,9 & 16,6 & 13,1 & 10,7 & 11,4 & 15,0 & 15,3 & 15,9 & 16,0 & 19,0 & 16,0 \\
\hline 1999 & 19,9 & 19,2 & 18,1 & 14,5 & 11,3 & 11,2 & 12,1 & 11,0 & 14,0 & 15,1 & 14,8 & 18,2 & 15,0 \\
\hline 2000 & 18,1 & 18,9 & 18,0 & 14,5 & 12,0 & 12,8 & 10,0 & 13,3 & 15,3 & 17,9 & 17,2 & 18,7 & 15,6 \\
\hline 2001 & 18,8 & 19,6 & 18,8 & 16,8 & 13,1 & 12,0 & 11,9 & 12,9 & 14,8 & 15,6 & 18,1 & 18,5 & 15,9 \\
\hline 2002 & 18,7 & 18,2 & 18,9 & 17,5 & 14,2 & 13,3 & 11,0 & 15,3 & 13,9 & 18,6 & 18,6 & 19,2 & 16,5 \\
\hline 2003 & 20,1 & 19,6 & 18,1 & 16,2 & 11,9 & 12,9 & 12,3 & 11,7 & 14,6 & 16,4 & 17,7 & 19,3 & 15,9 \\
\hline 2004 & 18,3 & 18,0 & 16,7 & & & & & & & & & & \\
\hline Média & 18,8 & 18,7 & 17,9 & 15,8 & 12,7 & 11,8 & 11,2 & 12,3 & 14,1 & 16,0 & 17,0 & 18,3 & 15,4 \\
\hline
\end{tabular}

Tabela 15. Precipitação total mensal (mm) entre os anos de 1989 e 2004, em Limeira-SP

\begin{tabular}{|c|c|c|c|c|c|c|c|c|c|c|c|c|c|}
\hline \multirow[t]{2}{*}{ Ano } & \multicolumn{12}{|c|}{ Mês } & \multirow[t]{2}{*}{ Total } \\
\hline & Jan & $\mathrm{Fev}$ & Mar & Abr & Mai & Jun & Jul & Ago & Set & Out & Nov & Dez & \\
\hline 1989 & 252 & 249 & 144 & 66 & 34 & 47 & 91 & 17 & 77 & 21 & 188 & 280 & 1465 \\
\hline 1990 & 249 & 64 & 197 & 65 & 49 & 4 & 66 & 60 & 58 & 188 & 113 & 199 & 1312 \\
\hline 1991 & 192 & 189 & 507 & 166 & 43 & 18 & 20 & 0 & 71 & 92 & 79 & 288 & 1664 \\
\hline 1992 & 158 & 174 & 158 & 77 & 107 & 1 & 61 & 19 & 101 & 238 & 214 & 101 & 1408 \\
\hline 1993 & 298 & 317 & 85 & 67 & 59 & 53 & 9 & 23 & 195 & 104 & 99 & 198 & 1506 \\
\hline 1994 & 154 & 163 & 101 & 51 & 54 & 47 & 21 & 0 & 0 & 97 & 244 & 248 & 1180 \\
\hline 1995 & 283 & 427 & 147 & 144 & 36 & 23 & 35 & 1 & 37 & 145 & 130 & 210 & 1618 \\
\hline 1996 & 341 & 159 & 199 & 58 & 50 & 20 & 1 & 55 & 172 & 148 & 274 & 247 & 1724 \\
\hline 1997 & 354 & 80 & 31 & 53 & 79 & 192 & 30 & 0 & 65 & 105 & 251 & 134 & 1374 \\
\hline 1998 & 157 & 349 & 179 & 79 & 79 & 14 & 32 & 22 & 62 & 152 & 50 & 242 & 1417 \\
\hline 1999 & 463 & 168 & 184 & 38 & 37 & 36 & 2 & 0 & 64 & 64 & 35 & 157 & 1247 \\
\hline 2000 & 223 & 195 & 265 & 3 & 16 & 5 & 51 & 53 & 82 & 96 & 294 & 251 & 1533 \\
\hline 2001 & 147 & 212 & 205 & 21 & 49 & 13 & 8 & 62 & 73 & 164 & 95 & 277 & 1327 \\
\hline 2002 & 284 & 221 & 138 & 12 & 112 & 0 & 4 & 98 & 69 & 78 & 222 & 144 & 1381 \\
\hline 2003 & 319 & 100 & 143 & 61 & 45 & 15 & 3 & 22 & 26 & 77 & 128 & 190 & 1129 \\
\hline 2004 & 251 & 230 & 85 & & & & & & & & & & \\
\hline Média & 258 & 206 & 173 & 64 & 57 & 33 & 29 & 29 & 77 & 118 & 161 & 211 & 1419 \\
\hline
\end{tabular}


Tabela 16. Evapotranspiração máxima total mensal (mm) entre os anos de 1989 e 2004, em Limeira-SP

\begin{tabular}{|c|c|c|c|c|c|c|c|c|c|c|c|c|c|}
\hline \multirow[t]{2}{*}{ Ano } & \multicolumn{12}{|c|}{ Mês } & \multirow[t]{2}{*}{ Total } \\
\hline & Jan & $\mathrm{Fev}$ & Mar & $\mathrm{Abr}$ & Mai & Jun & Jul & Ago & Set & Out & Nov & Dez & \\
\hline 1989 & 116 & 103 & 106 & 86 & 55 & 45 & 45 & 59 & 69 & 79 & 93 & 109 & 965 \\
\hline 1990 & 126 & 107 & 109 & 91 & 53 & 46 & 44 & 53 & 60 & 100 & 121 & 117 & 1025 \\
\hline 1991 & 111 & 98 & 93 & 77 & 58 & 51 & 44 & 66 & 68 & 93 & 105 & 118 & 982 \\
\hline 1992 & 114 & 96 & 97 & 74 & 66 & 59 & 51 & 56 & 64 & 93 & 98 & 107 & 975 \\
\hline 1993 & 123 & 94 & 109 & 83 & 59 & 46 & 54 & 49 & 69 & 95 & 115 & 114 & 1009 \\
\hline 1994 & 109 & 119 & 97 & 78 & 65 & 42 & 57 & 61 & 88 & 114 & 113 & 128 & 1070 \\
\hline 1995 & 135 & 101 & 103 & 77 & 58 & 51 & 62 & 83 & 83 & 86 & 97 & 113 & 1048 \\
\hline 1996 & 125 & 112 & 108 & 85 & 54 & 48 & 44 & 62 & 72 & 97 & 100 & 120 & 1026 \\
\hline 1997 & 118 & 108 & 97 & 78 & 57 & 46 & 56 & 65 & 90 & 104 & 119 & 130 & 1065 \\
\hline 1998 & 134 & 118 & 116 & 85 & 54 & 40 & 53 & 77 & 83 & 85 & 100 & 122 & 1066 \\
\hline 1999 & 129 & 108 & 110 & 77 & 54 & 45 & 56 & 60 & 81 & 93 & 93 & 123 & 1029 \\
\hline 2000 & 117 & 103 & 104 & 79 & 58 & 58 & 45 & 68 & 78 & 125 & 104 & 118 & 1055 \\
\hline 2001 & 130 & 117 & 117 & 91 & 57 & 50 & 57 & 65 & 78 & 91 & 115 & 112 & 1081 \\
\hline 2002 & 116 & 93 & 119 & 101 & 64 & 60 & 47 & 78 & 68 & 137 & 118 & 128 & 1128 \\
\hline 2003 & 122 & 119 & 106 & 82 & 54 & 58 & 56 & 59 & 83 & 104 & 109 & 131 & 1081 \\
\hline 2004 & 112 & 96 & 95 & & & & & & & & & & \\
\hline Média & 121 & 106 & 105 & 83 & 58 & 50 & 51 & 64 & 75 & 100 & 107 & 119 & 1040 \\
\hline
\end{tabular}

Tabela 17. Evapotranspiração real total mensal (mm) entre os anos de 1989 e 2004, em Limeira-SP

\begin{tabular}{cccccccccccccc}
\hline Ano & \multicolumn{10}{c}{ Mês } & \multicolumn{10}{c}{ Total } \\
\cline { 2 - 12 } & Jan & Fev & Mar & Abr & Mai & Jun & Jul & Ago & Set & Out & Nov & Dez & \\
\hline 1989 & 113 & 100 & 91 & 72 & 35 & 33 & 31 & 49 & 60 & 51 & 80 & 95 & 810 \\
1990 & 119 & 77 & 95 & 74 & 46 & 30 & 34 & 46 & 56 & 90 & 102 & 105 & 874 \\
1991 & 101 & 92 & 88 & 71 & 50 & 34 & 28 & 25 & 27 & 72 & 65 & 108 & 760 \\
1992 & 105 & 93 & 92 & 64 & 61 & 38 & 37 & 36 & 54 & 88 & 91 & 93 & 852 \\
1993 & 113 & 93 & 91 & 65 & 42 & 42 & 38 & 27 & 55 & 87 & 92 & 105 & 848 \\
1994 & 104 & 108 & 86 & 66 & 46 & 33 & 46 & 31 & 22 & 47 & 100 & 120 & 808 \\
1995 & 128 & 98 & 82 & 72 & 47 & 32 & 39 & 32 & 30 & 57 & 91 & 96 & 804 \\
1996 & 117 & 105 & 103 & 64 & 44 & 33 & 25 & 41 & 65 & 89 & 90 & 114 & 889 \\
1997 & 113 & 96 & 63 & 45 & 29 & 44 & 39 & 35 & 47 & 79 & 113 & 114 & 815 \\
1998 & 125 & 107 & 103 & 70 & 48 & 35 & 42 & 49 & 50 & 72 & 80 & 111 & 891 \\
1999 & 124 & 104 & 100 & 59 & 40 & 33 & 31 & 18 & 40 & 58 & 54 & 98 & 759 \\
2000 & 102 & 95 & 90 & 56 & 28 & 18 & 18 & 37 & 69 & 80 & 96 & 111 & 798 \\
2001 & 118 & 110 & 103 & 67 & 34 & 25 & 25 & 29 & 57 & 85 & 89 & 102 & 844 \\
2002 & 114 & 90 & 108 & 60 & 49 & 40 & 20 & 61 & 58 & 80 & 108 & 118 & 905 \\
2003 & 114 & 107 & 94 & 68 & 44 & 38 & 22 & 23 & 28 & 58 & 79 & 116 & 791 \\
2004 & 102 & 90 & 89 & & & & & & & & & & \\
Média & 113 & 98 & 92 & 65 & 43 & 34 & 32 & 36 & 48 & 73 & 89 & 107 & 830 \\
\hline
\end{tabular}


Tabela 18. Deficiência hídrica total mensal (mm) entre os anos de 1989 e 2004, em Limeira-SP

\begin{tabular}{|c|c|c|c|c|c|c|c|c|c|c|c|c|c|}
\hline \multirow[t]{2}{*}{ Ano } & \multicolumn{12}{|c|}{ Mês } & \multirow[t]{2}{*}{ Total } \\
\hline & Jan & $\mathrm{Fev}$ & Mar & $\mathrm{Abr}$ & Mai & Jun & $\mathrm{Jul}$ & Ago & Set & Out & Nov & Dez & \\
\hline 1989 & 3 & 3 & 15 & 14 & 20 & 12 & 14 & 10 & 8 & 29 & 13 & 15 & 156 \\
\hline 1990 & 7 & 30 & 14 & 17 & 7 & 17 & 10 & 8 & 4 & 10 & 18 & 11 & 152 \\
\hline 1991 & 10 & 7 & 5 & 5 & 7 & 17 & 16 & 41 & 41 & 21 & 40 & 11 & 222 \\
\hline 1992 & 8 & 3 & 5 & 9 & 5 & 21 & 14 & 20 & 10 & 5 & 7 & 14 & 121 \\
\hline 1993 & 10 & 1 & 18 & 18 & 18 & 3 & 17 & 23 & 15 & 8 & 23 & 10 & 162 \\
\hline 1994 & 5 & 10 & 11 & 12 & 18 & 9 & 12 & 30 & 67 & 68 & 13 & 8 & 262 \\
\hline 1995 & 7 & 4 & 22 & 5 & 11 & 19 & 22 & 51 & 53 & 29 & 6 & 16 & 243 \\
\hline 1996 & 8 & 7 & 5 & 21 & 10 & 15 & 19 & 21 & 7 & 9 & 10 & 6 & 136 \\
\hline 1997 & 4 & 12 & 34 & 33 & 28 & 2 & 16 & 30 & 44 & 24 & 6 & 16 & 249 \\
\hline 1998 & 9 & 11 & 14 & 15 & 6 & 5 & 11 & 29 & 33 & 13 & 20 & 11 & 177 \\
\hline 1999 & 5 & 5 & 10 & 18 & 14 & 11 & 25 & 42 & 41 & 36 & 40 & 25 & 270 \\
\hline 2000 & 16 & 7 & 14 & 23 & 30 & 40 & 28 & 30 & 9 & 45 & 8 & 7 & 255 \\
\hline 2001 & 13 & 6 & 13 & 24 & 23 & 25 & 32 & 37 & 21 & 7 & 26 & 9 & 235 \\
\hline 2002 & 2 & 3 & 11 & 41 & 16 & 20 & 27 & 17 & 10 & 56 & 10 & 10 & 224 \\
\hline 2003 & 8 & 13 & 12 & 14 & 10 & 20 & 34 & 36 & 55 & 46 & 30 & 15 & 291 \\
\hline 2004 & 10 & 6 & 6 & & & & & & & & & & \\
\hline Média & 8 & 8 & 13 & 18 & 15 & 16 & 20 & 28 & 28 & 27 & 18 & 12 & 210 \\
\hline
\end{tabular}

Tabela 19. Excedente hídrico total mensal (mm) entre os anos de 1989 e 2004, em Limeira-SP

\begin{tabular}{|c|c|c|c|c|c|c|c|c|c|c|c|c|c|}
\hline \multirow{2}{*}{ Ano } & \multicolumn{12}{|c|}{ Mês } & \multirow[t]{2}{*}{ Total } \\
\hline & Jan & $\mathrm{Fev}$ & Mar & Abr & Mai & Jun & Jul & Ago & Set & Out & Nov & Dez & \\
\hline 1989 & 132 & 145 & 49 & 30 & 0 & 0 & 33 & 0 & 0 & 0 & 69 & 180 & 637 \\
\hline 1990 & 151 & 0 & 82 & 2 & 0 & 0 & 0 & 3 & 5 & 120 & 5 & 97 & 465 \\
\hline 1991 & 73 & 114 & 394 & 101 & 10 & 0 & 0 & 0 & 0 & 42 & 0 & 154 & 888 \\
\hline 1992 & 42 & 83 & 64 & 31 & 42 & 0 & 0 & 0 & 5 & 150 & 128 & 29 & 574 \\
\hline 1993 & 178 & 208 & 14 & 12 & 0 & 5 & 0 & 0 & 98 & 25 & 8 & 80 & 628 \\
\hline 1994 & 61 & 61 & 8 & 4 & 0 & 0 & 0 & 0 & 0 & 0 & 110 & 140 & 383 \\
\hline 1995 & 150 & 346 & 41 & 91 & 0 & 0 & 0 & 0 & 0 & 21 & 52 & 91 & 791 \\
\hline 1996 & 251 & 34 & 108 & 0 & 0 & 0 & 0 & 0 & 93 & 52 & 183 & 128 & 848 \\
\hline 1997 & 227 & 11 & 0 & 0 & 2 & 166 & 0 & 0 & 0 & 0 & 124 & 17 & 546 \\
\hline 1998 & 43 & 231 & 86 & 12 & 19 & 0 & 0 & 0 & 0 & 34 & 0 & 116 & 542 \\
\hline 1999 & 323 & 67 & 90 & 0 & 0 & 0 & 0 & 0 & 0 & 0 & 0 & 28 & 508 \\
\hline 2000 & 129 & 90 & 143 & 0 & 0 & 0 & 0 & 0 & 17 & 0 & 181 & 140 & 699 \\
\hline 2001 & 38 & 116 & 84 & 1 & 0 & 0 & 0 & 0 & 3 & 83 & 0 & 159 & 486 \\
\hline 2002 & 172 & 140 & 33 & 0 & 10 & 0 & 0 & 4 & 0 & 0 & 89 & 54 & 502 \\
\hline 2003 & 176 & 20 & 45 & 0 & 0 & 0 & 0 & 0 & 0 & 0 & 3 & 104 & 348 \\
\hline 2004 & 122 & 130 & 12 & & & & & & & & & & \\
\hline Média & 142 & 112 & 78 & 19 & 6 & 11 & 2 & 1 & 15 & 35 & 63 & 101 & 590 \\
\hline
\end{tabular}


Tabela 20. Número de dias por mês com deficiência hídrica (NDH) entre os anos de 1989 e 2004, em Limeira-SP

\begin{tabular}{|c|c|c|c|c|c|c|c|c|c|c|c|c|c|}
\hline \multirow[t]{2}{*}{ Ano } & \multicolumn{12}{|c|}{ Mês } & \multirow[t]{2}{*}{ Total } \\
\hline & Jan & $\mathrm{Fev}$ & Mar & Abr & Mai & Jun & Jul & Ago & Set & Out & Nov & Dez & \\
\hline 1989 & 12 & 10 & 25 & 25 & 29 & 24 & 27 & 25 & 22 & 30 & 17 & 22 & 268 \\
\hline 1990 & 16 & 20 & 17 & 24 & 20 & 29 & 22 & 21 & 17 & 20 & 21 & 21 & 248 \\
\hline 1991 & 20 & 16 & 14 & 20 & 26 & 27 & 28 & 31 & 25 & 22 & 27 & 16 & 272 \\
\hline 1992 & 20 & 14 & 19 & 24 & 20 & 30 & 26 & 28 & 17 & 18 & 15 & 22 & 253 \\
\hline 1993 & 17 & 4 & 24 & 26 & 27 & 20 & 30 & 28 & 17 & 21 & 25 & 19 & 258 \\
\hline 1994 & 15 & 19 & 23 & 23 & 26 & 22 & 27 & 31 & 30 & 24 & 20 & 18 & 278 \\
\hline 1995 & 16 & 10 & 23 & 18 & 25 & 28 & 27 & 30 & 26 & 18 & 18 & 20 & 259 \\
\hline 1996 & 14 & 14 & 14 & 27 & 26 & 27 & 31 & 27 & 16 & 23 & 18 & 14 & 251 \\
\hline 1997 & 11 & 22 & 29 & 26 & 25 & 9 & 30 & 31 & 25 & 23 & 15 & 20 & 266 \\
\hline 1998 & 20 & 14 & 23 & 23 & 21 & 25 & 27 & 26 & 23 & 18 & 24 & 19 & 263 \\
\hline 1999 & 13 & 14 & 22 & 27 & 29 & 26 & 31 & 31 & 25 & 26 & 26 & 22 & 292 \\
\hline 2000 & 21 & 15 & 19 & 29 & 29 & 29 & 27 & 27 & 20 & 25 & 15 & 14 & 270 \\
\hline 2001 & 22 & 17 & 17 & 27 & 26 & 29 & 29 & 26 & 23 & 18 & 21 & 19 & 274 \\
\hline 2002 & 12 & 14 & 23 & 29 & 17 & 30 & 30 & 25 & 24 & 28 & 17 & 20 & 269 \\
\hline 2003 & 14 & 20 & 20 & 24 & 25 & 27 & 30 & 26 & 27 & 24 & 21 & 20 & 278 \\
\hline 2004 & 19 & 14 & 22 & & & & & & & & & & \\
\hline Média & 16 & 15 & 21 & 25 & 25 & 25 & 28 & 28 & 22 & 23 & 20 & 19 & 267 \\
\hline
\end{tabular}

Tabela 21. Relação mensal entre evapotranspiração real e máxima (ER/EM) entre os anos de 1989 e 2004, em Limeira-SP

\begin{tabular}{|c|c|c|c|c|c|c|c|c|c|c|c|c|c|}
\hline \multirow[t]{2}{*}{ Ano } & \multicolumn{12}{|c|}{ Mês } & \multirow[t]{2}{*}{ Total } \\
\hline & Jan & $\mathrm{Fev}$ & Mar & Abr & Mai & Jun & $\mathrm{Jul}$ & Ago & Set & Out & Nov & Dez & \\
\hline 1989 & 0,97 & 0,97 & 0,86 & 0,84 & 0,65 & 0,74 & 0,69 & 0,82 & 0,88 & 0,64 & 0,86 & 0,87 & 0,84 \\
\hline 1990 & 0,95 & 0,72 & 0,87 & 0,81 & 0,88 & 0,64 & 0,78 & 0,86 & 0,93 & 0,90 & 0,85 & 0,90 & 0,85 \\
\hline 1991 & 0,91 & 0,93 & 0,94 & 0,92 & 0,87 & 0,66 & 0,64 & 0,38 & 0,40 & 0,77 & 0,61 & 0,91 & 0,77 \\
\hline 1992 & 0,93 & 0,96 & 0,94 & 0,87 & 0,93 & 0,65 & 0,74 & 0,64 & 0,85 & 0,94 & 0,93 & 0,86 & 0,87 \\
\hline 14 & 0,92 & 0,99 & 0,83 & 0,79 & 0,70 & 0,93 & 0,69 & 0,55 & 0,79 & 0,92 & 0,80 & 0,92 & 0,84 \\
\hline 14 & 0,96 & 0,91 & 0,89 & 0,85 & 0,71 & 0,78 & 0,79 & 0,51 & 0,25 & 0,41 & 0,89 & 0,94 & 0,75 \\
\hline 14 & 0,95 & 0,96 & 0,79 & 0,94 & 0,82 & 0,63 & 0,63 & 0,39 & 0,36 & 0,66 & 0,93 & 0,85 & 0,77 \\
\hline 14 & 0,94 & 0,94 & 0,95 & 0,76 & 0,81 & 0,68 & 0,56 & 0,67 & 0,90 & 0,91 & 0,90 & 0,95 & 0,87 \\
\hline 97 & 0,96 & 0,89 & 0,65 & 0,58 & 0,51 & 0,95 & 0,70 & 0,53 & 0,52 & 0,76 & 0,95 & 0,88 & 0,77 \\
\hline 1998 & 0,93 & 0,91 & 0,88 & 0,83 & 0,88 & 0,87 & 0,80 & 0,63 & 0,60 & 0,85 & 0,80 & 0,91 & 0,84 \\
\hline 1999 & 0,96 & 0,96 & 0,91 & 0,77 & 0,74 & 0,74 & 0,56 & 0,30 & 0,49 & 0,62 & 0,58 & 0,80 & 0,74 \\
\hline 2000 & 0,87 & 0,93 & 0,87 & 0,71 & 0,48 & 0,31 & 0,39 & 0,55 & 0,89 & 0,64 & 0,92 & 0,94 & 0,76 \\
\hline 2001 & 0,90 & 0,95 & 0,89 & 0,74 & 0,60 & 0,50 & 0,43 & 0,44 & 0,73 & 0,93 & 0,77 & 0,91 & 0,78 \\
\hline 2002 & 0,98 & 0,97 & 0,91 & 0,59 & 0,76 & 0,67 & 0,43 & 0,79 & 0,85 & 0,59 & 0,91 & 0,92 & 0,80 \\
\hline 2003 & 0,93 & 0,90 & 0,89 & 0,84 & 0,81 & 0,66 & 0,39 & 0,39 & 0,34 & 0,56 & 0,72 & 0,89 & 0,73 \\
\hline 2004 & 0,91 & 0,94 & 0,94 & & & & & & & & & & \\
\hline Média & 0,94 & 0,93 & 0,88 & 0,79 & 0,74 & 0,69 & 0,61 & 0,56 & 0,65 & 0,74 & 0,83 & 0,90 & 0,80 \\
\hline
\end{tabular}


Tabela 22. Coeficientes de correlação (r) entre número de frutos por planta e variáveis agrometeorológicas de diferentes períodos, entre as safras de 1990 e 2004. Cultivar 'Pêra'. Idade 1. Limeira-SP

\begin{tabular}{|c|c|c|c|c|c|c|c|c|c|c|}
\hline \multirow{2}{*}{ Período $^{1}$} & \multicolumn{10}{|c|}{ Variável Meteorológica $^{2}$} \\
\hline & TMAX & TMIN & TMED & PREC & ETM & ETR & DEF & $\mathrm{EXC}$ & $\mathrm{NDH}$ & ER/EM \\
\hline 1 & 0,45 & $0,58 * *$ & $0,62 * *$ & 0,06 & $0,64 * *$ & $0,67 * * *$ & $-0,11$ & 0,04 & $-0,10$ & 0,18 \\
\hline $1 \mathrm{a} 2$ & $0,51 *$ & $0,72 * * *$ & $0,72 * * *$ & 0,35 & $0,75 * * *$ & $0,84 * * *$ & $-0,08$ & 0,31 & $-0,09$ & 0,20 \\
\hline $1 \mathrm{a} 3$ & $0,49 *$ & $0,67 * * *$ & $0,62 * *$ & 0,16 & $0,67 * * *$ & $0,58 * *$ & 0,13 & 0,13 & 0,03 & $-0,02$ \\
\hline $1 \mathrm{a} 4$ & 0,36 & $0,58 * *$ & $0,49 *$ & 0,18 & $0,56 * *$ & $0,56 * *$ & 0,00 & 0,13 & $-0,11$ & 0,08 \\
\hline 2 & 0,28 & $0,75 * * *$ & $0,54 * *$ & 0,36 & $0,57 * *$ & $0,62 * *$ & $-0,04$ & 0,33 & $-0,03$ & 0,09 \\
\hline $2 \mathrm{a} 3$ & 0,37 & $0,60 * *$ & $0,55 * *$ & 0,11 & $0,57 * *$ & 0,37 & 0,16 & 0,11 & 0,09 & $-0,10$ \\
\hline $2 \mathrm{a} 4$ & 0,24 & $0,49 *$ & 0,38 & 0,14 & 0,43 & 0,38 & 0,02 & 0,11 & $-0,05$ & 0,06 \\
\hline $2 \mathrm{a} 5$ & 0,08 & 0,31 & 0,21 & 0,10 & 0,32 & 0,22 & 0,02 & 0,08 & 0,09 & 0,02 \\
\hline 3 & 0,26 & 0,25 & 0,29 & $-0,18$ & 0,27 & 0,00 & 0,28 & $-0,17$ & 0,16 & $-0,25$ \\
\hline $3 a 4$ & 0,11 & 0,19 & 0,15 & $-0,09$ & 0,15 & 0,11 & 0,04 & $-0,12$ & $-0,03$ & $-0,03$ \\
\hline $3 a 5$ & $-0,06$ & $-0,01$ & $-0,07$ & $-0,15$ & $-0,01$ & $-0,03$ & 0,04 & $-0,15$ & 0,13 & $-0,06$ \\
\hline $3 a 6$ & $-0,31$ & $-0,21$ & $-0,28$ & $-0,07$ & $-0,24$ & $-0,06$ & $-0,12$ & $-0,11$ & $-0,05$ & 0,08 \\
\hline 4 & $-0,03$ & 0,11 & 0,03 & 0,18 & 0,01 & 0,21 & $-0,15$ & 0,08 & $-0,27$ & 0,16 \\
\hline $4 \mathrm{a} 5$ & $-0,27$ & $-0,14$ & $-0,22$ & 0,02 & $-0,26$ & $-0,05$ & $-0,08$ & $-0,03$ & 0,04 & 0,05 \\
\hline $4 a 6$ & $-0,49 *$ & $-0,32$ & $-0,45 *$ & 0,16 & $-0,51 *$ & $-0,08$ & $-0,24$ & 0,07 & $-0,15$ & 0,19 \\
\hline $4 a 7$ & $-0,25$ & $-0,10$ & $-0,20$ & 0,12 & $-0,29$ & 0,06 & $-0,18$ & 0,11 & $-0,07$ & 0,15 \\
\hline 5 & $-0,55 *$ & $-0,25$ & $-0,43$ & $-0,26$ & $-0,52 * *$ & $-0,27$ & 0,02 & $-0,32$ & 0,28 & $-0,06$ \\
\hline $5 \mathrm{a} 6$ & $-0,59$ * & $* * \quad-0,42$ & $-0,59 * *$ & 0,06 & $-0,68 * * *$ & $-0,23$ & $-0,24$ & 0,03 & $-0,02$ & 0,12 \\
\hline $5 \mathrm{a} 7$ & $-0,30$ & $-0,13$ & $-0,22$ & 0,02 & $-0,33$ & $-0,03$ & $-0,16$ & 0,08 & 0,05 & 0,12 \\
\hline $5 \mathrm{a} 8$ & 0,00 & 0,03 & $-0,01$ & $-0,10$ & $-0,02$ & $-0,05$ & 0,03 & 0,07 & 0,08 & $-0,03$ \\
\hline 6 & $-0,53$ & $* * \quad-0,46 *$ & $-0,54 * *$ & 0,22 & $-0,60 * *$ & $-0,09$ & $-0,35$ & 0,12 & $-0,21$ & 0,23 \\
\hline $6 a 7$ & $-0,16$ & $-0,03$ & $-0,09$ & 0,15 & $-0,16$ & 0,15 & $-0,21$ & 0,16 & $-0,13$ & 0,20 \\
\hline $6 a 8$ & 0,14 & 0,10 & 0,12 & 0,02 & 0,14 & 0,08 & 0,03 & 0,15 & $-0,08$ & 0,01 \\
\hline $6 a 9$ & 0,27 & 0,21 & 0,25 & $-0,07$ & 0,33 & $-0,02$ & 0,19 & 0,10 & 0,08 & $-0,14$ \\
\hline 7 & 0,43 & 0,34 & 0,40 & $-0,08$ & 0,43 & 0,28 & 0,02 & 0,24 & 0,18 & 0,12 \\
\hline $7 \mathrm{a} 8$ & 0,52 * & 0,33 & $0,45 *$ & $-0,25$ & $0,48 *$ & 0,14 & 0,23 & 0,18 & 0,15 & $-0,09$ \\
\hline $7 \mathrm{a} 9$ & 0,49 * & 0,37 & $0,48 *$ & $-0,24$ & $0,53 * *$ & 0,01 & 0,30 & 0,00 & 0,23 & $-0,21$ \\
\hline $7 \mathrm{a} 10$ & 0,17 & 0,13 & 0,16 & $-0,18$ & 0,03 & $-0,15$ & 0,11 & $-0,12$ & 0,10 & $-0,13$ \\
\hline 8 & $0,45^{*}$ & 0,21 & 0,33 & $-0,25$ & 0,35 & $-0,05$ & 0,32 & $-0,41$ & 0,09 & $-0,19$ \\
\hline $8 \mathrm{a} 9$ & 0,46 * & 0,33 & $0,46 *$ & $-0,21$ & $0,50 *$ & $-0,09$ & 0,32 & $-0,06$ & 0,21 & $-0,25$ \\
\hline $8 \mathrm{a} 10$ & 0,05 & 0,03 & 0,05 & $-0,17$ & $-0,09$ & $-0,21$ & 0,12 & $-0,16$ & 0,06 & $-0,16$ \\
\hline $8 \mathrm{a} 11$ & $-0,03$ & $-0,04$ & $-0,03$ & $-0,30$ & $-0,18$ & $-0,23$ & 0,12 & $-0,26$ & 0,11 & $-0,15$ \\
\hline 9 & 0,37 & 0,39 & $0,45 *$ & $-0,12$ & $0,49 *$ & $-0,11$ & 0,29 & $-0,04$ & 0,25 & $-0,26$ \\
\hline $9 \mathrm{a} 10$ & $-0,14$ & $-0,12$ & $-0,15$ & $-0,10$ & $-0,28$ & $-0,24$ & 0,04 & $-0,15$ & 0,04 & $-0,10$ \\
\hline $9 \mathrm{a} 11$ & $-0,23$ & $-0,18$ & $-0,23$ & $-0,27$ & $-0,34$ & $-0,27$ & 0,04 & $-0,26$ & 0,10 & $-0,11$ \\
\hline $9 \mathrm{a} 12$ & $-0,22$ & $-0,10$ & $-0,19$ & $-0,08$ & $-0,29$ & $-0,29$ & 0,06 & $-0,09$ & 0,12 & $-0,14$ \\
\hline 10 & $-0,60$ * & $* * \quad-0,47 *$ & $-0,59 * *$ & $-0,13$ & $-0,63 * *$ & $-0,32$ & $-0,24$ & $-0,15$ & $-0,21$ & 0,09 \\
\hline 10a11 & $-0,59 *$ & $* * \quad-0,39$ & $-0,54 * *$ & $-0,26$ & $-0,57 * *$ & $-0,31$ & $-0,20$ & $-0,28$ & $-0,06$ & 0,08 \\
\hline $10 \mathrm{a} 12$ & $-0,56$ * & $* * \quad-0,25$ & $-0,43$ & $-0,03$ & $-0,49 *$ & $-0,32$ & $-0,16$ & $-0,09$ & $-0,02$ & 0,05 \\
\hline $10 \mathrm{a} 13$ & $-0,55 *$ & $* * \quad-0,15$ & $-0,35$ & 0,30 & $-0,40$ & $-0,20$ & $-0,21$ & 0,32 & $-0,26$ & 0,14 \\
\hline 11 & $-0,28$ & $-0,24$ & $-0,29$ & $-0,29$ & $-0,30$ & $-0,20$ & 0,02 & $-0,22$ & 0,12 & $-0,06$ \\
\hline $11 \mathrm{a} 12$ & $-0,32$ & $-0,07$ & $-0,19$ & $-0,02$ & $-0,23$ & $-0,22$ & 0,08 & $-0,01$ & 0,14 & $-0,11$ \\
\hline $11 \mathrm{a} 13$ & $-0,30$ & 0,07 & $-0,09$ & 0,35 & $-0,12$ & $-0,06$ & $-0,03$ & 0,41 & $-0,19$ & 0,02 \\
\hline 12 & $-0,23$ & 0,19 & $-0,01$ & 0,40 & $-0,06$ & $-0,16$ & 0,18 & 0,29 & 0,08 & $-0,18$ \\
\hline $12 \mathrm{a} 13$ & $-0,14$ & 0,27 & 0,11 & $0,63 * *$ & 0,08 & 0,11 & $-0,10$ & $0,63 * *$ & $-0,36$ & 0,11 \\
\hline 13 & 0,02 & 0,30 & 0,17 & $0,51 *$ & 0,17 & 0,34 & $-0,46 *$ & $0,59 * *$ & $-0,52 * *$ & $0,50 *$ \\
\hline
\end{tabular}

'Períodos $1, \ldots 12$ = janeiro, $\ldots$ a dezembro do ano do florescimento; período $13=$ janeiro do ano da colheita.

${ }^{2}$ TMED, TMAX, TMIN = temperaturas média, média máxima e média mínima; PREC, ETM, ETR, DEF, EXC, NDH, ER/EM: totais de precipitação, evapotranspiração máxima e real, deficiência e excedente hídrico, dias com deficiência e relação ETR/ETM. $\stackrel{* * * * *}{,}:$ Significativo aos níveis de $0,10,0,05$ e 0,01 de probabilidade, respectivamente. 
Tabela 23. Coeficientes de correlação (r) entre número de frutos por planta e variáveis agrometeorológicas de diferentes períodos, entre as safras de 1990 e 2004. Cultivar 'Pêra'. Idade 2. Limeira-SP

\begin{tabular}{|c|c|c|c|c|c|c|c|c|c|c|}
\hline \multirow[t]{2}{*}{ Período $^{1}$} & \multicolumn{10}{|c|}{ Variável Meteorológica ${ }^{2}$} \\
\hline & TMAX & TMIN & TMED & PREC & ETM & ETR & DEF & EXC & $\mathrm{NDH}$ & ER/EM \\
\hline 1 & 0,31 & $0,47 *$ & $0,47 *$ & 0,19 & $0,50 *$ & $0,61 * *$ & $-0,28$ & 0,15 & $-0,15$ & 0,32 \\
\hline $1 \mathrm{a} 2$ & 0,32 & $0,51 *$ & $0,49 *$ & 0,38 & $0,54 * *$ & $0,73 * * *$ & $-0,26$ & 0,32 & $-0,20$ & 0,36 \\
\hline $1 \mathrm{a} 3$ & 0,37 & $0,54 * *$ & $0,48 *$ & 0,30 & $0,55 * *$ & $0,64 * *$ & $-0,17$ & 0,28 & $-0,09$ & 0,27 \\
\hline $1 \mathrm{a} 4$ & 0,27 & $0,46 *$ & 0,36 & 0,29 & $0,49 *$ & $0,59 * *$ & $-0,16$ & 0,24 & $-0,14$ & 0,23 \\
\hline 2 & 0,16 & $0,48 *$ & 0,34 & 0,28 & 0,38 & $0,51 * *$ & $-0,15$ & 0,23 & $-0,12$ & 0,19 \\
\hline $2 \mathrm{a} 3$ & 0,30 & $0,47 *$ & 0,44 & 0,18 & $0,49 *$ & $0,47 *$ & $-0,08$ & 0,18 & 0,01 & 0,14 \\
\hline $2 \mathrm{a} 4$ & 0,19 & 0,40 & 0,29 & 0,18 & 0,40 & $0,44 *$ & $-0,09$ & 0,15 & $-0,04$ & 0,16 \\
\hline $2 \mathrm{a} 5$ & 0,05 & 0,24 & 0,13 & 0,18 & 0,31 & 0,34 & $-0,13$ & 0,14 & 0,05 & 0,17 \\
\hline 3 & 0,28 & 0,32 & 0,34 & $-0,02$ & 0,37 & 0,24 & 0,03 & 0,02 & 0,15 & 0,00 \\
\hline $3 a 4$ & 0,11 & 0,22 & 0,17 & 0,03 & 0,24 & 0,24 & $-0,03$ & 0,02 & 0,05 & 0,05 \\
\hline $3 \mathrm{a} 5$ & $-0,05$ & 0,01 & $-0,04$ & 0,03 & 0,11 & 0,15 & $-0,08$ & 0,01 & 0,14 & 0,09 \\
\hline $3 a 6$ & $-0,34$ & $-0,20$ & $-0,30$ & 0,09 & $-0,17$ & 0,19 & $-0,31$ & 0,03 & $-0,01$ & 0,30 \\
\hline 4 & $-0,06$ & 0,12 & 0,01 & 0,15 & 0,09 & 0,16 & $-0,06$ & 0,03 & $-0,12$ & 0,08 \\
\hline $4 \mathrm{a} 5$ & $-0,29$ & $-0,13$ & $-0,22$ & 0,12 & $-0,15$ & 0,04 & $-0,12$ & 0,00 & 0,06 & 0,11 \\
\hline $4 a 6$ & $-0,53 *$ & $-0,34$ & $-0,49 *$ & 0,19 & $-0,47 *$ & 0,09 & $-0,37$ & 0,03 & $-0,11$ & 0,34 \\
\hline $4 a 7$ & $-0,34$ & $-0,20$ & $-0,30$ & 0,11 & $-0,34$ & 0,19 & $-0,32$ & 0,07 & 0,01 & 0,30 \\
\hline 5 & $-0,50 *$ & $-0,24$ & $-0,41$ & $-0,03$ & $-0,45 *$ & $-0,07$ & $-0,16$ & $-0,09$ & 0,17 & 0,11 \\
\hline $5 \mathrm{a} 6$ & $-0,64 *$ & $-0,46 *$ & $-0,63 * *$ & 0,12 & $-0,70 * * *$ & 0,02 & $-0,48 *$ & 0,01 & $-0,06$ & 0,38 \\
\hline $5 \mathrm{a} 7$ & $-0,39$ & $-0,25$ & $-0,35$ & 0,03 & $-0,45 *$ & 0,16 & $-0,38$ & 0,06 & 0,07 & 0,35 \\
\hline $5 \mathrm{a} 8$ & $-0,15$ & $-0,13$ & $-0,17$ & $-0,11$ & $-0,18$ & 0,10 & $-0,19$ & 0,05 & 0,13 & 0,16 \\
\hline 6 & $-0,62 *$ & $-0,51 * *$ & $-0,63 * *$ & 0,16 & $-0,67 * * *$ & 0,14 & $-0,54 * *$ & 0,04 & $-0,18$ & $0,45 *$ \\
\hline $6 a 7$ & $-0,30$ & $-0,21$ & $-0,25$ & 0,04 & $-0,35$ & 0,27 & $-0,40$ & 0,08 & $-0,04$ & 0,37 \\
\hline $6 a 8$ & $-0,04$ & $-0,08$ & $-0,07$ & $-0,12$ & $-0,06$ & 0,16 & $-0,16$ & 0,07 & 0,04 & 0,15 \\
\hline $6 \mathrm{a} 9$ & 0,09 & $-0,01$ & 0,03 & $-0,09$ & 0,08 & 0,05 & 0,01 & 0,01 & 0,16 & $-0,02$ \\
\hline 7 & 0,36 & 0,15 & 0,27 & $-0,20$ & 0,25 & 0,29 & $-0,11$ & 0,24 & 0,31 & 0,23 \\
\hline $7 \mathrm{a} 8$ & $0,44 *$ & 0,13 & 0,36 & $-0,35$ & 0,39 & 0,13 & 0,10 & 0,20 & 0,26 & $-0,02$ \\
\hline $7 \mathrm{a} 9$ & $0,44 *$ & 0,14 & 0,36 & $-0,21$ & 0,31 & 0,01 & 0,17 & $-0,03$ & 0,28 & $-0,14$ \\
\hline $7 \mathrm{a} 10$ & 0,05 & $-0,08$ & $-0,03$ & $-0,24$ & $-0,14$ & $-0,12$ & 0,01 & $-0,13$ & 0,21 & $-0,06$ \\
\hline 8 & 0,29 & 0,08 & 0,17 & $-0,27$ & 0,21 & $-0,05$ & 0,22 & $-0,25$ & 0,16 & $-0,18$ \\
\hline $8 \mathrm{a} 9$ & 0,30 & 0,10 & 0,23 & $-0,14$ & 0,29 & $-0,10$ & 0,22 & $-0,09$ & 0,22 & $-0,20$ \\
\hline $8 \mathrm{a} 10$ & $-0,06$ & $-0,16$ & $-0,13$ & $-0,19$ & $-0,22$ & $-0,19$ & 0,03 & $-0,16$ & 0,16 & $-0,10$ \\
\hline $8 \mathrm{a} 11$ & $-0,10$ & $-0,27$ & $-0,20$ & $-0,49 *$ & $-0,32$ & $-0,33$ & 0,13 & $-0,42$ & 0,35 & $-0,19$ \\
\hline 9 & 0,24 & 0,12 & 0,23 & $-0,01$ & 0,27 & $-0,11$ & 0,19 & $-0,08$ & 0,21 & $-0,20$ \\
\hline $9 \mathrm{a} 10$ & $-0,22$ & $-0,31$ & $-0,30$ & $-0,12$ & $-0,38$ & $-0,21$ & $-0,04$ & $-0,15$ & 0,12 & $-0,04$ \\
\hline 9a11 & $-0,25$ & $-0,43$ & $-0,37$ & $-0,48 *$ & $-0,44 *$ & $-0,38$ & 0,09 & $-0,42$ & 0,36 & $-0,18$ \\
\hline $9 \mathrm{a} 12$ & $-0,20$ & $-0,32$ & $-0,30$ & $-0,37$ & $-0,36$ & $-0,41$ & 0,13 & $-0,35$ & 0,41 & $-0,22$ \\
\hline 10 & $-0,58 *$ & $-0,52 * *$ & $-0,60 * *$ & $-0,16$ & $-0,62 * *$ & $-0,28$ & $-0,27$ & $-0,13$ & $-0,04$ & 0,13 \\
\hline 10a11 & $-0,51 *$ & $-0,55 * *$ & $-0,58 * *$ & $-0,57 * *$ & $-0,60 * *$ & $-0,48 *$ & $-0,03$ & $-0,46 *$ & 0,35 & $-0,13$ \\
\hline $10 \mathrm{a} 12$ & $-0,44 *$ & $-0,42$ & $-0,47 *$ & $-0,43$ & $-0,49 *$ & $-0,49 *$ & 0,05 & $-0,37$ & 0,43 & $-0,17$ \\
\hline $10 \mathrm{a} 13$ & $-0,49 *$ & $-0,31$ & $-0,41$ & $-0,02$ & $-0,45 *$ & $-0,42$ & 0,01 & 0,07 & 0,15 & $-0,11$ \\
\hline 11 & $-0,13$ & $-0,49 *$ & $-0,38$ & $-0,57 * *$ & $-0,37$ & $-0,52 * *$ & 0,39 & $-0,44 *$ & $0,47 *$ & $-0,44 *$ \\
\hline $11 \mathrm{a} 12$ & $-0,14$ & $-0,29$ & $-0,23$ & $-0,44 *$ & $-0,25$ & $-0,48 *$ & $0,44 *$ & $-0,32$ & $0,44 *$ & $-0,49 *$ \\
\hline $11 \mathrm{a} 13$ & $-0,19$ & $-0,15$ & $-0,20$ & 0,04 & $-0,22$ & $-0,35$ & 0,36 & 0,13 & 0,20 & $-0,37$ \\
\hline 12 & $-0,07$ & 0,10 & 0,04 & 0,22 & $-0,01$ & $-0,23$ & 0,40 & 0,07 & 0,26 & $-0,38$ \\
\hline $12 \mathrm{a} 13$ & $-0,17$ & 0,15 & 0,01 & $0,49 *$ & $-0,01$ & $-0,08$ & 0,14 & $0,45 *$ & $-0,14$ & $-0,14$ \\
\hline 13 & $-0,15$ & 0,17 & $-0,01$ & $0,45 *$ & 0,00 & 0,10 & $-0,26$ & $0,50 *$ & $-0,38$ & 0,27 \\
\hline
\end{tabular}

'Períodos $1, \ldots 12$ = janeiro, $\ldots$ a dezembro do ano do florescimento; período 13 = janeiro do ano da colheita.

²TMED, TMAX, TMIN = temperaturas média, média máxima e média mínima; PREC, ETM, ETR, DEF, EXC, NDH, ER/EM: totais de precipitação, evapotranspiração máxima e real, deficiência e excedente hídrico, dias com deficiência e relação ETR/ETM.

$\stackrel{* * * * *}{,}$ : Significativo aos níveis de $0,10,0,05$ e 0,01 de probabilidade, respectivamente. 
Tabela 24. Coeficientes de correlação (r) entre número de frutos por planta e variáveis agrometeorológicas de diferentes períodos, entre as safras de 1990 e 2004. Cultivar 'Pêra'. Idade 3. Limeira-SP

\begin{tabular}{|c|c|c|c|c|c|c|c|c|c|c|c|}
\hline \multirow{2}{*}{ Período ${ }^{1}$} & \multicolumn{11}{|c|}{ Variável Meteorológica $^{2}$} \\
\hline & TMAX & TMIN & TMED & PREC & & ETM & ETR & DEF & EXC & $\mathrm{NDH}$ & ER/EM \\
\hline 1 & 0,23 & 0,40 & 0,37 & 0,10 & & 0,37 & $0,53 * *$ & $-0,39$ & 0,05 & $-0,19$ & 0,43 \\
\hline $1 \mathrm{a} 2$ & 0,31 & 0,44 & $0,45 *$ & 0,26 & & 0,43 & $0,57 * *$ & $-0,18$ & 0,23 & $-0,10$ & 0,28 \\
\hline $1 \mathrm{a} 3$ & $0,45 *$ & $0,49 *$ & $0,49 *$ & 0,17 & & $0,52 * *$ & $0,56 * *$ & $-0,09$ & 0,16 & 0,11 & 0,18 \\
\hline $1 \mathrm{a} 4$ & 0,42 & $0,51 *$ & $0,46 *$ & 0,16 & & $0,53 * *$ & $0,51 *$ & 0,03 & 0,12 & 0,06 & 0,06 \\
\hline 2 & 0,20 & 0,41 & 0,34 & 0,22 & & 0,33 & 0,35 & 0,00 & 0,22 & 0,03 & 0,05 \\
\hline $2 \mathrm{a} 3$ & 0,42 & $0,46 *$ & $0,50 *$ & 0,11 & & $0,52 * *$ & 0,41 & 0,04 & 0,13 & 0,22 & 0,01 \\
\hline $2 \mathrm{a} 4$ & 0,39 & $0,50 *$ & $0,46 *$ & 0,10 & & $0,51 *$ & 0,38 & 0,11 & 0,09 & 0,15 & $-0,02$ \\
\hline $2 \mathrm{a} 5$ & 0,32 & 0,43 & 0,39 & 0,13 & & $0,49 *$ & 0,33 & 0,03 & 0,08 & 0,08 & 0,05 \\
\hline 3 & 0,43 & 0,38 & 0,41 & $-0,06$ & & 0,41 & 0,29 & 0,07 & $-0,04$ & 0,28 & $-0,02$ \\
\hline $3 \mathrm{a} 4$ & 0,32 & 0,39 & 0,37 & $-0,04$ & & 0,41 & 0,26 & 0,13 & $-0,05$ & 0,17 & $-0,07$ \\
\hline $3 a 5$ & 0,22 & 0,27 & 0,27 & 0,00 & & 0,34 & 0,21 & 0,03 & $-0,06$ & 0,07 & 0,02 \\
\hline $3 \mathrm{a} 6$ & $-0,06$ & 0,05 & $-0,01$ & 0,05 & & 0,06 & 0,28 & $-0,22$ & $-0,05$ & $-0,08$ & 0,26 \\
\hline 4 & 0,18 & 0,36 & 0,27 & 0,04 & & 0,30 & 0,12 & 0,14 & $-0,06$ & $-0,08$ & $-0,08$ \\
\hline $4 \mathrm{a} 5$ & 0,01 & 0,17 & 0,13 & 0,14 & & 0,15 & 0,09 & 0,01 & $-0,08$ & $-0,14$ & 0,03 \\
\hline $4 a 6$ & $-0,24$ & $-0,08$ & $-0,19$ & 0,18 & & $-0,22$ & 0,18 & $-0,28$ & $-0,03$ & $-0,25$ & 0,30 \\
\hline $4 a 7$ & $-0,04$ & 0,05 & 0,01 & 0,05 & & $-0,07$ & 0,26 & $-0,25$ & $-0,03$ & $-0,15$ & 0,28 \\
\hline 5 & $-0,22$ & $-0,03$ & $-0,13$ & 0,19 & & $-0,23$ & 0,03 & $-0,15$ & $-0,09$ & $-0,12$ & 0,15 \\
\hline $5 \mathrm{a} 6$ & $-0,40$ & $-0,28$ & $-0,39$ & 0,19 & & $-0,53 * *$ & 0,15 & $-0,49 *$ & 0,01 & $-0,24$ & 0,44 \\
\hline $5 \mathrm{a} 7$ & $-0,14$ & $-0,08$ & $-0,12$ & 0,03 & & $-0,29$ & 0,26 & $-0,39$ & 0,02 & $-0,14$ & 0,39 \\
\hline $5 \mathrm{a} 8$ & 0,07 & 0,06 & 0,06 & $-0,03$ & & $-0,01$ & 0,25 & $-0,21$ & 0,02 & $-0,08$ & 0,22 \\
\hline 6 & $-0,44 *$ & $-0,44 *$ & $-0,48 *$ & 0,12 & & $-0,59 * *$ & 0,25 & $-0,57 * *$ & 0,03 & $-0,17$ & $0,50 *$ \\
\hline $6 a 7$ & $-0,09$ & $-0,10$ & $-0,08$ & $-0,06$ & & $-0,26$ & 0,34 & $-0,40$ & 0,04 & $-0,07$ & 0,41 \\
\hline $6 a 8$ & 0,16 & 0,08 & 0,11 & $-0,14$ & & 0,06 & 0,31 & $-0,19$ & 0,04 & $-0,02$ & 0,21 \\
\hline $6 \mathrm{a} 9$ & 0,28 & 0,08 & 0,19 & $-0,27$ & & 0,18 & 0,05 & 0,07 & $-0,15$ & 0,24 & $-0,07$ \\
\hline 7 & $0,46 *$ & 0,24 & 0,36 & $-0,32$ & & 0,29 & 0,31 & $-0,10$ & 0,03 & 0,23 & 0,22 \\
\hline $7 \mathrm{a} 8$ & $0,49 *$ & 0,30 & 0,41 & $-0,32$ & & 0,39 & 0,25 & 0,08 & 0,05 & 0,18 & 0,03 \\
\hline $7 \mathrm{a} 9$ & $0,48 *$ & 0,22 & 0,39 & $-0,38$ & & 0,38 & $-0,02$ & 0,24 & $-0,27$ & 0,36 & $-0,20$ \\
\hline $7 \mathrm{a} 10$ & 0,31 & 0,10 & 0,22 & $-0,40$ & & 0,14 & $-0,16$ & 0,19 & $-0,35$ & 0,30 & $-0,20$ \\
\hline 8 & 0,39 & 0,25 & 0,32 & $-0,12$ & & 0,31 & 0,07 & 0,18 & 0,10 & 0,09 & $-0,13$ \\
\hline $8 \mathrm{a} 9$ & $0,44 *$ & 0,16 & 0,35 & $-0,25$ & & 0,37 & $-0,13$ & 0,29 & $-0,28$ & 0,34 & $-0,26$ \\
\hline $8 \mathrm{a} 10$ & 0,22 & 0,02 & 0,14 & $-0,31$ & & 0,07 & $-0,22$ & 0,22 & $-0,35$ & 0,28 & $-0,25$ \\
\hline $8 \mathrm{a} 11$ & 0,26 & $-0,04$ & 0,13 & $-0,61$ & $* *$ & 0,05 & $-0,30$ & 0,31 & $-0,65 * * *$ & $0,50 *$ & $-0,32$ \\
\hline 9 & 0,39 & 0,00 & 0,29 & $-0,25$ & & 0,30 & $-0,26$ & 0,32 & $-0,28$ & 0,43 & $-0,32$ \\
\hline $9 \mathrm{a} 10$ & 0,10 & $-0,15$ & $-0,01$ & $-0,32$ & & $-0,07$ & $-0,31$ & 0,20 & $-0,35$ & 0,30 & $-0,25$ \\
\hline $9 \mathrm{a} 11$ & 0,14 & $-0,21$ & $-0,02$ & $-0,65$ & $* * *$ & $-0,06$ & $-0,38$ & 0,32 & $-0,65 * * *$ & $0,56 * *$ & $-0,37$ \\
\hline $9 \mathrm{a} 12$ & 0,20 & $-0,09$ & 0,05 & $-0,60$ & $* *$ & 0,02 & $-0,34$ & 0,35 & $-0,61 * *$ & $0,62 * *$ & $-0,39$ \\
\hline 10 & $-0,24$ & $-0,20$ & $-0,24$ & $-0,23$ & & $-0,26$ & $-0,30$ & 0,03 & $-0,24$ & 0,02 & $-0,09$ \\
\hline $10 \mathrm{a} 11$ & $-0,09$ & $-0,23$ & $-0,18$ & $-0,65$ & $* * *$ & $-0,19$ & $-0,38$ & 0,26 & $-0,64 * *$ & $0,47 *$ & $-0,33$ \\
\hline $10 \mathrm{a} 12$ & 0,00 & $-0,11$ & $-0,07$ & $-0,58$ & $* *$ & $-0,07$ & $-0,31$ & 0,31 & $-0,59 * *$ & $0,56 * *$ & $-0,35$ \\
\hline 10a13 & $-0,08$ & $-0,02$ & $-0,02$ & $-0,15$ & & $-0,06$ & $-0,26$ & 0,26 & $-0,15$ & 0,30 & $-0,28$ \\
\hline 11 & 0,24 & $-0,22$ & $-0,02$ & $-0,62$ & $* *$ & $-0,02$ & $-0,34$ & 0,44 & $-0,59 * *$ & $0,56 * *$ & $-0,46 *$ \\
\hline $11 \mathrm{a} 12$ & 0,29 & $-0,01$ & 0,16 & $-0,48$ & & 0,14 & $-0,22$ & $0,48 *$ & $-0,51 *$ & $0,65 * * *$ & $-0,46 *$ \\
\hline $11 \mathrm{a} 13$ & 0,20 & 0,10 & 0,17 & $-0,07$ & & 0,14 & $-0,14$ & 0,39 & $-0,06$ & 0,35 & $-0,37$ \\
\hline 12 & 0,29 & 0,28 & 0,35 & 0,10 & & 0,29 & 0,07 & 0,34 & $-0,05$ & 0,33 & $-0,26$ \\
\hline $12 \mathrm{a} 13$ & 0,02 & 0,32 & 0,23 & 0,40 & & 0,20 & 0,11 & 0,13 & 0,32 & $-0,02$ & $-0,10$ \\
\hline 13 & $-0,22$ & 0,27 & 0,02 & 0,44 & & 0,03 & 0,10 & $-0,19$ & $0,44 *$ & $-0,28$ & 0,18 \\
\hline
\end{tabular}

'Períodos $1, \ldots 12$ = janeiro, $\ldots$ a dezembro do ano do florescimento; período 13 = janeiro do ano da colheita.

${ }^{2}$ TMED, TMAX, TMIN = temperaturas média, média máxima e média mínima; PREC, ETM, ETR, DEF, EXC, NDH, ER/EM: totais de precipitação, evapotranspiração máxima e real, deficiência e excedente hídrico, dias com deficiência e relação ETR/ETM.

$\stackrel{* * * * *}{,}$ : Significativo aos níveis de $0,10,0,05$ e 0,01 de probabilidade, respectivamente. 
Tabela 25. Coeficientes de correlação (r) entre número de frutos por planta e variáveis agrometeorológicas de diferentes períodos, entre as safras de 1990 e 2004. Cultivar 'Valência'. Idade 1. Limeira-SP

\begin{tabular}{|c|c|c|c|c|c|c|c|c|c|c|}
\hline \multirow{2}{*}{ Período ${ }^{1}$} & \multicolumn{10}{|c|}{ Variável Meteorológica ${ }^{2}$} \\
\hline & TMAX & TMIN & TMED & PREC & ETM & ETR & DEF & EXC & $\mathrm{NDH}$ & ER/EM \\
\hline 1 & 0,31 & 0,31 & 0,38 & $-0,17$ & 0,43 & 0,41 & 0,03 & $-0,24$ & 0,15 & 0,01 \\
\hline $1 \mathrm{a} 2$ & 0,27 & $0,50 *$ & $0,45 *$ & 0,27 & $0,53 * *$ & $0,71 * * *$ & $-0,25$ & 0,19 & $-0,14$ & 0,29 \\
\hline $1 \mathrm{a} 3$ & 0,25 & $0,48 *$ & 0,40 & 0,17 & $0,47 *$ & $0,57 * *$ & $-0,19$ & 0,08 & $-0,05$ & 0,30 \\
\hline $1 \mathrm{a} 4$ & 0,09 & 0,36 & 0,23 & 0,19 & 0,35 & $0,62 * *$ & $-0,41$ & 0,10 & $-0,20$ & $0,47 *$ \\
\hline 2 & 0,10 & $0,62 * *$ & 0,36 & $0,48 *$ & 0,42 & $0,67 * * *$ & $-0,29$ & 0,43 & $-0,29$ & 0,33 \\
\hline $2 \mathrm{a} 3$ & 0,16 & $0,49 *$ & 0,35 & 0,28 & 0,42 & $0,49 *$ & $-0,21$ & 0,23 & $-0,14$ & 0,26 \\
\hline $2 \mathrm{a} 4$ & $-0,01$ & 0,34 & 0,15 & 0,28 & 0,25 & $0,57 * *$ & $-0,41$ & 0,22 & $-0,26$ & $0,48 *$ \\
\hline $2 \mathrm{a} 5$ & $-0,15$ & 0,23 & 0,02 & 0,23 & 0,18 & 0,43 & $-0,33$ & 0,22 & $-0,03$ & 0,35 \\
\hline 3 & 0,13 & 0,17 & 0,17 & $-0,07$ & 0,19 & 0,14 & $-0,02$ & $-0,11$ & 0,12 & 0,04 \\
\hline $3 \mathrm{a} 4$ & $-0,07$ & 0,07 & $-0,02$ & 0,00 & 0,03 & 0,31 & $-0,33$ & $-0,04$ & $-0,07$ & 0,32 \\
\hline $3 \mathrm{a} 5$ & $-0,21$ & $-0,06$ & $-0,17$ & $-0,07$ & $-0,07$ & 0,19 & $-0,24$ & $-0,04$ & 0,17 & 0,23 \\
\hline $3 \mathrm{a} 6$ & $-0,39$ & $-0,22$ & $-0,35$ & $-0,10$ & $-0,25$ & 0,12 & $-0,30$ & $-0,14$ & 0,24 & 0,27 \\
\hline 4 & $-0,26$ & $-0,02$ & $-0,16$ & 0,18 & $-0,15$ & 0,43 & $-0,45 *$ & 0,17 & $-0,29$ & $0,47 *$ \\
\hline $4 \mathrm{a} 5$ & $-0,41$ & $-0,16$ & $-0,33$ & $-0,02$ & $-0,29$ & 0,17 & $-0,30$ & 0,13 & 0,13 & 0,27 \\
\hline $4 a 6$ & $-0,53 * *$ & $-0,33$ & $-0,50 *$ & $-0,06$ & $-0,46 *$ & 0,07 & $-0,34$ & $-0,11$ & 0,13 & 0,30 \\
\hline $4 a 7$ & $-0,35$ & $-0,13$ & $-0,27$ & 0,00 & $-0,25$ & 0,17 & $-0,26$ & $-0,03$ & 0,13 & 0,23 \\
\hline 5 & $-0,49 *$ & $-0,17$ & $-0,33$ & $-0,33$ & $-0,31$ & $-0,11$ & $-0,04$ & $-0,06$ & 0,42 & 0,00 \\
\hline $5 \mathrm{a} 6$ & $-0,54 * *$ & $-0,37$ & $-0,52 * *$ & $-0,21$ & $-0,49 *$ & $-0,18$ & $-0,16$ & $-0,26$ & 0,30 & 0,07 \\
\hline $5 \mathrm{a} 7$ & $-0,29$ & $-0,12$ & $-0,23$ & $-0,12$ & $-0,18$ & 0,02 & $-0,10$ & $-0,16$ & 0,30 & 0,09 \\
\hline $5 \mathrm{a} 8$ & $-0,13$ & $-0,08$ & $-0,12$ & $-0,32$ & $-0,05$ & $-0,09$ & 0,05 & $-0,18$ & 0,30 & $-0,06$ \\
\hline 6 & $-0,48 *$ & $-0,43$ & $-0,49 *$ & $-0,06$ & $-0,48 *$ & $-0,20$ & $-0,18$ & $-0,24$ & 0,04 & 0,09 \\
\hline $6 \mathrm{a} 7$ & $-0,19$ & $-0,05$ & $-0,13$ & 0,02 & $-0,07$ & 0,10 & $-0,11$ & $-0,15$ & 0,06 & 0,12 \\
\hline $6 a 8$ & $-0,03$ & $-0,04$ & $-0,04$ & $-0,21$ & 0,04 & $-0,06$ & 0,07 & $-0,17$ & 0,10 & $-0,06$ \\
\hline $6 a 9$ & 0,04 & 0,06 & 0,05 & $-0,23$ & 0,16 & $-0,12$ & 0,17 & $-0,23$ & 0,19 & $-0,16$ \\
\hline 7 & 0,33 & 0,27 & 0,33 & 0,16 & 0,42 & 0,29 & 0,01 & 0,44 & 0,04 & 0,15 \\
\hline $7 \mathrm{a} 8$ & 0,28 & 0,14 & 0,23 & $-0,18$ & 0,30 & 0,02 & 0,20 & 0,40 & 0,07 & $-0,10$ \\
\hline $7 \mathrm{a} 9$ & 0,25 & 0,20 & 0,23 & $-0,21$ & 0,32 & $-0,07$ & 0,23 & $-0,04$ & 0,16 & $-0,18$ \\
\hline $7 \mathrm{a} 10$ & $-0,06$ & $-0,11$ & $-0,10$ & $-0,19$ & $-0,21$ & $-0,28$ & 0,08 & $-0,06$ & 0,07 & $-0,13$ \\
\hline 8 & 0,17 & $-0,01$ & 0,07 & $-0,44 *$ & 0,12 & $-0,19$ & 0,27 & $-0,58 * *$ & 0,08 & $-0,23$ \\
\hline $8 \mathrm{a} 9$ & 0,18 & 0,13 & 0,17 & $-0,28$ & 0,24 & $-0,17$ & 0,25 & $-0,17$ & 0,18 & $-0,22$ \\
\hline $8 \mathrm{a} 10$ & $-0,19$ & $-0,23$ & $-0,23$ & $-0,25$ & $-0,35$ & $-0,34$ & 0,08 & $-0,13$ & 0,07 & $-0,15$ \\
\hline $8 \mathrm{a} 11$ & $-0,28$ & $-0,36$ & $-0,36$ & $-0,44$ & $-0,50 *$ & $-0,44$ & 0,12 & $-0,33$ & 0,16 & $-0,19$ \\
\hline 9 & 0,14 & 0,28 & 0,24 & $-0,13$ & 0,28 & $-0,12$ & 0,21 & $-0,14$ & 0,21 & $-0,21$ \\
\hline $9 \mathrm{a} 10$ & $-0,32$ & $-0,36$ & $-0,38$ & $-0,14$ & $-0,49 *$ & $-0,34$ & 0,01 & $-0,12$ & 0,05 & $-0,09$ \\
\hline 9a11 & $-0,41$ & $-0,49 *$ & $-0,52 * *$ & $-0,39$ & $-0,61 * *$ & $-0,47 *$ & 0,06 & $-0,32$ & 0,16 & $-0,16$ \\
\hline $9 \mathrm{a} 12$ & $-0,43$ & $-0,45 *$ & $-0,49 *$ & $-0,17$ & $-0,59 * *$ & $-0,56 * *$ & 0,09 & $-0,08$ & 0,23 & $-0,21$ \\
\hline 10 & $-0,62 * *$ & $-0,73 * * *$ & $-0,73 * * *$ & $-0,19$ & $-0,76 * * *$ & $-0,49 *$ & $-0,21$ & $-0,05$ & $-0,15$ & 0,02 \\
\hline 10a11 & $-0,67 * *$ & $-0,71 * * *$ & $-0,76 * * *$ & $-0,40$ & $-0,78 * * *$ & $-0,59 * *$ & $-0,09$ & $-0,32$ & 0,06 & $-0,08$ \\
\hline $10 \mathrm{a} 12$ & $-0,69 * *$ & $-0,63 * *$ & $-0,71 * * *$ & $-0,14$ & $-0,75 * * *$ & $-0,67 * * *$ & $-0,03$ & $-0,04$ & 0,17 & $-0,12$ \\
\hline $10 \mathrm{a} 13$ & $-0,63 * *$ & $-0,53 * *$ & $-0,63 * *$ & 0,17 & $-0,66 * * *$ & $-0,55 * *$ & $-0,08$ & 0,32 & $-0,06$ & $-0,04$ \\
\hline 11 & $-0,43$ & $-0,58 * *$ & $-0,59 * *$ & $-0,41$ & $-0,57 * *$ & $-0,49 *$ & 0,18 & $-0,34$ & 0,21 & $-0,23$ \\
\hline $11 \mathrm{a} 12$ & $-0,54 * *$ & $-0,49 *$ & $-0,56 * *$ & $-0,09$ & $-0,59 * *$ & $-0,58 * *$ & 0,24 & $-0,02$ & 0,32 & $-0,31$ \\
\hline $11 \mathrm{a} 13$ & $-0,43$ & $-0,35$ & $-0,44 *$ & 0,23 & $-0,46 *$ & $-0,39$ & 0,14 & 0,36 & 0,02 & $-0,18$ \\
\hline 12 & $-0,46 *$ & $-0,19$ & $-0,36$ & $0,45 *$ & $-0,40$ & $-0,50 *$ & 0,27 & 0,42 & 0,26 & $-0,34$ \\
\hline $12 \mathrm{a} 13$ & $-0,21$ & $-0,08$ & $-0,15$ & $0,60 * *$ & $-0,18$ & $-0,17$ & 0,01 & $0,65 * * *$ & $-0,16$ & $-0,05$ \\
\hline 13 & 0,15 & 0,05 & 0,11 & 0,43 & 0,10 & 0,23 & $-0,36$ & $0,53 * *$ & $-0,41$ & 0,40 \\
\hline
\end{tabular}

Períodos $1, \ldots 12$ = janeiro, $\ldots$ a dezembro do ano do florescimento; período 13 = janeiro do ano da colheita.

${ }^{2}$ TMED, TMAX, TMIN = temperaturas média, média máxima e média mínima; PREC, ETM, ETR, DEF, EXC, NDH, ER/EM: totais de precipitação, evapotranspiração máxima e real, deficiência e excedente hídrico, dias com deficiência e relação ETR/ETM.

$\stackrel{* * * * *}{*}$ : Significativo aos níveis de $0,10,0,05$ e 0,01 de probabilidade, respectivamente. 
Tabela 26. Coeficientes de correlação (r) entre número de frutos por planta e variáveis agrometeorológicas de diferentes períodos, entre as safras de 1990 e 2004. Cultivar 'Valência'. Idade 2. Limeira-SP

\begin{tabular}{|c|c|c|c|c|c|c|c|c|c|c|c|}
\hline \multirow{2}{*}{ Período ${ }^{1}$} & \multicolumn{11}{|c|}{ Variável Meteorológica ${ }^{2}$} \\
\hline & TMAX & TMIN & TMED & PREC & & ETM & ETR & DEF & EXC & $\mathrm{NDH}$ & ER/EM \\
\hline 1 & 0,37 & $0,56 * *$ & $0,58 * *$ & $-0,02$ & & $0,60 * *$ & $0,58 * *$ & 0,00 & $-0,10$ & 0,16 & 0,04 \\
\hline $1 \mathrm{a} 2$ & $0,59 *$ & $0,65 * * *$ & $0,71 * * *$ & 0,15 & & $0,76 * * *$ & $0,79 * * *$ & 0,03 & 0,08 & 0,22 & 0,07 \\
\hline $1 \mathrm{a} 3$ & $0,54 *$ & $0,63 * *$ & $0,62 * *$ & 0,18 & & $0,69 * * *$ & $0,69 * * *$ & $-0,04$ & 0,11 & 0,20 & 0,17 \\
\hline $1 \mathrm{a} 4$ & 0,34 & $0,52 * *$ & 0,43 & 0,21 & & $0,54 * *$ & $0,68 * * *$ & $-0,21$ & 0,11 & 0,02 & 0,27 \\
\hline 2 & 0,43 & $0,62 * *$ & $0,59 * *$ & 0,20 & & $0,63 * *$ & $0,63 * *$ & 0,03 & 0,18 & 0,14 & 0,04 \\
\hline $2 \mathrm{a} 3$ & $0,47 *$ & $0,55 * *$ & $0,58 * *$ & 0,19 & & $0,63 * *$ & $0,55 * *$ & $-0,04$ & 0,18 & 0,08 & 0,11 \\
\hline $2 \mathrm{a} 4$ & 0,23 & 0,43 & 0,35 & 0,21 & & 0,43 & $0,56 * *$ & $-0,20$ & 0,16 & $-0,07$ & 0,30 \\
\hline $2 \mathrm{a} 5$ & 0,09 & 0,31 & 0,21 & 0,21 & & 0,34 & 0,43 & $-0,29$ & 0,16 & $-0,05$ & 0,35 \\
\hline 3 & 0,23 & 0,28 & 0,29 & 0,07 & & 0,29 & 0,27 & $-0,09$ & 0,07 & $-0,04$ & 0,12 \\
\hline $3 \mathrm{a} 4$ & 0,00 & 0,19 & 0,08 & 0,12 & & 0,11 & 0,32 & $-0,25$ & 0,07 & $-0,21$ & 0,27 \\
\hline $3 \mathrm{a} 5$ & $-0,16$ & 0,05 & $-0,09$ & 0,12 & & $-0,02$ & 0,29 & $-0,31$ & 0,08 & $-0,15$ & 0,30 \\
\hline $3 a 6$ & $-0,27$ & $-0,08$ & $-0,21$ & 0,10 & & $-0,18$ & 0,28 & $-0,41$ & 0,04 & $-0,12$ & 0,40 \\
\hline 4 & $-0,21$ & 0,08 & $-0,09$ & 0,21 & & $-0,08$ & 0,29 & $-0,29$ & 0,06 & $-0,30$ & 0,30 \\
\hline $4 \mathrm{a} 5$ & $-0,40$ & $-0,07$ & $-0,25$ & 0,17 & & $-0,30$ & 0,22 & $-0,36$ & 0,08 & $-0,16$ & 0,34 \\
\hline $4 a 6$ & $-0,43$ & $-0,21$ & $-0,37$ & 0,07 & & $-0,44$ & 0,19 & $-0,44$ & $-0,02$ & $-0,08$ & 0,42 \\
\hline $4 a 7$ & $-0,17$ & 0,03 & $-0,08$ & $-0,03$ & & $-0,20$ & 0,25 & $-0,31$ & $-0,03$ & $-0,02$ & 0,31 \\
\hline 5 & $-0,51 *$ & $-0,14$ & $-0,33$ & $-0,04$ & & $-0,44$ & 0,11 & $-0,35$ & 0,09 & 0,04 & 0,30 \\
\hline $5 \mathrm{a} 6$ & $-0,43$ & $-0,28$ & $-0,40$ & $-0,07$ & & $-0,51 *$ & 0,08 & $-0,41$ & $-0,07$ & 0,08 & 0,34 \\
\hline $5 \mathrm{a} 7$ & $-0,11$ & 0,00 & $-0,05$ & $-0,18$ & & $-0,17$ & 0,17 & $-0,25$ & $-0,08$ & 0,14 & 0,25 \\
\hline $5 \mathrm{a} 8$ & 0,08 & 0,10 & 0,08 & $-0,34$ & & 0,04 & 0,00 & 0,03 & $-0,09$ & 0,17 & $-0,04$ \\
\hline 6 & $-0,34$ & $-0,31$ & $-0,36$ & $-0,06$ & & $-0,42$ & 0,00 & $-0,29$ & $-0,10$ & 0,05 & 0,20 \\
\hline $6 \mathrm{a} 7$ & 0,04 & 0,08 & 0,10 & $-0,19$ & & 0,01 & 0,17 & $-0,13$ & $-0,11$ & 0,13 & 0,17 \\
\hline $6 a 8$ & 0,23 & 0,17 & 0,19 & $-0,40$ & & 0,18 & $-0,06$ & 0,16 & $-0,12$ & 0,19 & $-0,15$ \\
\hline $6 \mathrm{a} 9$ & 0,32 & 0,22 & 0,29 & $-0,47$ & & 0,31 & $-0,26$ & 0,35 & $-0,30$ & 0,34 & $-0,35$ \\
\hline 7 & $0,52 *$ & 0,39 & $0,49 *$ & $-0,26$ & & $0,46 *$ & 0,25 & 0,10 & $-0,06$ & 0,16 & 0,09 \\
\hline $7 \mathrm{a} 8$ & $0,50 *$ & 0,34 & 0,44 & $-0,43$ & & 0,43 & $-0,08$ & 0,37 & $-0,12$ & 0,16 & $-0,28$ \\
\hline $7 \mathrm{a} 9$ & $0,47 *$ & 0,34 & 0,44 & $-0,47 *$ & & $0,45 *$ & $-0,27$ & $0,44 *$ & $-0,34$ & 0,29 & $-0,41$ \\
\hline $7 \mathrm{a} 10$ & 0,14 & 0,15 & 0,15 & $-0,26$ & & $-0,02$ & $-0,32$ & 0,22 & $-0,14$ & 0,09 & $-0,27$ \\
\hline 8 & 0,34 & 0,18 & 0,26 & $-0,31$ & & 0,25 & $-0,28$ & $0,46 *$ & $-0,36$ & 0,12 & $-0,42$ \\
\hline $8 \mathrm{a} 9$ & 0,41 & 0,23 & 0,37 & $-0,37$ & & 0,39 & $-0,35$ & $0,46 *$ & $-0,32$ & 0,29 & $-0,45 *$ \\
\hline $8 \mathrm{a} 10$ & 0,00 & 0,02 & 0,00 & $-0,19$ & & $-0,14$ & $-0,37$ & 0,22 & $-0,13$ & 0,05 & $-0,29$ \\
\hline $8 \mathrm{a} 11$ & $-0,05$ & $-0,09$ & $-0,07$ & $-0,56$ * & $* *$ & $-0,25$ & $-0,49 *$ & 0,32 & $-0,49 *$ & 0,27 & $-0,38$ \\
\hline 9 & 0,36 & 0,25 & 0,38 & $-0,29$ & & 0,39 & $-0,33$ & 0,41 & $-0,30$ & 0,34 & $-0,42$ \\
\hline $9 \mathrm{a} 10$ & $-0,17$ & $-0,11$ & $-0,16$ & $-0,10$ & & $-0,31$ & $-0,34$ & 0,10 & $-0,12$ & 0,01 & $-0,18$ \\
\hline 9a11 & $-0,21$ & $-0,24$ & $-0,26$ & $-0,55 *$ & $* *$ & $-0,38$ & $-0,51 *$ & 0,24 & $-0,49 *$ & 0,27 & $-0,33$ \\
\hline $9 \mathrm{a} 12$ & $-0,17$ & $-0,15$ & $-0,19$ & $-0,46 *$ & & $-0,29$ & $-0,52 * *$ & 0,28 & $-0,41$ & 0,33 & $-0,36$ \\
\hline 10 & $-0,63 *$ & * $\quad-0,34$ & $-0,54 * *$ & $-0,11$ & & $-0,60 * *$ & $-0,29$ & 0,25 & $-0,16$ & $-0,37$ & 0,12 \\
\hline 10a11 & $-0,56 *$ & * $\quad-0,39$ & $-0,52 * *$ & $-0,51$ * & & $-0,57 * *$ & $-0,52 * *$ & 0,03 & $-0,44 *$ & 0,12 & $-0,19$ \\
\hline 10a12 & $-0,48 *$ & $-0,26$ & $-0,41$ & $-0,40$ & & $-0,45 *$ & $-0,52 * *$ & 0,12 & $-0,36$ & 0,22 & $-0,21$ \\
\hline $10 \mathrm{a} 13$ & $-0,53 *$ & * $\quad-0,21$ & $-0,37$ & 0,05 & & $-0,44$ & $-0,47 *$ & 0,09 & 0,12 & 0,04 & $-0,17$ \\
\hline 11 & $-0,17$ & $-0,38$ & $-0,33$ & $-0,67$ * & $* * *$ & $-0,35$ & $-0,57 * *$ & $0,48 *$ & $-0,56 * *$ & $0,49 *$ & $-0,52 * *$ \\
\hline $11 \mathrm{a} 12$ & $-0,13$ & $-0,17$ & $-0,17$ & $-0,49$ * & & $-0,20$ & $-0,51 *$ & $0,44 *$ & $-0,43$ & $0,45 *$ & $-0,46 *$ \\
\hline $11 \mathrm{a} 13$ & $-0,20$ & $-0,10$ & $-0,17$ & 0,01 & & $-0,21$ & $-0,41$ & 0,42 & 0,11 & 0,27 & $-0,41$ \\
\hline 12 & $-0,02$ & 0,17 & 0,10 & 0,16 & & 0,05 & $-0,19$ & 0,41 & 0,06 & 0,26 & $-0,40$ \\
\hline $12 \mathrm{a} 13$ & $-0,16$ & 0,13 & 0,01 & 0,54 & $* *$ & $-0,01$ & $-0,11$ & 0,19 & $0,51 *$ & $-0,06$ & $-0,19$ \\
\hline 13 & $-0,16$ & 0,06 & $-0,07$ & 0,55 * & $* *$ & $-0,06$ & 0,01 & $-0,16$ & $0,58 * *$ & $-0,27$ & 0,15 \\
\hline
\end{tabular}

Períodos $1, \ldots 12$ = janeiro, ... a dezembro do ano do florescimento; período 13 = janeiro do ano da colheita.

${ }^{2}$ TMED, TMAX, TMIN = temperaturas média, média máxima e média mínima; PREC, ETM, ETR, DEF, EXC, NDH, ER/EM: totais de precipitação, evapotranspiração máxima e real, deficiência e excedente hídrico, dias com deficiência e relação ETR/ETM.

$\stackrel{* * * * *}{, *}$ : Significativo aos níveis de $0,10,0,05$ e 0,01 de probabilidade, respectivamente. 
Tabela 27. Coeficientes de correlação (r) entre número de frutos por planta e variáveis agrometeorológicas de diferentes períodos, entre as safras de 1990 e 2004. Cultivar 'Valência'. Idade 3. Limeira-SP

\begin{tabular}{|c|c|c|c|c|c|c|c|c|c|c|}
\hline \multirow{2}{*}{ Período $^{1}$} & \multicolumn{10}{|c|}{ Variável Meteorológica ${ }^{2}$} \\
\hline & TMAX & TMIN & TMED & PREC & ETM & ETR & DEF & EXC & $\mathrm{NDH}$ & ER/EM \\
\hline 1 & 0,21 & 0,44 & 0,40 & 0,02 & 0,42 & 0,39 & 0,03 & $-0,01$ & 0,11 & 0,01 \\
\hline $1 \mathrm{a} 2$ & $0,55 * *$ & $0,59 * *$ & $0,66 * * *$ & 0,09 & $0,69 * * *$ & $0,60 * *$ & 0,23 & 0,03 & 0,26 & $-0,15$ \\
\hline 1a3 & 0,43 & $0,58 * *$ & $0,55 * *$ & 0,24 & $0,60 * *$ & $0,58 * *$ & 0,00 & 0,18 & 0,16 & 0,13 \\
\hline $1 \mathrm{a} 4$ & 0,25 & $0,46 *$ & 0,36 & 0,25 & $0,45 *$ & $0,59 * *$ & $-0,21$ & 0,15 & $-0,01$ & 0,25 \\
\hline 2 & $0,51 *$ & $0,63 * *$ & $0,67 * * *$ & 0,09 & $0,68 * * *$ & $0,52 * *$ & 0,24 & 0,05 & 0,22 & $-0,17$ \\
\hline $2 \mathrm{a} 3$ & 0,44 & $0,57 * *$ & $0,56 * *$ & 0,22 & $0,61 * *$ & $0,52 * *$ & $-0,01$ & 0,19 & 0,08 & 0,08 \\
\hline $2 \mathrm{a} 4$ & 0,21 & 0,42 & 0,31 & 0,23 & 0,39 & $0,54 * *$ & $-0,21$ & 0,15 & $-0,07$ & 0,30 \\
\hline $2 \mathrm{a} 5$ & 0,11 & 0,22 & 0,18 & 0,20 & 0,29 & 0,44 & $-0,30$ & 0,14 & $-0,01$ & 0,36 \\
\hline 3 & 0,06 & 0,32 & 0,20 & 0,22 & 0,18 & 0,30 & $-0,25$ & 0,21 & $-0,14$ & 0,27 \\
\hline $3 a 4$ & $-0,10$ & 0,16 & 0,00 & 0,24 & 0,03 & 0,35 & $-0,37$ & 0,17 & $-0,28$ & 0,38 \\
\hline $3 a 5$ & $-0,20$ & $-0,05$ & $-0,17$ & 0,20 & $-0,11$ & 0,31 & $-0,41$ & 0,16 & $-0,17$ & 0,38 \\
\hline $3 a 6$ & $-0,25$ & $-0,28$ & $-0,28$ & 0,14 & $-0,29$ & 0,27 & $-0,48 *$ & 0,07 & $-0,11$ & $0,46 *$ \\
\hline 4 & $-0,23$ & $-0,01$ & $-0,15$ & 0,18 & $-0,14$ & 0,30 & $-0,34$ & $-0,01$ & $-0,30$ & 0,34 \\
\hline $4 a 5$ & $-0,33$ & $-0,22$ & $-0,29$ & 0,04 & $-0,36$ & 0,24 & $-0,41$ & $-0,04$ & $-0,12$ & 0,37 \\
\hline $4 a 6$ & $-0,34$ & $-0,42$ & $-0,42$ & $-0,10$ & $-0,52 * *$ & 0,16 & $-0,46 *$ & $-0,23$ & $-0,01$ & 0,42 \\
\hline $4 \mathrm{a} 7$ & $-0,17$ & $-0,24$ & $-0,21$ & $-0,21$ & $-0,39$ & 0,21 & $-0,37$ & $-0,26$ & 0,01 & 0,35 \\
\hline 5 & $-0,30$ & $-0,27$ & $-0,34$ & $-0,22$ & $-0,46 *$ & 0,12 & $-0,38$ & $-0,08$ & 0,10 & 0,34 \\
\hline $5 a 6$ & $-0,29$ & $-0,48 *$ & $-0,42$ & $-0,26$ & $-0,57 * *$ & 0,02 & $-0,40$ & $-0,27$ & 0,15 & 0,34 \\
\hline $5 \mathrm{a} 7$ & $-0,10$ & $-0,27$ & $-0,19$ & $-0,38$ & $-0,35$ & 0,12 & $-0,30$ & $-0,31$ & 0,16 & 0,28 \\
\hline $5 a 8$ & 0,07 & $-0,11$ & $-0,04$ & $-0,55 * *$ & $-0,10$ & $-0,03$ & $-0,03$ & $-0,32$ & 0,20 & 0,00 \\
\hline 6 & $-0,27$ & $-0,52 * *$ & $-0,39$ & $-0,18$ & $-0,50 *$ & $-0,13$ & $-0,25$ & $-0,25$ & 0,09 & 0,16 \\
\hline $6 a 7$ & $-0,01$ & $-0,19$ & $-0,09$ & $-0,32$ & $-0,21$ & 0,09 & $-0,18$ & $-0,29$ & 0,12 & 0,18 \\
\hline $6 a 8$ & 0,19 & $-0,04$ & 0,06 & $-0,54 * *$ & 0,03 & $-0,11$ & 0,10 & $-0,30$ & 0,20 & $-0,13$ \\
\hline $6 \mathrm{a} 9$ & 0,36 & 0,01 & 0,20 & $-0,64 * *$ & 0,23 & $-0,37$ & 0,38 & $-0,41$ & 0,39 & $-0,40$ \\
\hline 7 & 0,34 & 0,16 & 0,27 & $-0,32$ & 0,25 & 0,22 & $-0,04$ & $-0,20$ & 0,06 & 0,14 \\
\hline $7 a 8$ & 0,38 & 0,18 & 0,30 & $-0,47 *$ & 0,30 & $-0,07$ & 0,27 & $-0,24$ & 0,12 & $-0,23$ \\
\hline $7 \mathrm{a} 9$ & $0,48 *$ & 0,16 & 0,36 & $-0,57 * *$ & 0,39 & $-0,35$ & $0,46 *$ & $-0,30$ & 0,31 & $-0,45 *$ \\
\hline $7 \mathrm{a} 10$ & 0,28 & 0,09 & 0,20 & $-0,44$ & 0,12 & $-0,44$ & 0,38 & $-0,32$ & 0,19 & $-0,42$ \\
\hline 8 & 0,32 & 0,13 & 0,22 & $-0,32$ & 0,22 & $-0,25$ & 0,41 & $-0,25$ & 0,14 & $-0,39$ \\
\hline $8 \mathrm{a} 9$ & $0,50 *$ & 0,11 & 0,36 & $-0,45 *$ & 0,39 & $-0,42$ & $0,51 *$ & $-0,25$ & 0,35 & $-0,51 *$ \\
\hline $8 \mathrm{a} 10$ & 0,23 & 0,04 & 0,13 & $-0,36$ & 0,07 & $-0,44$ & 0,41 & $-0,28$ & 0,21 & $-0,46 *$ \\
\hline $8 \mathrm{a} 11$ & 0,20 & $-0,09$ & 0,07 & $-0,61 * *$ & $-0,05$ & $-0,58 * *$ & $0,52 * *$ & $-0,52 * *$ & $0,47 *$ & $-0,55 * *$ \\
\hline 9 & $0,52 * *$ & 0,07 & 0,42 & $-0,39$ & 0,43 & $-0,44$ & $0,52 * *$ & $-0,24$ & 0,42 & $-0,53 * *$ \\
\hline 9a10 & 0,13 & $-0,04$ & 0,07 & $-0,30$ & $-0,03$ & $-0,49 *$ & 0,36 & $-0,27$ & 0,19 & $-0,41$ \\
\hline 9a11 & 0,09 & $-0,19$ & $-0,05$ & $-0,61 * *$ & $-0,14$ & $-0,61 * *$ & $0,50 *$ & $-0,51 * *$ & $0,50 *$ & $-0,56 * *$ \\
\hline 9 a12 & 0,15 & $-0,07$ & 0,04 & $-0,46 *$ & $-0,03$ & $-0,55 * *$ & $0,51 *$ & $-0,38$ & $0,45 *$ & $-0,55 * *$ \\
\hline 10 & $-0,33$ & $-0,09$ & $-0,24$ & $-0,18$ & $-0,30$ & $-0,42$ & 0,09 & $-0,18$ & $-0,16$ & $-0,19$ \\
\hline 10a11 & $-0,26$ & $-0,26$ & $-0,28$ & $-0,53 * *$ & $-0,34$ & $-0,61 * *$ & 0,37 & $-0,50 *$ & 0,39 & $-0,48 *$ \\
\hline 10a12 & $-0,16$ & $-0,11$ & $-0,14$ & $-0,35$ & $-0,18$ & $-0,48 *$ & 0,40 & $-0,35$ & 0,32 & $-0,45 *$ \\
\hline $10 \mathrm{a} 13$ & $-0,19$ & $-0,06$ & $-0,11$ & 0,03 & $-0,17$ & $-0,44 *$ & 0,37 & 0,03 & 0,23 & $-0,41$ \\
\hline 11 & $-0,02$ & $-0,40$ & $-0,26$ & $-0,57 * *$ & $-0,30$ & $-0,59 * *$ & $0,54 * *$ & $-0,47 *$ & $0,61 * *$ & $-0,58 * *$ \\
\hline $11 \mathrm{a} 12$ & 0,11 & $-0,07$ & 0,01 & $-0,32$ & $-0,02$ & $-0,37$ & 0,43 & $-0,28$ & 0,41 & $-0,40$ \\
\hline $11 \mathrm{a} 13$ & 0,10 & $-0,03$ & 0,02 & 0,07 & $-0,02$ & $-0,30$ & 0,41 & 0,10 & 0,38 & $-0,41$ \\
\hline 12 & 0,25 & 0,37 & 0,38 & 0,29 & 0,35 & 0,17 & 0,23 & 0,17 & $-0,04$ & $-0,14$ \\
\hline $12 \mathrm{a} 13$ & 0,09 & 0,25 & 0,22 & $0,52 * *$ & 0,21 & 0,10 & 0,17 & $0,44 *$ & $-0,05$ & $-0,16$ \\
\hline 13 & $-0,09$ & 0,06 & $-0,02$ & $0,44 *$ & 0,00 & $-0,02$ & 0,05 & 0,43 & $-0,03$ & $-0,08$ \\
\hline
\end{tabular}

'Períodos $1, \ldots 12$ = janeiro, ... a dezembro do ano do florescimento; período 13 = janeiro do ano da colheita.

2 TMED, TMAX, TMIN = temperaturas média, média máxima e média mínima; PREC, ETM, ETR, DEF, EXC, NDH, ER/EM: totais de precipitação, evapotranspiração máxima e real, deficiência e excedente hídrico, dias com deficiência e relação ETR/ETM. $\stackrel{* * * * *}{, *}$ : Significativo aos níveis de $0,10,0,05$ e 0,01 de probabilidade, respectivamente. 
Tabela 28. Coeficientes de correlação (r) entre número de frutos por planta e variáveis agrometeorológicas de diferentes períodos, entre as safras de 1990 e 2004. Cultivar 'Hamlin'. Idade 1. Limeira-SP

\begin{tabular}{|c|c|c|c|c|c|c|c|c|c|c|}
\hline \multicolumn{5}{|c|}{ Período $^{1}$} & \multicolumn{6}{|c|}{ Variável Meteorológica $^{2}$} \\
\hline & TMAX & TMIN & TMED & PREC & ETM & ETR & DEF & EXC & $\mathrm{NDH}$ & ER/EM \\
\hline 1 & 0,20 & $0,66^{* * *}$ & $0,54 * *$ & 0,39 & $0,55 * *$ & $0,62 * *$ & $-0,20$ & 0,32 & $-0,21$ & 0,23 \\
\hline $1 \mathrm{a} 2$ & 0,03 & $0,61 * *$ & 0,35 & $0,65 * * *$ & 0,41 & $0,66 * * *$ & $-0,36$ & $0,60 * *$ & $-0,41$ & $0,45 *$ \\
\hline $1 \mathrm{a} 3$ & 0,14 & $0,61 * *$ & 0,40 & $0,53 * *$ & $0,45 *$ & $0,63 * *$ & $-0,32$ & $0,51 *$ & $-0,40$ & 0,41 \\
\hline $1 \mathrm{a} 4$ & 0,06 & $0,53 * *$ & 0,30 & $0,54 * *$ & 0,39 & $0,60 * *$ & $-0,32$ & $0,47 *$ & $-0,47 *$ & 0,36 \\
\hline 2 & $-0,11$ & 0,40 & 0,12 & 0,44 & 0,14 & 0,40 & $-0,30$ & 0,41 & $-0,33$ & 0,35 \\
\hline $2 \mathrm{a} 3$ & 0,07 & $0,46 *$ & 0,30 & 0,28 & 0,32 & $0,45 *$ & $-0,26$ & 0,30 & $-0,23$ & 0,29 \\
\hline $2 \mathrm{a} 4$ & 0,00 & 0,39 & 0,18 & 0,32 & 0,24 & $0,46 *$ & $-0,26$ & 0,28 & $-0,31$ & 0,32 \\
\hline $2 \mathrm{a} 5$ & $-0,11$ & 0,29 & 0,08 & 0,34 & 0,16 & 0,43 & $-0,38$ & 0,28 & $-0,30$ & 0,43 \\
\hline 3 & 0,24 & 0,37 & 0,34 & $-0,03$ & 0,35 & 0,31 & $-0,09$ & 0,01 & 0,05 & 0,12 \\
\hline $3 \mathrm{a} 4$ & 0,06 & 0,27 & 0,16 & 0,09 & 0,20 & 0,32 & $-0,15$ & 0,06 & $-0,10$ & 0,20 \\
\hline $3 \mathrm{a} 5$ & $-0,06$ & 0,14 & 0,00 & 0,11 & 0,09 & 0,35 & $-0,30$ & 0,06 & $-0,11$ & 0,32 \\
\hline $3 a 6$ & $-0,07$ & 0,10 & $-0,02$ & 0,09 & 0,01 & 0,44 & $-0,45 *$ & 0,01 & $-0,10$ & $0,49 *$ \\
\hline 4 & $-0,10$ & 0,12 & 0,00 & 0,34 & 0,03 & 0,23 & $-0,15$ & 0,18 & $-0,24$ & 0,20 \\
\hline $4 \mathrm{a} 5$ & $-0,27$ & $-0,03$ & $-0,14$ & 0,36 & $-0,18$ & 0,28 & $-0,34$ & 0,17 & $-0,18$ & 0,37 \\
\hline $4 a 6$ & $-0,19$ & $-0,04$ & $-0,14$ & 0,19 & $-0,22$ & 0,42 & $-0,48 *$ & 0,00 & $-0,11$ & $0,51 *$ \\
\hline $4 a 7$ & $-0,01$ & 0,08 & 0,03 & 0,01 & $-0,09$ & 0,34 & $-0,33$ & $-0,01$ & 0,07 & 0,34 \\
\hline 5 & $-0,38$ & $-0,13$ & $-0,27$ & 0,10 & $-0,39$ & 0,26 & $-0,49 *$ & 0,04 & $-0,04$ & $0,45 *$ \\
\hline $5 \mathrm{a} 6$ & $-0,18$ & $-0,10$ & $-0,16$ & $-0,03$ & $-0,31$ & 0,40 & $-0,57 * *$ & $-0,13$ & 0,00 & $0,56 * *$ \\
\hline $5 \mathrm{a} 7$ & 0,02 & 0,04 & 0,04 & $-0,23$ & $-0,12$ & 0,30 & $-0,34$ & $-0,14$ & 0,20 & 0,36 \\
\hline $5 \mathrm{a} 8$ & 0,16 & 0,14 & 0,14 & $-0,33$ & 0,11 & 0,22 & $-0,11$ & $-0,15$ & 0,23 & 0,13 \\
\hline 6 & $-0,08$ & $-0,04$ & $-0,07$ & $-0,09$ & $-0,17$ & 0,42 & $-0,40$ & $-0,14$ & 0,03 & 0,40 \\
\hline $6 a 7$ & 0,17 & 0,13 & 0,18 & $-0,31$ & 0,06 & 0,25 & $-0,18$ & $-0,15$ & 0,26 & 0,21 \\
\hline $6 a 8$ & 0,29 & 0,21 & 0,27 & $-0,45 *$ & 0,25 & 0,14 & 0,05 & $-0,16$ & 0,33 & 0,00 \\
\hline $6 \mathrm{a} 9$ & 0,27 & 0,24 & 0,27 & $-0,19$ & 0,26 & $-0,04$ & 0,18 & 0,00 & 0,31 & $-0,15$ \\
\hline 7 & 0,36 & 0,24 & 0,32 & $-0,46 *$ & 0,26 & 0,05 & 0,14 & $-0,05$ & $0,51 *$ & $-0,06$ \\
\hline $7 \mathrm{a} 8$ & 0,40 & 0,29 & 0,37 & $-0,47 *$ & 0,37 & $-0,03$ & 0,29 & $-0,08$ & 0,35 & $-0,23$ \\
\hline $7 \mathrm{a} 9$ & 0,30 & 0,27 & 0,32 & $-0,14$ & 0,32 & $-0,16$ & 0,30 & 0,19 & 0,28 & $-0,28$ \\
\hline $7 \mathrm{a} 10$ & 0,08 & 0,12 & 0,11 & $-0,17$ & 0,00 & $-0,20$ & 0,15 & $-0,09$ & 0,19 & $-0,19$ \\
\hline 8 & 0,32 & 0,22 & 0,28 & $-0,18$ & 0,32 & $-0,07$ & 0,32 & $-0,17$ & 0,12 & $-0,27$ \\
\hline $8 \mathrm{a} 9$ & 0,26 & 0,24 & 0,29 & 0,05 & 0,30 & $-0,17$ & 0,29 & 0,20 & 0,13 & $-0,27$ \\
\hline $8 \mathrm{a} 10$ & $-0,03$ & 0,05 & 0,01 & $-0,04$ & $-0,06$ & $-0,21$ & 0,13 & $-0,08$ & 0,06 & $-0,19$ \\
\hline 8 a11 & $-0,10$ & $-0,08$ & $-0,10$ & $-0,33$ & $-0,21$ & $-0,33$ & 0,20 & $-0,31$ & 0,24 & $-0,25$ \\
\hline 9 & 0,17 & 0,17 & 0,20 & 0,17 & 0,19 & $-0,22$ & 0,24 & 0,21 & 0,11 & $-0,27$ \\
\hline 9a10 & $-0,19$ & $-0,09$ & $-0,15$ & 0,02 & $-0,24$ & $-0,23$ & 0,05 & $-0,08$ & 0,02 & $-0,13$ \\
\hline 9a11 & $-0,25$ & $-0,25$ & $-0,28$ & $-0,32$ & $-0,36$ & $-0,38$ & 0,14 & $-0,31$ & 0,24 & $-0,22$ \\
\hline 9a12 & $-0,19$ & $-0,15$ & $-0,20$ & $-0,34$ & $-0,24$ & $-0,36$ & 0,17 & $-0,35$ & 0,25 & $-0,24$ \\
\hline 10 & $-0,45 *$ & $-0,26$ & $-0,40$ & $-0,13$ & $-0,40$ & $-0,19$ & $-0,17$ & $-0,24$ & $-0,09$ & 0,07 \\
\hline 10a11 & $-0,44 *$ & $-0,38$ & $-0,44$ & $-0,47 *$ & $-0,47 *$ & $-0,41$ & 0,01 & $-0,44$ & 0,26 & $-0,12$ \\
\hline 10a12 & $-0,37$ & $-0,23$ & $-0,33$ & $-0,48 *$ & $-0,33$ & $-0,37$ & 0,08 & $-0,47 *$ & 0,27 & $-0,15$ \\
\hline $10 \mathrm{a} 13$ & $-0,51 *$ & $-0,17$ & $-0,34$ & 0,01 & $-0,38$ & $-0,38$ & 0,05 & 0,05 & 0,01 & $-0,13$ \\
\hline 11 & $-0,21$ & $-0,43$ & $-0,39$ & $-0,47 *$ & $-0,42$ & $-0,49 *$ & 0,30 & $-0,35$ & 0,41 & $-0,36$ \\
\hline $11 \mathrm{a} 12$ & $-0,13$ & $-0,19$ & $-0,17$ & $-0,44$ & $-0,19$ & $-0,37$ & 0,36 & $-0,38$ & 0,39 & $-0,36$ \\
\hline $11 \mathrm{a} 13$ & $-0,37$ & $-0,08$ & $-0,27$ & 0,06 & $-0,30$ & $-0,36$ & 0,29 & 0,15 & 0,07 & $-0,31$ \\
\hline 12 & 0,07 & 0,22 & 0,19 & $-0,04$ & 0,17 & $-0,02$ & 0,31 & $-0,14$ & 0,09 & $-0,26$ \\
\hline $12 \mathrm{a} 13$ & $-0,34$ & 0,18 & $-0,05$ & 0,44 & $-0,07$ & $-0,13$ & 0,12 & 0,42 & $-0,28$ & $-0,13$ \\
\hline 13 & $-0,51 *$ & 0,11 & $-0,25$ & $0,56 * *$ & $-0,26$ & $-0,18$ & $-0,17$ & $0,59 * *$ & $-0,42$ & 0,13 \\
\hline
\end{tabular}

Períodos $1, \ldots 12$ = janeiro, $\ldots$ a dezembro do ano do florescimento; período 13 = janeiro do ano da colheita.

${ }^{2}$ TMED, TMAX, TMIN = temperaturas média, média máxima e média mínima; PREC, ETM, ETR, DEF, EXC, NDH, ER/EM: totais de precipitação, evapotranspiração máxima e real, deficiência e excedente hídrico, dias com deficiência e relação ETR/ETM. $*^{* * * * *}:$ Significativo aos níveis de $0,10,0,05$ e 0,01 de probabilidade, respectivamente. 
Tabela 29. Coeficientes de correlação (r) entre número de frutos por planta e variáveis agrometeorológicas de diferentes períodos, entre as safras de 1990 e 2004. Cultivar 'Hamlin'. Idade 2. Limeira-SP

\begin{tabular}{|c|c|c|c|c|c|c|c|c|c|c|}
\hline \multirow{2}{*}{ Período ${ }^{1}$} & \multicolumn{10}{|c|}{ Variável Meteorológica ${ }^{2}$} \\
\hline & TMAX & TMIN & TMED & PREC & ETM & ETR & DEF & EXC & $\mathrm{NDH}$ & ER/EM \\
\hline 1 & 0,18 & 0,40 & 0,37 & $-0,02$ & 0,42 & 0,33 & 0,17 & $-0,06$ & 0,21 & $-0,15$ \\
\hline $1 \mathrm{a} 2$ & $0,46 *$ & $0,46 *$ & $0,52 * *$ & $-0,05$ & $0,60 * *$ & $0,50 *$ & 0,22 & $-0,13$ & 0,26 & $-0,16$ \\
\hline $1 \mathrm{a} 3$ & 0,37 & $0,53 * *$ & $0,48 *$ & 0,23 & $0,57 * *$ & $0,59 * *$ & $-0,08$ & 0,16 & $-0,03$ & 0,19 \\
\hline $1 \mathrm{a} 4$ & 0,22 & $0,48 *$ & 0,35 & 0,24 & $0,49 *$ & $0,62 * *$ & $-0,21$ & 0,14 & $-0,08$ & 0,28 \\
\hline 2 & 0,41 & 0,42 & $0,49 *$ & $-0,04$ & $0,55 * *$ & 0,44 & 0,16 & $-0,10$ & 0,16 & $-0,10$ \\
\hline $2 \mathrm{a} 3$ & 0,36 & $0,50 *$ & $0,49 *$ & 0,24 & $0,57 * *$ & $0,57 * *$ & $-0,14$ & 0,20 & $-0,15$ & 0,21 \\
\hline $2 \mathrm{a} 4$ & 0,17 & 0,44 & 0,31 & 0,24 & 0,44 & $0,61 * *$ & $-0,24$ & 0,16 & $-0,19$ & 0,33 \\
\hline $2 \mathrm{a} 5$ & 0,01 & 0,18 & 0,12 & 0,23 & 0,30 & 0,44 & $-0,36$ & 0,17 & $-0,15$ & 0,40 \\
\hline 3 & 0,04 & 0,44 & 0,24 & 0,36 & 0,29 & 0,44 & $-0,36$ & 0,37 & $-0,39$ & 0,38 \\
\hline $3 \mathrm{a} 4$ & $-0,07$ & 0,32 & 0,10 & 0,35 & 0,18 & 0,43 & $-0,36$ & 0,30 & $-0,37$ & 0,40 \\
\hline $3 \mathrm{a} 5$ & $-0,26$ & 0,00 & $-0,17$ & 0,34 & $-0,01$ & 0,40 & $-0,43$ & 0,30 & $-0,27$ & 0,41 \\
\hline $3 \mathrm{a} 6$ & $-0,27$ & $-0,12$ & $-0,22$ & 0,28 & $-0,12$ & 0,37 & $-0,46 *$ & 0,23 & $-0,14$ & $0,46 *$ \\
\hline 4 & $-0,17$ & 0,18 & $-0,02$ & 0,18 & 0,05 & 0,36 & $-0,24$ & $-0,01$ & $-0,12$ & 0,26 \\
\hline $4 \mathrm{a} 5$ & $-0,42$ & $-0,21$ & $-0,34$ & 0,10 & $-0,29$ & 0,26 & $-0,39$ & 0,02 & $-0,04$ & 0,37 \\
\hline $4 \mathrm{a} 6$ & $-0,37$ & $-0,29$ & $-0,37$ & $-0,09$ & $-0,35$ & 0,20 & $-0,39$ & $-0,16$ & 0,13 & 0,38 \\
\hline $4 a 7$ & $-0,28$ & $-0,32$ & $-0,34$ & $-0,14$ & $-0,40$ & 0,11 & $-0,29$ & $-0,15$ & 0,16 & 0,25 \\
\hline 5 & $-0,63 * *$ & $-0,40$ & $-0,58 * *$ & $-0,11$ & $-0,65 * * *$ & 0,10 & $-0,46 *$ & 0,11 & 0,05 & 0,38 \\
\hline $5 \mathrm{a} 6$ & $-0,36$ & $-0,44$ & $-0,44$ & $-0,25$ & $-0,51 *$ & 0,03 & $-0,37$ & $-0,18$ & 0,21 & 0,30 \\
\hline $5 \mathrm{a} 7$ & $-0,28$ & $-0,41$ & $-0,38$ & $-0,30$ & $-0,49 *$ & $-0,03$ & $-0,24$ & $-0,17$ & 0,25 & 0,20 \\
\hline $5 \mathrm{a} 8$ & $-0,19$ & $-0,27$ & $-0,26$ & $-0,35$ & $-0,32$ & $-0,09$ & $-0,12$ & $-0,18$ & 0,15 & 0,06 \\
\hline 6 & $-0,21$ & $-0,29$ & $-0,26$ & $-0,23$ & $-0,28$ & $-0,06$ & $-0,15$ & $-0,21$ & 0,19 & 0,07 \\
\hline $6 \mathrm{a} 7$ & $-0,12$ & $-0,31$ & $-0,20$ & $-0,28$ & $-0,29$ & $-0,10$ & $-0,06$ & $-0,20$ & 0,25 & 0,04 \\
\hline $6 a 8$ & $-0,06$ & $-0,18$ & $-0,13$ & $-0,44 *$ & $-0,16$ & $-0,16$ & 0,03 & $-0,21$ & 0,15 & $-0,09$ \\
\hline $6 a 9$ & $-0,02$ & $-0,12$ & $-0,08$ & $-0,25$ & $-0,10$ & $-0,15$ & 0,04 & $-0,22$ & 0,11 & $-0,09$ \\
\hline 7 & 0,10 & $-0,17$ & $-0,04$ & $-0,31$ & $-0,08$ & $-0,10$ & 0,05 & 0,05 & 0,13 & $-0,02$ \\
\hline $7 \mathrm{a} 8$ & 0,06 & $-0,08$ & $-0,01$ & $-0,18$ & $-0,03$ & $-0,17$ & 0,12 & 0,01 & $-0,04$ & $-0,15$ \\
\hline $7 \mathrm{a} 9$ & 0,05 & $-0,05$ & $-0,01$ & $-0,11$ & $-0,01$ & $-0,14$ & 0,09 & $-0,06$ & $-0,03$ & $-0,13$ \\
\hline $7 \mathrm{a} 10$ & $-0,20$ & $-0,17$ & $-0,21$ & $-0,04$ & $-0,33$ & $-0,11$ & $-0,11$ & 0,09 & $-0,10$ & 0,03 \\
\hline 8 & 0,01 & 0,01 & 0,01 & $-0,18$ & 0,01 & $-0,13$ & 0,13 & $-0,28$ & $-0,17$ & $-0,16$ \\
\hline $8 \mathrm{a} 9$ & 0,03 & 0,00 & 0,02 & $-0,04$ & 0,03 & $-0,09$ & 0,08 & $-0,07$ & $-0,09$ & $-0,12$ \\
\hline $8 \mathrm{a} 10$ & $-0,27$ & $-0,15$ & $-0,25$ & 0,01 & $-0,34$ & $-0,08$ & $-0,12$ & 0,08 & $-0,16$ & 0,05 \\
\hline $8 \mathrm{a} 11$ & $-0,29$ & $-0,24$ & $-0,29$ & $-0,35$ & $-0,41$ & $-0,29$ & 0,03 & $-0,28$ & 0,09 & $-0,10$ \\
\hline 9 & 0,02 & 0,03 & 0,02 & 0,00 & 0,03 & $-0,05$ & 0,05 & $-0,06$ & $-0,01$ & $-0,09$ \\
\hline $9 \mathrm{a} 10$ & $-0,36$ & $-0,22$ & $-0,34$ & 0,04 & $-0,44$ & $-0,04$ & $-0,20$ & 0,09 & $-0,12$ & 0,13 \\
\hline 9a11 & $-0,37$ & $-0,34$ & $-0,39$ & $-0,37$ & $-0,47 *$ & $-0,31$ & 0,00 & $-0,28$ & 0,17 & $-0,09$ \\
\hline $9 \mathrm{a} 12$ & $-0,33$ & $-0,23$ & $-0,31$ & $-0,21$ & $-0,37$ & $-0,31$ & 0,01 & $-0,12$ & 0,15 & $-0,08$ \\
\hline 10 & $-0,57 * *$ & $-0,32$ & $-0,49 *$ & $-0,16$ & $-0,54 * *$ & $-0,03$ & $-0,10$ & $-0,15$ & $-0,19$ & 0,30 \\
\hline 10a11 & $-0,50 *$ & $-0,40$ & $-0,50 *$ & $-0,44$ & $-0,53 * *$ & $-0,41$ & $-0,05$ & $-0,30$ & 0,27 & $-0,09$ \\
\hline $10 \mathrm{a} 12$ & $-0,46 *$ & $-0,28$ & $-0,41$ & $-0,24$ & $-0,42$ & $-0,38$ & $-0,02$ & $-0,11$ & 0,23 & $-0,06$ \\
\hline $10 \mathrm{a} 13$ & $-0,58 * *$ & $-0,26$ & $-0,43$ & 0,07 & $-0,48 *$ & $-0,41$ & $-0,04$ & 0,17 & 0,09 & $-0,07$ \\
\hline 11 & $-0,15$ & $-0,41$ & $-0,33$ & $-0,56 * *$ & $-0,35$ & $-0,64 * * *$ & $0,57 * *$ & $-0,46 *$ & $0,51 *$ & $-0,60 * *$ \\
\hline $11 \mathrm{a} 12$ & $-0,16$ & $-0,19$ & $-0,20$ & $-0,29$ & $-0,22$ & $-0,50 *$ & 0,43 & $-0,21$ & 0,42 & $-0,41$ \\
\hline $11 \mathrm{a} 13$ & $-0,37$ & $-0,20$ & $-0,31$ & 0,06 & $-0,35$ & $-0,48 *$ & 0,42 & 0,12 & 0,23 & $-0,41$ \\
\hline 12 & $-0,14$ & 0,16 & 0,04 & 0,32 & 0,03 & $-0,05$ & 0,15 & 0,27 & $-0,02$ & $-0,11$ \\
\hline $12 \mathrm{a} 13$ & $-0,41$ & 0,01 & $-0,19$ & $0,50 *$ & $-0,20$ & $-0,18$ & 0,01 & $0,45 *$ & $-0,14$ & $-0,04$ \\
\hline 13 & $-0,38$ & $-0,15$ & $-0,32$ & 0,40 & $-0,32$ & $-0,23$ & $-0,18$ & 0,38 & $-0,17$ & 0,10 \\
\hline
\end{tabular}

'Períodos $1, \ldots 12$ = janeiro, ... a dezembro do ano do florescimento; período 13 = janeiro do ano da colheita.

2 TMED, TMAX, TMIN = temperaturas média, média máxima e média mínima; PREC, ETM, ETR, DEF, EXC, NDH, ER/EM: totais de precipitação, evapotranspiração máxima e real, deficiência e excedente hídrico, dias com deficiência e relação ETR/ETM. $\stackrel{* * * * *}{,}$ : Significativo aos níveis de $0,10,0,05$ e 0,01 de probabilidade, respectivamente. 
Tabela 30. Coeficientes de correlação (r) entre número de frutos por planta e variáveis agrometeorológicas de diferentes períodos, entre as safras de 1990 e 2004. Cultivar 'Hamlin'. Idade 3. Limeira-SP

\begin{tabular}{|c|c|c|c|c|c|c|c|c|c|c|}
\hline \multirow{2}{*}{ Período ${ }^{1}$} & \multicolumn{10}{|c|}{ Variável Meteorológica $^{2}$} \\
\hline & TMAX & TMIN & TMED & PREC & ETM & ETR & DEF & EXC & $\mathrm{NDH}$ & ER/EM \\
\hline 1 & 0,27 & 0,36 & 0,40 & $-0,04$ & 0,42 & 0,36 & 0,11 & $-0,06$ & 0,14 & $-0,06$ \\
\hline $1 \mathrm{a} 2$ & $0,51 * *$ & $0,50 *$ & $0,57 * *$ & 0,05 & $0,63 * *$ & $0,51 *$ & 0,26 & 0,03 & 0,22 & $-0,19$ \\
\hline $1 \mathrm{a} 3$ & 0,29 & $0,52 * *$ & 0,44 & 0,35 & $0,50 *$ & $0,52 * *$ & $-0,07$ & 0,29 & $-0,19$ & 0,19 \\
\hline $1 \mathrm{a} 4$ & 0,15 & $0,44 *$ & 0,31 & 0,42 & 0,39 & $0,66 * * *$ & $-0,39$ & 0,31 & $-0,43$ & $0,45 *$ \\
\hline 2 & 0,41 & $0,54 * *$ & $0,55 * *$ & 0,09 & $0,58 * *$ & 0,42 & 0,23 & 0,08 & 0,16 & $-0,19$ \\
\hline $2 \mathrm{a} 3$ & 0,23 & $0,53 * *$ & 0,42 & 0,37 & $0,46 *$ & $0,46 *$ & $-0,10$ & 0,32 & $-0,25$ & 0,18 \\
\hline $2 \mathrm{a} 4$ & 0,06 & 0,43 & 0,24 & 0,42 & 0,31 & $0,63 * *$ & $-0,41$ & 0,33 & $-0,46 *$ & $0,50 *$ \\
\hline $2 \mathrm{a} 5$ & $-0,06$ & 0,17 & 0,07 & 0,36 & 0,19 & $0,60 * *$ & $-0,51 *$ & 0,31 & $-0,34$ & $0,54 * *$ \\
\hline 3 & $-0,15$ & 0,33 & 0,06 & 0,42 & 0,07 & 0,30 & $-0,38$ & 0,37 & $-0,53 * *$ & 0,39 \\
\hline $3 a 4$ & $-0,20$ & 0,23 & $-0,03$ & 0,41 & 0,00 & $0,53 * *$ & $-0,59 * *$ & 0,39 & $-0,71 * * *$ & $0,63 * *$ \\
\hline $3 a 5$ & $-0,33$ & $-0,04$ & $-0,24$ & 0,41 & $-0,16$ & $0,48 *$ & $-0,62 * *$ & 0,35 & $-0,49 *$ & $0,59 * *$ \\
\hline $3 a 6$ & $-0,23$ & $-0,19$ & $-0,23$ & 0,29 & $-0,23$ & 0,38 & $-0,56 * *$ & 0,20 & $-0,22$ & $0,56 * *$ \\
\hline 4 & $-0,21$ & 0,10 & $-0,07$ & 0,40 & $-0,07$ & $0,65 * * *$ & $-0,56 * *$ & 0,31 & $-0,52 * *$ & $0,61 * *$ \\
\hline $4 \mathrm{a} 5$ & $-0,35$ & $-0,22$ & $-0,30$ & 0,16 & $-0,34$ & $0,48 *$ & $-0,62 * *$ & 0,20 & $-0,21$ & $0,60 * *$ \\
\hline $4 \mathrm{a} 6$ & $-0,22$ & $-0,36$ & $-0,33$ & $-0,16$ & $-0,37$ & 0,31 & $-0,49 *$ & $-0,22$ & 0,15 & $0,48 *$ \\
\hline $4 a 7$ & $-0,12$ & $-0,24$ & $-0,22$ & $-0,24$ & $-0,30$ & 0,22 & $-0,34$ & $-0,23$ & 0,13 & 0,32 \\
\hline 5 & $-0,40$ & $-0,37$ & $-0,45 *$ & $-0,38$ & $-0,54 * *$ & 0,21 & $-0,52 * *$ & $-0,24$ & 0,16 & $0,47 *$ \\
\hline $5 \mathrm{a} 6$ & $-0,16$ & $-0,47 *$ & $-0,35$ & $-0,40$ & $-0,43$ & 0,00 & $-0,29$ & $-0,28$ & 0,44 & 0,22 \\
\hline $5 \mathrm{a} 7$ & $-0,06$ & $-0,32$ & $-0,20$ & $-0,42$ & $-0,30$ & $-0,02$ & $-0,15$ & $-0,30$ & 0,42 & 0,12 \\
\hline $5 \mathrm{a} 8$ & 0,11 & $-0,18$ & $-0,06$ & $-0,60 * *$ & $-0,10$ & $-0,17$ & 0,08 & $-0,53 * *$ & 0,36 & $-0,09$ \\
\hline 6 & $-0,04$ & $-0,39$ & $-0,20$ & $-0,39$ & $-0,24$ & $-0,27$ & 0,02 & $-0,43$ & 0,37 & $-0,15$ \\
\hline $6 a 7$ & 0,08 & $-0,19$ & $-0,04$ & 0,43 & $-0,10$ & $-0,17$ & 0,08 & $-0,43$ & 0,37 & $-0,09$ \\
\hline $6 a 8$ & 0,22 & $-0,09$ & 0,06 & $-0,62 * *$ & 0,06 & $-0,32$ & 0,27 & $-0,46 *$ & 0,35 & $-0,30$ \\
\hline $6 a 9$ & 0,29 & $-0,11$ & 0,09 & $-0,61 * *$ & 0,11 & $-0,43$ & 0,41 & $-0,44 *$ & 0,41 & $-0,43$ \\
\hline 7 & 0,17 & 0,05 & 0,11 & $-0,25$ & 0,12 & $-0,04$ & 0,13 & $-0,06$ & $-0,03$ & $-0,06$ \\
\hline $7 \mathrm{a} 8$ & 0,27 & 0,06 & 0,18 & $-0,31$ & 0,20 & $-0,26$ & 0,35 & $-0,10$ & $-0,03$ & $-0,31$ \\
\hline $7 \mathrm{a} 9$ & 0,31 & $-0,02$ & 0,17 & $-0,39$ & 0,19 & $-0,40$ & 0,42 & $-0,10$ & 0,13 & $-0,43$ \\
\hline $7 \mathrm{a} 10$ & 0,09 & $-0,11$ & $-0,02$ & $-0,25$ & $-0,12$ & $-0,43$ & 0,27 & $-0,02$ & 0,01 & $-0,34$ \\
\hline 8 & 0,31 & 0,04 & 0,17 & $-0,17$ & 0,17 & $-0,28$ & 0,40 & $-0,24$ & $-0,03$ & $-0,35$ \\
\hline $8 \mathrm{a} 9$ & 0,35 & $-0,05$ & 0,18 & $-0,30$ & 0,19 & $-0,41$ & 0,42 & $-0,09$ & 0,17 & $-0,42$ \\
\hline $8 \mathrm{a} 10$ & 0,05 & $-0,16$ & $-0,08$ & $-0,19$ & $-0,16$ & $-0,40$ & 0,27 & $-0,01$ & 0,02 & $-0,33$ \\
\hline $8 \mathrm{a} 11$ & 0,00 & $-0,22$ & $-0,12$ & $-0,42$ & $-0,25$ & $-0,54 * *$ & 0,37 & $-0,31$ & 0,23 & $-0,42$ \\
\hline 9 & 0,29 & $-0,15$ & 0,14 & $-0,28$ & 0,14 & $-0,43$ & 0,38 & $-0,08$ & 0,27 & $-0,43$ \\
\hline 9a10 & $-0,09$ & $-0,28$ & $-0,19$ & $-0,15$ & $-0,29$ & $-0,44$ & 0,19 & $-0,01$ & 0,04 & $-0,26$ \\
\hline 9a11 & $-0,14$ & $-0,32$ & $-0,26$ & $-0,42$ & $-0,35$ & $-0,56 * *$ & 0,32 & $-0,31$ & 0,29 & $-0,40$ \\
\hline 9a12 & $-0,12$ & $-0,23$ & $-0,20$ & $-0,16$ & $-0,27$ & $-0,53 * *$ & 0,31 & $-0,04$ & 0,21 & $-0,38$ \\
\hline 10 & $-0,44$ & $-0,27$ & $-0,39$ & $-0,14$ & $-0,43$ & $-0,34$ & $-0,07$ & $-0,14$ & $-0,24$ & $-0,05$ \\
\hline 10a11 & $-0,39$ & $-0,31$ & $-0,38$ & $-0,36$ & $-0,44$ & $-0,53 * *$ & 0,19 & $-0,33$ & 0,21 & $-0,29$ \\
\hline $10 \mathrm{a} 12$ & $-0,35$ & $-0,21$ & $-0,30$ & $-0,06$ & $-0,34$ & $-0,46 *$ & 0,18 & $-0,02$ & 0,10 & $-0,26$ \\
\hline $10 \mathrm{a} 13$ & $-0,47 *$ & $-0,22$ & $-0,34$ & 0,20 & $-0,41$ & $-0,49 *$ & 0,14 & 0,25 & $-0,03$ & $-0,22$ \\
\hline 11 & $-0,16$ & $-0,30$ & $-0,26$ & $-0,45 *$ & $-0,30$ & $-0,54 * *$ & $0,47 *$ & $-0,42$ & $0,48 *$ & $-0,48 *$ \\
\hline $11 \mathrm{a} 12$ & $-0,12$ & $-0,12$ & $-0,13$ & $-0,08$ & $-0,18$ & $-0,40$ & 0,41 & $-0,05$ & 0,31 & $-0,40$ \\
\hline $11 \mathrm{a} 13$ & $-0,33$ & $-0,15$ & $-0,25$ & 0,21 & $-0,31$ & $-0,40$ & 0,33 & 0,25 & 0,11 & $-0,34$ \\
\hline 12 & $-0,05$ & 0,16 & 0,08 & $0,53 * *$ & 0,04 & 0,01 & 0,04 & $0,48 *$ & $-0,18$ & $-0,03$ \\
\hline $12 \mathrm{a} 13$ & $-0,33$ & $-0,01$ & $-0,15$ & $0,60 * *$ & $-0,19$ & $-0,14$ & $-0,06$ & $0,58 * *$ & $-0,28$ & 0,02 \\
\hline 13 & $-0,36$ & $-0,17$ & $-0,32$ & 0,39 & $-0,32$ & $-0,23$ & $-0,19$ & 0,40 & $-0,23$ & 0,12 \\
\hline
\end{tabular}

'Períodos $1, \ldots 12$ = janeiro, ... a dezembro do ano do florescimento; período 13 = janeiro do ano da colheita.

2 TMED, TMAX, TMIN = temperaturas média, média máxima e média mínima; PREC, ETM, ETR, DEF, EXC, NDH, ER/EM: totais de precipitação, evapotranspiração máxima e real, deficiência e excedente hídrico, dias com deficiência e relação ETR/ETM. $\stackrel{*}{* * * *},^{*}$ : Significativo aos níveis de $0,10,0,05$ e 0,01 de probabilidade, respectivamente. 
Tabela 31. Valores observados e preditos do número de frutos por planta com respectivos erros

padrão e resíduos para 'Pêra' em três classes de idade

\begin{tabular}{|c|c|c|c|c|c|c|c|}
\hline Idade & Safra & $\begin{array}{c}\text { Valor } \\
\text { observado }\end{array}$ & $\begin{array}{l}\text { Valor } \\
\text { predito }\end{array}$ & $\begin{array}{c}\text { Erro } \\
\text { padrão }\end{array}$ & $\begin{array}{c}\text { Erro padrão } \\
\text { relativo }\end{array}$ & Resíduo & $\begin{array}{c}\text { Resíduo } \\
\text { padronizado }\end{array}$ \\
\hline 1 & 1990 & 367 & 333,02 & 16,00 & 0,05 & 33,98 & 1,17 \\
\hline 1 & 1991 & 242 & 232,36 & 22,95 & 0,10 & 9,64 & 0,38 \\
\hline 1 & 1992 & 239 & 243,71 & 21,92 & 0,09 & $-4,71$ & $-0,18$ \\
\hline 1 & 1993 & 184 & 202,95 & 27,21 & 0,13 & $-18,95$ & $-0,96$ \\
\hline 1 & 1994 & 235 & 260,67 & 16,01 & 0,06 & $-25,67$ & $-0,86$ \\
\hline 1 & 1995 & 286 & 285,18 & 14,61 & 0,05 & 0,82 & 0,03 \\
\hline 1 & 1996 & 401 & 394,01 & 22,90 & 0,06 & 6,99 & 0,27 \\
\hline 1 & 1997 & 367 & 330,63 & 15,61 & 0,05 & 36,37 & 1,26 \\
\hline 1 & 1998 & 332 & 313,33 & 17,87 & 0,06 & 18,67 & 0,64 \\
\hline 1 & 1999 & 403 & 435,05 & 19,73 & 0,05 & $-32,05$ & $-1,21$ \\
\hline 1 & 2000 & 315 & 368,94 & 15,81 & 0,04 & $-53,94$ & $-2,11$ \\
\hline 1 & 2001 & 186 & 199,85 & 19,07 & 0,10 & $-13,85$ & $-0,48$ \\
\hline 1 & 2002 & 407 & 357,17 & 16,09 & 0,05 & 49,83 & 1,90 \\
\hline 1 & 2003 & 193 & 178,73 & 24,62 & 0,14 & 14,27 & 0,60 \\
\hline 1 & 2004 & 281 & 302,40 & 14,52 & 0,05 & $-21,40$ & $-0,69$ \\
\hline 2 & 1990 & 637 & 595,30 & 23,92 & 0,04 & 41,70 & 0,69 \\
\hline 2 & 1991 & 452 & 485,21 & 32,50 & 0,07 & $-33,21$ & $-0,58$ \\
\hline 2 & 1992 & 544 & 476,76 & 41,93 & 0,09 & 67,24 & 1,46 \\
\hline 2 & 1993 & 419 & 360,28 & 37,33 & 0,10 & 58,72 & 1,15 \\
\hline 2 & 1994 & 488 & 562,40 & 27,22 & 0,05 & $-74,40$ & $-1,33$ \\
\hline 2 & 1995 & 493 & 567,17 & 32,40 & 0,06 & $-74,17$ & $-1,40$ \\
\hline 2 & 1996 & 541 & 591,13 & 26,96 & 0,05 & $-50,13$ & $-0,85$ \\
\hline 2 & 1997 & 590 & 547,30 & 37,87 & 0,07 & 42,70 & 0,82 \\
\hline 2 & 1998 & 554 & 522,97 & 26,34 & 0,05 & 31,03 & 0,51 \\
\hline 2 & 1999 & 735 & 711,76 & 34,72 & 0,05 & 23,24 & 0,42 \\
\hline 2 & 2000 & 728 & 692,48 & 36,56 & 0,05 & 35,52 & 0,66 \\
\hline 2 & 2001 & 310 & 377,50 & 31,95 & 0,08 & $-67,50$ & $-1,25$ \\
\hline 2 & 2002 & 646 & 608,43 & 27,74 & 0,05 & 37,57 & 0,63 \\
\hline 2 & 2003 & 473 & 423,62 & 33,10 & 0,08 & 49,38 & 0,89 \\
\hline 2 & 2004 & 453 & 540,71 & 39,06 & 0,07 & $-87,71$ & $-1,93$ \\
\hline 3 & 1990 & 700 & 773,32 & 30,72 & 0,04 & $-73,32$ & $-0,90$ \\
\hline 3 & 1991 & 635 & 641,03 & 34,04 & 0,05 & $-6,03$ & $-0,07$ \\
\hline 3 & 1992 & 706 & 692,05 & 42,31 & 0,06 & 13,95 & 0,18 \\
\hline 3 & 1993 & 470 & 490,11 & 51,11 & 0,10 & $-20,11$ & $-0,28$ \\
\hline 3 & 1994 & 631 & 703,25 & 40,34 & 0,06 & $-72,25$ & $-0,94$ \\
\hline 3 & 1995 & 724 & 701,68 & 43,03 & 0,06 & 22,32 & 0,29 \\
\hline 3 & 1996 & 639 & 734,20 & 31,90 & 0,04 & $-95,20$ & $-1,22$ \\
\hline 3 & 1997 & 589 & 638,40 & 47,65 & 0,07 & $-49,40$ & $-0,67$ \\
\hline 3 & 1998 & 700 & 571,25 & 47,33 & 0,08 & 128,75 & 2,03 \\
\hline 3 & 1999 & 973 & 963,67 & 64,40 & 0,07 & 9,33 & 0,16 \\
\hline 3 & 2000 & 902 & 846,31 & 47,44 & 0,06 & 55,69 & 0,76 \\
\hline 3 & 2001 & 382 & 443,65 & 48,99 & 0,11 & $-61,65$ & $-0,86$ \\
\hline 3 & 2002 & 786 & 714,50 & 24,08 & 0,03 & 71,50 & 0,85 \\
\hline 3 & 2003 & 780 & 626,10 & 50,20 & 0,08 & 153,90 & 2,80 \\
\hline 3 & 2004 & 599 & 676,47 & 47,58 & 0,07 & $-77,47$ & $-1,09$ \\
\hline
\end{tabular}


Tabela 32. Valores observados e preditos do número de frutos por planta com respectivos erros

padrão e resíduos para 'Valência' em três classes de idade

\begin{tabular}{|c|c|c|c|c|c|c|c|}
\hline Idade & Safra & $\begin{array}{c}\text { Valor } \\
\text { observado }\end{array}$ & $\begin{array}{l}\text { Valor } \\
\text { predito }\end{array}$ & $\begin{array}{c}\text { Erro } \\
\text { padrão }\end{array}$ & $\begin{array}{c}\text { Erro padrão } \\
\text { relativo }\end{array}$ & Resíduo & $\begin{array}{c}\text { Resíduo } \\
\text { padronizado }\end{array}$ \\
\hline 1 & 1990 & 492 & 410,32 & 25,23 & 0,06 & 81,68 & 2,33 \\
\hline 1 & 1991 & 207 & 262,23 & 21,29 & 0,08 & $-55,23$ & $-1,31$ \\
\hline 1 & 1992 & 266 & 280,05 & 28,00 & 0,10 & $-14,05$ & $-0,34$ \\
\hline 1 & 1993 & 297 & 297,33 & 22,56 & 0,08 & $-0,33$ & $-0,01$ \\
\hline 1 & 1994 & 289 & 293,81 & 20,54 & 0,07 & $-4,81$ & $-0,10$ \\
\hline 1 & 1995 & 330 & 282,05 & 20,86 & 0,07 & 47,95 & 1,10 \\
\hline 1 & 1996 & 403 & 423,66 & 20,16 & 0,05 & $-20,66$ & $-0,45$ \\
\hline 1 & 1997 & 300 & 380,71 & 19,47 & 0,05 & $-80,71$ & $-2,07$ \\
\hline 1 & 1998 & 234 & 249,60 & 29,99 & 0,12 & $-15,60$ & $-0,39$ \\
\hline 1 & 1999 & 434 & 468,43 & 28,74 & 0,06 & $-34,43$ & $-0,87$ \\
\hline 1 & 2000 & 374 & 354,59 & 32,23 & 0,09 & 19,41 & 0,52 \\
\hline 1 & 2001 & 225 & 181,20 & 25,82 & 0,14 & 43,80 & 1,07 \\
\hline 1 & 2002 & 460 & 407,70 & 19,88 & 0,05 & 52,30 & 1,20 \\
\hline 1 & 2003 & 156 & 172,50 & 35,08 & 0,20 & $-16,50$ & $-0,47$ \\
\hline 1 & 2004 & 317 & 319,83 & 18,57 & 0,06 & $-2,83$ & $-0,06$ \\
\hline 2 & 1990 & 592 & 562,76 & 19,90 & 0,04 & 29,24 & 0,48 \\
\hline 2 & 1991 & 545 & 648,77 & 25,16 & 0,04 & $-103,77$ & $-2,11$ \\
\hline 2 & 1992 & 627 & 566,65 & 38,68 & 0,07 & 60,35 & 1,29 \\
\hline 2 & 1993 & 583 & 530,58 & 33,50 & 0,06 & 52,42 & 1,01 \\
\hline 2 & 1994 & 490 & 578,32 & 30,76 & 0,05 & $-88,32$ & $-1,81$ \\
\hline 2 & 1995 & 583 & 570,03 & 23,86 & 0,04 & 12,97 & 0,22 \\
\hline 2 & 1996 & 660 & 707,96 & 22,50 & 0,03 & $-47,96$ & $-0,82$ \\
\hline 2 & 1997 & 607 & 614,69 & 36,03 & 0,06 & $-7,69$ & $-0,15$ \\
\hline 2 & 1998 & 582 & 507,61 & 32,66 & 0,06 & 74,39 & 1,50 \\
\hline 2 & 1999 & 877 & 876,18 & 44,96 & 0,05 & 0,82 & 0,02 \\
\hline 2 & 2000 & 787 & 730,69 & 31,24 & 0,04 & 56,31 & 1,06 \\
\hline 2 & 2001 & 416 & 450,38 & 37,05 & 0,08 & $-34,38$ & $-0,68$ \\
\hline 2 & 2002 & 788 & 750,70 & 28,59 & 0,04 & 37,30 & 0,66 \\
\hline 2 & 2003 & 480 & 528,42 & 38,04 & 0,07 & $-48,42$ & $-0,99$ \\
\hline 2 & 2004 & 699 & 692,26 & 24,66 & 0,04 & 6,74 & 0,11 \\
\hline 3 & 1990 & 711 & 863,02 & 41,97 & 0,05 & $-152,02$ & $-1,80$ \\
\hline 3 & 1991 & 856 & 928,87 & 42,46 & 0,05 & $-72,87$ & $-0,77$ \\
\hline 3 & 1992 & 980 & 920,39 & 51,55 & 0,06 & 59,61 & 0,66 \\
\hline 3 & 1993 & 603 & 592,34 & 63,10 & 0,11 & 10,66 & 0,13 \\
\hline 3 & 1994 & 637 & 632,50 & 53,83 & 0,09 & 4,50 & 0,05 \\
\hline 3 & 1995 & 1044 & 1097,40 & 46,09 & 0,04 & $-53,40$ & $-0,57$ \\
\hline 3 & 1996 & 850 & 1043,74 & 41,56 & 0,04 & $-193,74$ & $-2,56$ \\
\hline 3 & 1997 & 897 & 846,66 & 57,27 & 0,07 & 50,34 & 0,58 \\
\hline 3 & 1998 & 675 & 643,90 & 56,26 & 0,09 & 31,10 & 0,35 \\
\hline 3 & 1999 & 1398 & 1262,27 & 75,41 & 0,06 & 135,73 & 2,37 \\
\hline 3 & 2000 & 1223 & 1125,17 & 50,70 & 0,05 & 97,83 & 1,12 \\
\hline 3 & 2001 & 707 & 630,28 & 49,10 & 0,08 & 76,72 & 0,85 \\
\hline 3 & 2002 & 867 & 915,36 & 27,48 & 0,03 & $-48,36$ & $-0,48$ \\
\hline 3 & 2003 & 640 & 621,91 & 64,78 & 0,10 & 18,09 & 0,22 \\
\hline 3 & 2004 & 1049 & 1013,18 & 48,74 & 0,05 & 35,82 & 0,39 \\
\hline
\end{tabular}


Tabela 33. Valores observados e preditos do número de frutos por planta com respectivos erros

padrão e resíduos para 'Hamlin' em três classes de idade

\begin{tabular}{|c|c|c|c|c|c|c|c|}
\hline Idade & Safra & $\begin{array}{c}\text { Valor } \\
\text { observado }\end{array}$ & $\begin{array}{l}\text { Valor } \\
\text { predito }\end{array}$ & $\begin{array}{c}\text { Erro } \\
\text { padrão }\end{array}$ & $\begin{array}{c}\text { Erro padrão } \\
\text { relativo }\end{array}$ & Resíduo & $\begin{array}{c}\text { Resíduo } \\
\text { padronizado }\end{array}$ \\
\hline 1 & 1990 & 441 & 455,38 & 22,39 & 0,05 & $-14,38$ & $-0,22$ \\
\hline 1 & 1991 & 287 & 270,44 & 53,33 & 0,20 & 16,56 & 0,39 \\
\hline 1 & 1992 & 478 & 403,15 & 33,61 & 0,08 & 74,85 & 1,34 \\
\hline 1 & 1993 & 379 & 414,44 & 30,90 & 0,07 & $-35,44$ & $-0,57$ \\
\hline 1 & 1994 & 513 & 553,22 & 42,51 & 0,08 & $-40,22$ & $-0,76$ \\
\hline 1 & 1995 & 295 & 406,34 & 29,92 & 0,07 & $-111,34$ & $-2,17$ \\
\hline 1 & 1996 & 595 & 594,68 & 51,61 & 0,09 & 0,32 & 0,01 \\
\hline 1 & 1997 & 618 & 614,26 & 34,78 & 0,06 & 3,74 & 0,06 \\
\hline 1 & 1998 & 394 & 442,04 & 32,78 & 0,07 & $-48,04$ & $-0,81$ \\
\hline 1 & 1999 & 689 & 638,45 & 45,28 & 0,07 & 50,55 & 1,02 \\
\hline 1 & 2000 & 587 & 602,49 & 34,79 & 0,06 & $-15,49$ & $-0,26$ \\
\hline 1 & 2001 & 233 & 204,93 & 57,32 & 0,28 & 28,07 & 0,79 \\
\hline 1 & 2002 & 384 & 395,78 & 39,31 & 0,10 & $-11,78$ & $-0,21$ \\
\hline 1 & 2003 & 492 & 519,56 & 25,53 & 0,05 & $-27,56$ & $-0,43$ \\
\hline 1 & 2004 & 615 & 484,84 & 26,94 & 0,06 & 130,16 & 2,70 \\
\hline 2 & 1990 & 1122 & 1297,17 & 69,35 & 0,05 & $-175,17$ & $-0,92$ \\
\hline 2 & 1991 & 1023 & 1008,21 & 119,7 & 0,12 & 14,79 & 0,09 \\
\hline 2 & 1992 & 1325 & 1237,20 & 107,4 & 0,09 & 87,80 & 0,50 \\
\hline 2 & 1993 & 929 & 687,49 & 120,8 & 0,18 & 241,51 & 1,60 \\
\hline 2 & 1994 & 733 & 840,89 & 78,63 & 0,09 & $-107,89$ & $-0,56$ \\
\hline 2 & 1995 & 673 & 786,22 & 113,4 & 0,14 & $-113,22$ & $-0,66$ \\
\hline 2 & 1996 & 724 & 1121,50 & 67,57 & 0,06 & $-397,50$ & $-2,58$ \\
\hline 2 & 1997 & 1351 & 1324,41 & 99,18 & 0,07 & 26,59 & 0,14 \\
\hline 2 & 1998 & 809 & 662,40 & 134,5 & 0,20 & 146,60 & 0,98 \\
\hline 2 & 1999 & 1723 & 1514,64 & 130,3 & 0,09 & 208,36 & 1,42 \\
\hline 2 & 2000 & 1301 & 1389,66 & 147,0 & 0,11 & $-88,66$ & $-0,63$ \\
\hline 2 & 2001 & 698 & 893,41 & 66,21 & 0,07 & $-195,41$ & $-1,03$ \\
\hline 2 & 2002 & 1325 & 1169,91 & 69,76 & 0,06 & 155,09 & 0,81 \\
\hline 2 & 2003 & 676 & 652,67 & 106,9 & 0,16 & 23,33 & 0,13 \\
\hline 2 & 2004 & 1419 & 1245,22 & 78,05 & 0,06 & 173,78 & 0,93 \\
\hline 3 & 1990 & 1513 & 1269,55 & 96,98 & 0,08 & 243,45 & 1,91 \\
\hline 3 & 1991 & 1739 & 1857,85 & 103,6 & 0,06 & $-118,85$ & $-0,84$ \\
\hline 3 & 1992 & 2016 & 1940,48 & 138,2 & 0,07 & 75,52 & 0,71 \\
\hline 3 & 1993 & 1135 & 1343,33 & 105,5 & 0,08 & $-208,33$ & $-1,64$ \\
\hline 3 & 1994 & 1110 & 1294,86 & 85,12 & 0,07 & $-184,86$ & $-1,26$ \\
\hline 3 & 1995 & 1689 & 1466,90 & 107,3 & 0,07 & 222,10 & 1,81 \\
\hline 3 & 1996 & 1996 & 1925,50 & 70,50 & 0,04 & 70,50 & 0,43 \\
\hline 3 & 1997 & 2053 & 1995,03 & 71,87 & 0,04 & 57,97 & 0,35 \\
\hline 3 & 1998 & 973 & 962,98 & 133,8 & 0,14 & 10,02 & 0,09 \\
\hline 3 & 1999 & 1887 & 1980,91 & 94,27 & 0,05 & $-93,91$ & $-0,63$ \\
\hline 3 & 2000 & 1733 & 1774,46 & 118,0 & 0,07 & $-41,46$ & $-0,31$ \\
\hline 3 & 2001 & 1163 & 1377,90 & 57,90 & 0,04 & $-214,90$ & $-1,37$ \\
\hline 3 & 2002 & 1843 & 1890,14 & 94,40 & 0,05 & $-47,14$ & $-0,31$ \\
\hline 3 & 2003 & 1094 & 978,44 & 103,5 & 0,11 & 115,56 & 0,82 \\
\hline 3 & 2004 & 2120 & 2005,67 & 83,41 & 0,04 & 114,33 & 0,74 \\
\hline
\end{tabular}




\section{REFERÊNCIAS BIBLIOGRÁFICAS}

ACOCK, B.; ACOCK, M. Potencial for using long-term field research data to develop and validate crop simulators. Agronomy Journal, v.83, p.56-61, 1991.

AGOSTINI, J.P.; HABERLE, T.J.; MORÓN, P.P. El colletotrichum y la caída prematura de frutas en la citricultura del alto Parana, Misiones, Argentina. Laranja, v.16, n.2, p.97-106, 1995.

ALBISU, L.M. Empirical evidence of the main factors affecting orange yields in the Mediterranean Area. Scientia Horticulturae, v.18, p.119-124, 1982.

ALBRIGO, G. Influências ambientais no desenvolvimento dos frutos cítricos. In: SEMINÁRIO INTERNACIONAL DE CITROS-FISIOLOGIA, 2, Bebedouro, 1992. Anais. Campinas: Fundação Cargill, 1992, p.100-106.

BELLOWS, T.S.; MORSE, J.G. Modelling flower development in navel oranges. Scientia Horticulturae, v.30, p.117-26. 1986.

BEN MECHLIA, N.; CARROL, J.J. Agroclimatic modeling for the simulation of phenology, yield and quality of crop production. I - Citrus response formulation. International Journal of Biometeoroly, v.33, p.36-51, 1989.

BERLATO, M.A. Modelo de relação entre o rendimento de grãos da soja e o déficit hídrico para o Estado do Rio Grande do Sul. São José dos Campos, 1987. 93p. Tese (Doutorado). Instituto de Pesquisas Espaciais.

CAMARGO, M.B.P.; PEDRO JUNIOR, M.J.; ORTOLANI, A.A.; ROSA, J.M. Desenvolvimento e teste de modelos agrometeorológicos de estimatima de produtividade de laranjais no Estado de São Paulo. In: CONGRESSO BRASILEIRO DE AGROMETEOROLOGIA, 9. Campina Grande, 1995. Anais. Campina Grande: UFPB/SBA, 1995. p.412-414. 
CAMARGO, M.B.P.; ORTOLANI, A.A.; PEDRO JR, M.J.; ROSA, S.M. Modelo agrometeorológico de estimativa de produtividade para o cultivar de laranja Valência. Bragantia, v.58, n.11, p.171-178, 1999.

CHAIKIATTIYOS, S.; MENZEL, C.M.; RASMUSEN, T.S. Floral induction in tropical fruit trees: effects of temperature and water supply. Journal of Horticultural Science, v.69, n.3, p.397-415, 1994.

CHITARRA, M.I.F.; CHITARRA, A.B. Pós-colheita de frutos e hortaliças: fisiologia e manuseio. Lavras: ESAL/FAEPE, 1990. 320p.

COCHRAN, W.G. Técnicas de amostragem. Rio de Janeiro: Ed. Fundo de Cultura, $1965,555 \mathrm{p}$.

DAVENPORT, T.L. Citrus flowering. Horticultural Reviews, v.12, p.349-408, 1990.

DAVIES, F.S.; ALBRIGO, L.G. Crop production science in horticulture. Citrus. Wallingford: CAB International, 1994. 254p.

DI GIORGI, F., IDE, B.Y, DIB, K., MARCHI, R.J., TRIBONI, H.R., WAGNER, R.L., ANDRADE, G. Influência climática na produção de laranja. Laranja, v.12, n.1, p.163-192, 1991.

DONADIO, L.C; FIGUEIREDO, J.O.; PIO, R.M. Variedades cítricas brasileiras. Jaboticabal: UNESP, FUNEP, 1995. 228p.

DOORENBOS, J.; KASSAM, A.H. Yield response to water. Roma: FAO. 1979. 193 p. (Irrigation and Drainage Paper, 33)

DOURADO-NETO, D.; SAAD, A.M.; JONG van LIER, Q. Curso de agricultura irrigada. Piracicaba: ESALQ, Departamento de Agricultura, 1991. 190p.

DOURADO-NETO, D.; TERUEL, D.A.; REICHARDT, K.; NIELSEN, D.R., FRIZZONE, J..A.; BACCHI, O.O.S. Principles of crop modeling and simulation: I. Uses of mathematical models in agricultural science. Scientia Agricola, v.55, p.4650, 1998a.

DOURADO-NETO, D.; TERUEL, D.A.; REICHARDT, K.; NIELSEN, D.R., FRIZZONE, J..A.; BACCHI, O.O.S. Principles of crop modeling and simulation: II. The implications of the objective in model development. Scientia Agricola, v.55, p.51-57, $1998 b$. 
DRAPER, N.R.; SMITH, H. Applied Regression Analysis. 2. ed. New York: Wiley, 1981. 459p.

DU PLESSIS, S.F. Crop forecasting for navels in South Africa. Proceedings of the Florida State Horticultural Society, v.96, p.40-43, 1983.

FAO. Citrus Fruit Fresh and Processed: Annual Statistics 2003. In: www.fao.org. Roma: FAO, 2003.

FIGUEIREDO, J.O. Variedades copa de valor comercial. In: RODRIGUES, O., VIEGAS, F., POMPEU JR., J., AMARO, A.A. (Ed.). Citricultura Brasileira. 2. ed. Campinas: Fundação Cargill, 1991, v.1, p.228-264.

FONFRIA, M.A.; FERRER, M.J.; ORENGA, V.A; ROMERO, V.E; ALCAINA, M.A. Laranja, limão e tangerina: técnicas comprovadas para a produção de frutos de primeira qualidade. (Trad.) Porto Alegre: Cinco Continentes. 1996. 102p.

FORD, H.W. The influence of rootstock and tree age on root distribution of citrus. Proceedings of the American Society for Horticultural Science, v.63, p.137-142, 1954.

FRIZZONE, J.A. Função de Produção. In: FARIA, M.A. (Ed.). Manejo de Irrigação. Lavras: UFLA/SBEA, 1998. p. 86-116.

FROST, H.B.; SOOST, R.K. Seed reproduction: development of gametes and embryos. In: REUTHER, W. BATCHELOR, L.D.; WEBBER, H.J. (Eds). The citrus industry. Riverside: University of California Press, 1968, p.290-324.

FUNDECITRUS. Censo Citrícola 1999. In: www.fundecitrus.com.br. 27/01/1999.

GALLO, J.R.; RODRIGUES, O.; CAMARGO, A.P.; IGUE, T. Variações anuais na produção de frutos e concentração de macronutrientes em folhas de citros, relacionados ao balanço hídrico meteorológico e adubação, no período de 1957 a 1975. Bragantia, v.36, n.1, p.271-290, 1977.

GARCÍA-LUÍS, A.; KANDUSER, M.; SANTAMARINA, P.; GUARDIOLA, J.L. Low temperature influence on flowering in Citrus. The separation of inductive and bud dormency releasing effects. Physiologia Plantarum, v.86, p.648-652, 1992. 
GAT, Z.; ERNER, Y.; GOLDSCHMIDT, E.E. The effect of temperature on the citrus orchard. Geneva: World Meteorological Organization, 1997. 27p. (WMO. Technical Note, 198).

GINESTAR, C.; CASTEL, J.R. Responses of young clementine citrus trees to water stress during different phenological periods. Journal of Horticultural Science, v.71, n.4, p.551-559, 1996.

GOLDSCHMIDT, E.E.; GOLOMB, A. The carbohydrate balance of alternate-bearing citrus trees and the significance of reserves for flowering and fruiting. Journal of the American Society Horticultural Science, v.107, n.2, p.206-208, 1982.

GUARDIOLA, J.L. Frutificação e crescimento. In: SEMINÁRIO INTERNACIONAL DE CITROS-FISIOLOGIA, 2, Bebedouro, 1992. Anais. Campinas: Fundação Cargill, 1992. p.1-26.

JENSEN, M.E. Water consumption by agricultural plants. In: KOZLOWSKI, T.T. (Ed.). Water deficits and plant growth. New York: Academic Press, 1968. v.2, p.1-22.

JONES, W.W.; CREE, C.B. Environmental factors related to fruiting of 'Washington' navel oranges over a 38-year period. Proceedings of the American Society Horticultural Science, v. 86, p.267-271, 1965.

KIMBALL, D.A. Factors affecting the rate of maturation of citrus fruits. Proceedings of the Florida State Horticultural Society, v.97, p.40-44, 1984.

LOMAS, J.; BURD, P. Prediction of the commencement and duration of the flowering period of citrus. Agricultural Meteorology, v.28, p.387-396, 1983.

LOVATT, C.J.; STREETER, S.M.; MINTER, T.C. Phenology of flowering in Citrus sinensis L. Osbeck, cv. Washington navel orange. Proceedings of the International Society of Citriculture, v.1, p.186-190, 1984.

LOVATT, C.J.; ZHENG, Y.; HAKE, K.D. A new look at the Kraus-Kraybill hipothesis and flowering in citrus. In: INTERNATIONAL CITRUS CONGRESS, 6, Tel Aviv, Israel, 1988. Proceedings. Philadelphia: Balaban Publishers, 1988. p.475-483.

MONSELISE, S.P. Citrus. In: MONSELISE, S.P. (Ed.). Handbook of fruit set and development. Flórida:CRC, 1986. p.87-108. 
MOREIRA, C.S. Estudo da distribuição do sistema radicular da laranjeira Pêra (Citrus sinensis, Osbeck) com diferentes manejos de solo. Piracicaba, 1983. 97p. Tese (Livre-docência) - Escola Superior de Agricultura “Luiz de Queiroz”, Universidade de São Paulo.

MOREIRA, C.S. Clima e produtividade na citricultura. In: SIMPÓSIO SOBRE PRODUTIVIDADE DE CITROS, 1, Jaboticabal, 1984. Anais. Jaboticabal: FCAV, 1985, p.13-29.

MOSS, G.I.; MUIRHEAD, W.A. Climatic and tree factors relating to the yield of orange trees. I. Investigations on 'Washington Navel' and 'Late Valência' cultivars. Horticultural Research. v.11, p.3-17, 1971.

NEVES, E.M. Economia da produção citrícola e efeitos alocativos. Preços Agrícolas, n.162, p. 9-12, 2000.

NOGUEIRA, D.J.P. O clima na citricultura. In: Citrus/Tecnologia de produção. Informe Agropecuário, v.52, p.3-12, 1979.

ORTOLANI, A.A.; PEDRO JUNIOR, M.J; ALFONSI, R.R. Agroclimatologia e o cultivo dos citros. In: RODRIGUES, O.; VIEGAS, F.; POMPEU JUNIOR, J.; AMARO, A.A. (Ed.). Citricultura Brasileira. 2. ed. Campinas: Fundação Cargill, 1991, v.1, p.153-188.

PALTRIDGE, G.W.; PLATT, C.M.R. Radiative processes in meteorology and climatology. Amsterdam, Elsevier Scientific Publishing Company, 1976. (Developments in Atmospheric Sciece, 5).

PASQUA, S.E. Influência de algumas variáveis meteorológicas na produtividade e qualidade de frutos de laranjeira 'Pêra'. Jaboticabal, 2000. 107p. Dissertação (Mestrado) - Faculdade de Ciências Agrárias e Veterinárias, Universidade Estadual Paulista.

PINO, F.A.; AMARO, A.A. Previsão de safra de citros: algumas possibilidades no Estado de São Paulo. Laranja, v.7, n.2, p.403-422, 1986.

PRADO, H. Os solos do Estado de São Paulo: mapas pedológicos. Piracicaba, Divisão de Biblioteca e Documentação, ESALQ/USP, 1997. 205p. 
PRATES, H.S.; ROGRIGUES, J.C.V. Situação atual, prejuízos e perspectivas de controle da podridão floral causada por Colletotrichum gloeosporioides em citros, Laranja, v.16, n.2, p.107-126, 1995.

RASMUSSEN, G.K.; PEYNADO, A.; HIGEMAN, R. The organic acid content of Valência oranges from four locations in the United States. Proceedings of the American Society for Horticultural Science, v.89, p.206-210, 1966.

REUTHER, W. Climates and citrus behavior. In: REUTHER, W. (Ed.). The citrus industry. Riverside: University of California Press, 1973, v.1, cap.9, p.280-337.

REUTHER, W. Climate and fruit quality. In: FERGUSON, J.J.; WARDOWSKI, W.F. (Ed.). Factors affecting fruit quality. Florida, University of Florida, 1988, p.9-23.

RODRIGUES, O. Aspectos fisiológicos, nutrição e adubação dos citros. In: RODRIGUES, O.; VIEGAS, F.; POMPEU JUNIOR., J.; AMARO, A.A. (Ed.). Citricultura Brasileira. 2. ed. Campinas: Fundação Cargill, 1991, v.1, p.419-475.

SAS INSTITUTE. SAS/STAT ${ }^{\circledR}$ users guide: version 6.12 Edition. Cary: SAS Institute, 1998. 1848p.

SENTELHAS, P.C. Agrometeorologia dos citros. In: MATTOS JUNIOR., D. et al. (Ed.). Citros. Campinas: Instituto Agronômico. 2005. (no prelo)

SHUMWAY, R.H. Applied statistical time series analysis. New Jersey: Prentice-Hall, 1988, 379p.

SILVA, G.L.S.P.; VICENTE, J.R.; CASER, D.V. Efeito das condições de tempo sobre a produtividade da laranja no Estado de São Paulo. Laranja, v.7, n.2, p.423-438, 1986.

SOULE, J.; GRIERSON, W. Anatomy and physiology. In: WARDOWSKI, W.F.; NAGY, S.; GRIERSON, W. (Ed.). Fresh citrus fruits. Florida: University of Florida, 1986, p.1-21.

SOUTHWICK, S.M.; DAVENPORT, T.L. Characterization of water stress and low temperature effects on flower induction in citrus. Plant Physiology, v.81, p.26-29, 1986.

SPIEGEL ROY, P.; GOLDSCHMIDT, E.E. Biology of citrus. Cambridge: Cambridge University Press, 1996. 230p. 
SUSANTO, S.; NAKAJIMA, Y.; HASEGAWA, K.; OZAWA, Y. Effect of early season day/night temperatures on vegetative and reproductive growth of cultivar 'Tosa Buntan' pummelo (Citrus grandis (L.) Osbeck). Scientia Horticulturae, v.50, p.147-151, 1992.

SYVERTSEN, J.P.; LLOYD, J.J. Citrus. In: SHAFFER, B., ANDERSEN, P.C. (Ed.). Handbook of environmental physiology of fruit crops. Sub-tropical and tropical crops. cap.4, v.2, 1994, p.65-99.

THORNTHWAITE, C. W. An approach a rational classification of climate. Geographical Review, v.38, p.55-94, 1948.

THORNTHWAITE, C.W.; MATHER, J.R. The water balance. Centertion, New Jersey: Drexel Institute of Technology, 1955. 104p. (Publications in Climatology, v.8, n.1).

TUBELIS, A. Clima: fator que afeta a produção e qualidade da laranja. Laranja, v.16, n.2, p.179-211, 1995.

TUBELIS, A.; SALIBE, A.A. Relações entre a produção de laranjeira 'Hamlin' sobre porta-enxerto de laranjeira 'Caipira' e as precipitações mensais no altiplano de Botucatu. Pesquisa Agropecuária Brasileira, v.23, n.3, p.239-246, 1988.

TUBELIS, A.; SALIBE, A.A. Produção de laranjeira 'Hamlin' sobre porta-enxerto de tangerineira 'Sunki' e precipitações mensais no altiplano de Botucatu. Pesquisa Agropecuária Brasileira, v.24, n.7, p.787-792, 1989.

TUBELIS, A.; SALIBE, A.A. Relações entre a produção de laranjeira 'Hamlin' sobre porta-enxerto de limoeiro 'Rugoso da Flórida' e as precipitações mensais no altiplano de Botucatu. Pesquisa Agropecuária Brasileira, v.19, n.1, p.207-219, 1991.

VAUX, H.J.; PRUITT, W.O. Crop-water production functions. In: HILLEL, D. (Ed.). Advances in irrigation. New York: Academic Press, v.2, 1983. p.61-97.

VOLPE, C.A. Fenologia de citros. In: SEMINÁRIO INTERNACIONAL DE CITROSFISIOLOGIA, 2, Bebedouro, 1992. Anais. Campinas: Fundação Cargill, 1992, p.107-120.

WEISS, N.A. Introductory statistics. New York: Addison-Wesley, 1982, 586p. 
WERKEMA, M.C.C.; AGUIAR, S. Análise de regressão: como entender o relacionamento entre as variáveis de um processo. Belo Horizonte: Fundação Christiano Ottoni, 1996. 311p.

WIT, C.T. Simulation of living systems. In: PENNING DE VRIES, F.W.T.; VAN LAAR, H.H. (Ed.). Simulation of plant growt and crop production. Wagningen: Pudoc, 1982. p.3-8. 